\title{
CORREÇÃO QUANTITATIVA DOS EFEITOS DE METASSOMATISMO \\ EM ROCHAS VULCÂNICAS BÁSICAS. EXEMPLO DOS METABASITOS DO ESPINHAÇO MERIDIONAL (MG-BRASIL)
}

\author{
JOÃO C. BIONDI*
}

\begin{abstract}
A new correction procedure is described, by which analytical data for basic metavolcanic rocks may be tested to detect and correct for qualitative and quantitative variations, due to metassomatic modifications. The method involves plotting the analytical data in terms of oxide molecular proportion ratios, in form $\log X / Z$ vs. $\log Y / Z$ just as described in Beswick and Soucie's paper from 1978. The quantitative correction follow the results obtained by this method, and is based on the assumption that the $\mathrm{K}_{2} \mathrm{O}$ grades plotted on graphs evaluate regularly, because the primary mineralogy of the analysed rocks was all qualitatively identical.

The metabasic suite of lavas from the southern part of the Espinhaço (MG-Brazil) is analysed and corrected, testing the proposed method. The differences observed between the results obtained with corrected and non corrected original analyses are commented, and the results are dimentioned and compared. It has shown that alkalies, lime, magnesia, iron and silica have moved appreciably and differently in parts of the studied mafic bodies. Caution is suggested in the characterization of ancient volcanics by simple comparison of their non corrected compositions with those of young volcanics.
\end{abstract}

INTRODUÇÃO Vários autores têm se preocupado com o problema das interpretações petrológicas e tectônicas apoiadas em análises químicas de rochas vulcânicas, que sabidamente sofreram um ou mais processos de transformação metamórfica-metassomática. As possibilidades que têm estas rochas, de idades Proterozóicas ou Arqueanas, ainda que não modificadas profundamente na sua textura, de terem recebido ou perdido quantidades variadas dos elementos químicos que as compõem são muitas, e a mobilidade de cada um de seus componentes é diferente. Assim, mesmo que não sejam evidentes quaisquer modificações mineralógicas, quase sempre os elementos alcalinos se deslocam em diferentes escalas, devido, por exemplo, à alteração na basicidade dos plagioclásios. $\mathrm{O} \mathrm{Fe}$, o $\mathrm{Mg}$ e o $\mathrm{Ca}$ costumam também migrar, seja devido a pequenas alterações de composição dos peridotos e piroxênios, seja devido à mudança do estado de oxidação do Fe. Já quanto ao alumínio, diversos autores (Carmichael, 1969; Fisher, 1970) consideram-no imóvel, ainda que as rochas tenham sido submetidas a transformações algo rigorosas durante suas histórias geológicas.

Em rochas com alterações morfológicas e mineralógicas, evidentes devidas ao metamorfismo ou ao intemperismo, é ainda mais preocupante o problema da escala de migração dos elementos químicos. $\mathrm{Na}$ turalmente, sempre que qualquer elemento considerado em um estudo petrológico foi capaz de migrar por uma distância maior que as dimensões médias das amostras de rocha analisadas, há boas possibilidades de que as análises químicas das rochas consideradas não seja representativas. Há, portanto, ao menos dois procedimentos distintos a serem adotados na seleção de amostras para análise:

1) Para os casos em que, comprovadamente, as migrações de elementos químicos se tenham processado em escala centimétrica ou decimétrica, a rigor, com base em estudos estatísticos, o problema de amostragem pode ser contornado, coletando-se amostras com dimensões e em quantidade adequadas.

2) Caso as migrações tenham ocorrido em escala equivalente à dos afloramentos, dificilmente qualquer amostra coletada viria a ser representativa do corpo estudado. Neste caso, somente a determinação quantitativa das perdas e ganhos, dos diversos componentes de uma rocha, poderá conduzir a resultados aceitáveis.

Diversos autores têm tentado desenvolver técnicas de determinação da intensidade das modificações químicas ocorridas em uma rocha. Os estudos mais conhecidos são os de Mason (1967, p. 226), Pearce (1968, 1970), Miyashiro (1975) e Beswick e Soucie (1978). Tais estudos têm sempre em comum que a determinação de possíveis migrações são feitas por comparação e são apenas qualitativas. A técnica de correção a ser descrita é uma extensão daquela de Beswick e Soucie (1978), que, entre as conhecidas, é aquela que trabalha com o maior número de elementos químicos e mais se aproxima da quantificação das informações obtidas.

* MEtaMIG, Metais de Minas Gerais S.A. - Rua Aimorés, 1697 - Belo Horizonte, Minas Gerais (MG) - Brasil 
TÉCNICA DE CORREÇÃO DE ANÁLISES Não será aqui descrita a técnica adotada como base, visto ser ela exaustivamente comentada por seus autores (Beswick e Soucie, 1978, pp. 235-248). Baseia-se, a exemplo dos outros trabalhos conhecidos, na comr . ração do çomportamento de uma sequiência qualqı «r em estudo com uma outra sequiência constituída por rochas vulcânicas pós-mesozóicas tida como padrão. $\mathrm{O}$ método se desenvolve em função de alguns dos principais óxidos componentes das rochas, expressos sob a forma de logaritmo de proporções moleculares em relação aos alcalinos $(\log X / Z \times \log Y / Z$, onde $\mathrm{X}$ e $\mathrm{Y}$ são proporções moleculares de óxidos e $\mathrm{Z}$ é a proporção molecular de $\mathrm{K}_{2} \mathrm{O}$ e, posteriormente, de $\mathrm{Na}_{2} \mathrm{O}$ ). Maiores detalhes são dados no artigo de referência. Duas das premissas adotadas por estes autores devem ser ressaltadas:

1) Premissa de ordem química: a exemplo de outros autores, e fundamentados nos argumentos por eles apresentados, Beswick e Soucie consideram também $\mathrm{o} \mathrm{Al}_{2} \mathrm{O}_{3}$ como invariável durante todas as modificações sofridas pelas rochas estudadas. Quanto às modificações advindas de ações metamórficas, existem boas razões que comprovam a validade desta premissa (Carmichael, 1969; Fisher, 1970), o mesmo, entretanto, não sendo válido quanto às modificações intempéricas sofridas pelas rochas (White e Sarcia, 1978). E, raramente, durante a amostragem de uma rocha metamorfisada, é possivel determinar o seu grau de intemperismo antes de submetida ao metamorfismo.

2) Premissa de ordem geológica: admite-se que os processos vulcanogênicos Arqueanos e Proterozójcos tenham sido idênticos àqueles de idade Pós-Mesozóica. A simples presença dos komateitos junto ao vulcanismo Arqueano e a sua inexistência associada às sequiências vulcânicas modernas, permite antever a fragilidade desta premissa. Além dos gradientes de pressão e temperatura da crosta, comprovadamente diferentes em tempos arqueanos, houve, também, modificações profundas nas condições de temperatura e de oxirredução dos ambientes vulcânicos daquela época (Hutchinson, 1973) em relação ao presente. Todas estas diferenças podem ter contribuído para um comportamento diferente na evolução do vulcanismo antigo em relação ao atual, com a consequiente gênese de rochas ou sequiências rochosas não comparáveis entre as épocas, a exemplo dos komateitos.

Técnica adotada Nos diagramas de Beswick e Soucie (Figs. 1A e B) é feita a determinação geométrica das variações químicas necessárias para adaptar um ponto $P$ qualquer, representativo de uma rocha $\mathrm{em}$ estudo, em relação à faixa que contém todos os pontos que perfazem a sequiência de referência (hachurada). O primeiro diagrama (Fig. 1A) determina a variação da sílica em relação ao $\mathrm{K}_{2} \mathrm{O}, \mathrm{o} \mathrm{Al}_{2} \mathrm{O}_{3}$ admitido como invariável. Nos outros diagramas, são determinadas posições equivalentes para o ponto $\mathrm{P}$, con- siderando-se as variações de $\mathrm{SiO}_{2}$ e $\mathrm{K}_{2} \mathrm{O}$ do primeiro diagrama, sendo feitas as correções para adaptar $\mathbf{P}$ à sequiência de referência. Na Fig. 1A, admitindo-se que a posição de $P$ antes das modificações químicas fosse em $A$, determina-se que houve uma variação de $\mathrm{K}_{2} \mathrm{O}$ na rocha igual a $\overline{\mathrm{P}^{\prime} \mathrm{K}}$ e de $\mathrm{SiO}_{2}$ igual a $\overline{\mathrm{PP}^{\prime}}$. Estas variações podem ser quantificadas em unidades logaritmicas de $\mathrm{SiO}_{2} / \mathrm{K}_{2} \mathrm{O}$, lendo-se diretamente em ordenada os valores de $\mathrm{P}$ e $\mathrm{P}^{\prime}$, determinando-se o $\Delta \mathrm{P}$ equivalente à variação de $\mathrm{SiO}_{2}$ e medindo-se, na mesma escala, $\overline{\mathrm{P}^{\prime} \mathrm{K}}$ para a variação de $\mathrm{K}_{2} \mathrm{O}$. A ressaltar que estes resultados são expressos apenas em logaritmo de uma razão de óxidos.

Nos outros diagramas (Fig. 1B) o ponto P é deslocado de $\overline{\mathrm{AP}}^{\prime}$, corrigindo-se a sílica. Nota-se que, feitas as correções determinadas no primeiro diagra$\mathrm{ma}$, o ponto $\mathrm{P}^{\prime}$ obtido como posição de $\mathrm{P}$ corrigida para $\mathrm{K}_{2} \mathrm{O}$ e $\mathrm{SiO}_{2}$, está fora da sequiência de referência.
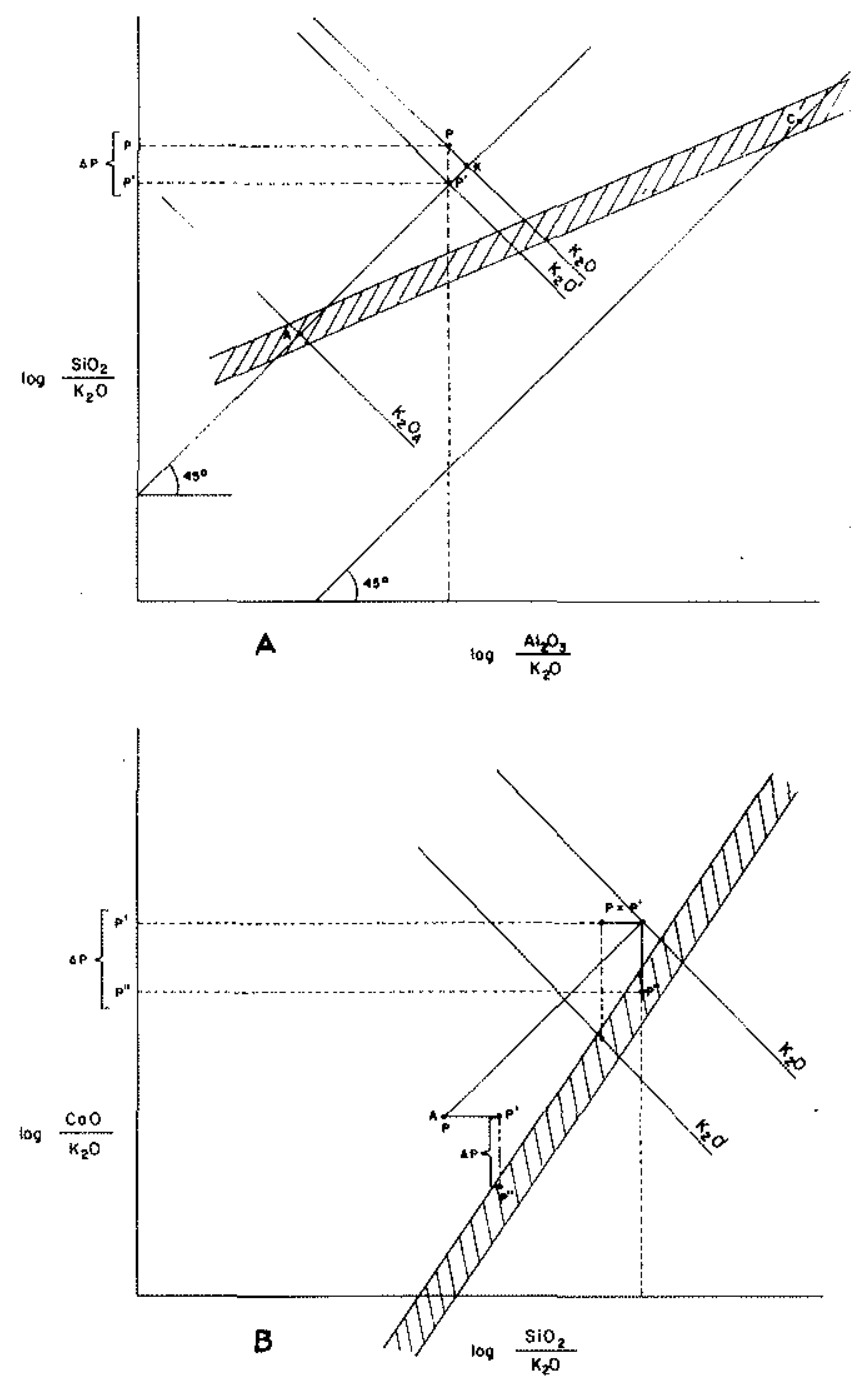

Figura 1 - Esquemas explicativos dos problemas relacionados à quantificação de variações quimicas nos diagramas de Beswick e Soucie (1978). Em 1A, o caso específico do $\mathrm{SiO}_{2}$ e em 1 B o caso geral, válido para os outros óxidos 
Quadro 1 - Análises químicas e composição normativa (CIPW) das amostras lançadas em diagrama (análises novas-Laboratório Geosol). Indice ce localização

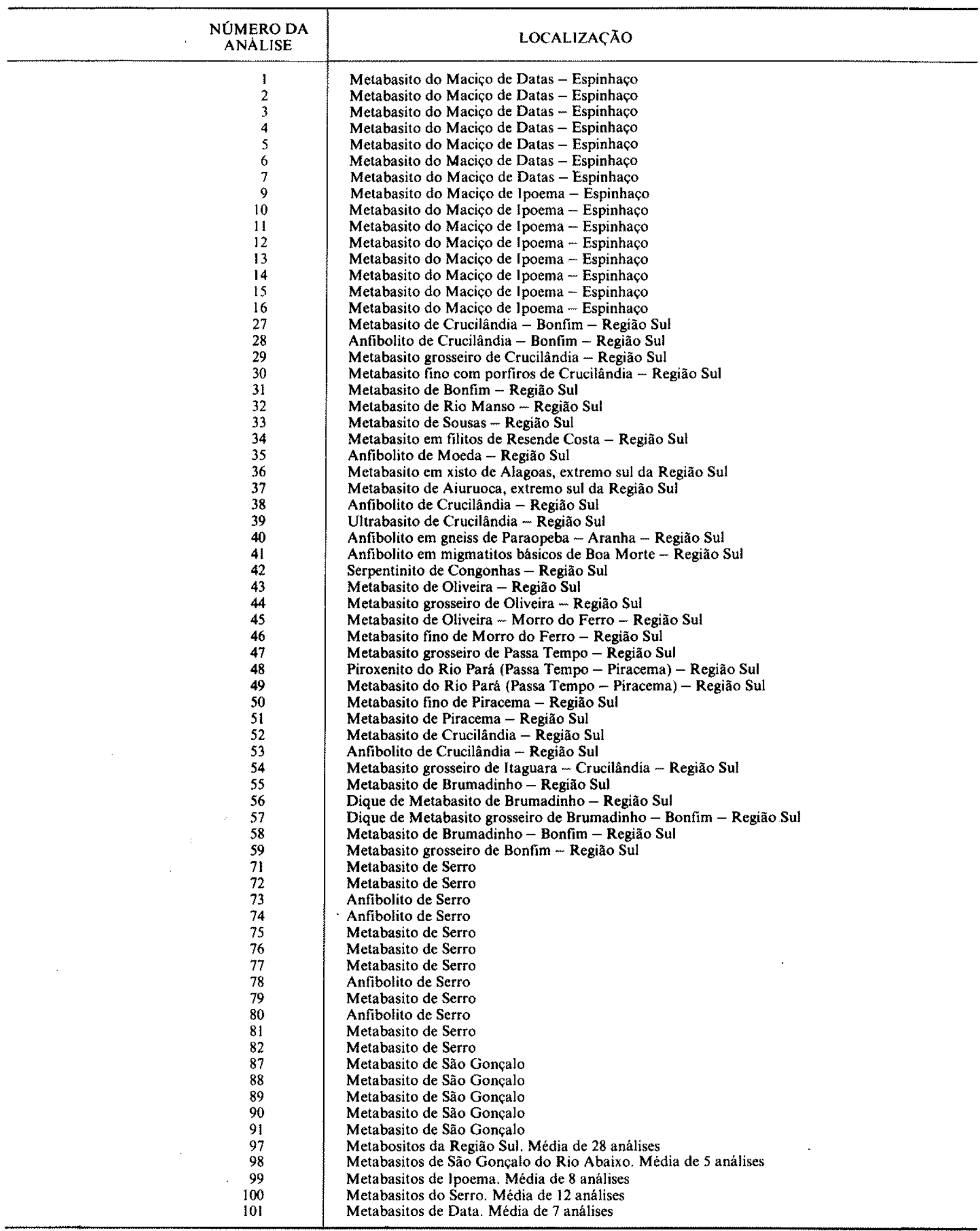




\begin{tabular}{|c|c|c|c|c|c|c|c|c|c|c|c|c|c|c|c|c|c|}
\hline & 1 & 2 & 3 & 4 & 5 & 6 & 7 & 9 & 10 & 11 & 12 & 13 & 14 & 15 & 16 & 27 & 28 \\
\hline $\mathrm{SiO}_{2}$ & 47,1 & 46,5 & 46,8 & 47,6 & 47,2 & 41,5 & 47,5 & 45,6 & 43,1 & 48,8 & 46,7 & 46,9 & 46,9 & 49,9 & 46,5 & 45,2 & 50,70 \\
\hline $\mathrm{TiO}_{2}$ & 1,6 & 1,9 & 1,5 & 1,2 & 1,3 & 1,5 & 1,3 & 3,2 & 3,2 & 1,4 & 1,3 & 3,0 & 3,8 & 2,5 & 3,2 & 3,4 & 2,3 \\
\hline $\mathrm{Al}_{2} \mathrm{O}_{3}$ & 14,5 & 15,6 & 15,1 & 14,2 & 14,9 & 18,6 & 15,8 & 13,8 & 13,2 & 13,8 & 15,3 & 13,2 & 13,6 & 16,8 & 13,3 & 12,4 & 12,1 \\
\hline $\mathrm{Fe}_{2} \mathrm{O}_{3}$ & 3,18 & 3,91 & 2,89 & 1,58 & 1,83 & 4,26 & 2,63 & 2,37 & 3,39 & 3,30 & 4,50 & 3,63 & 3,84 & 3,66 & 4,44 & 6,09 & 5,53 \\
\hline $\mathrm{FeO}$ & 8,21 & 8,36 & 7,93 & 8,93 & 8,79 & 7,78 & 7,27 & 11,10 & 13,69 & 7,20 & 6,48 & 11,67 & 10,95 & 7,42 & 10,95 & 11,11 & 10,76 \\
\hline $\mathrm{MnO}$ & 0,31 & 0,26 & 0,21 & 0,28 & 0,29 & 0,29 & 0,24 & 0,21 & 0,29 & 0,25 & 0,22 & 0,30 & 0,32 & 0,28 & 0,30 & 0,34 & 0,29 \\
\hline $\mathrm{MgO}$ & 6,5 & 5,9 & 6,9 & 8,0 & 6,9 & 6,2 & 6,4 & 4,6 & 4,3 & 6,3 & 7,5 & 5,2 & 3,1 & 2,0 & 4,2 & 4,3 & 4,4 \\
\hline $\mathrm{CaO}$ & 10,9 & 10,3 & 11,6 & 11,9 & 12,1 & 9,8 & 11,8 & 8,7 & 7,4 & 10,4 & 11,0 & 8,6 & 7,4 & 7,4 & 8,4 & 8,5 & 7,8 \\
\hline $\mathrm{Na}_{2} \mathrm{O}$ & 4,85 & 4,24 & 4,32 & 3,84 & 4,24 & 4,24 & 4,04 & 7,03 & 4,93 & 5,05 & 3,76 & 3,92 & 5,90 & 7,31 & 5,58 & 3,92 & 2,35 \\
\hline $\mathrm{K}_{2} \mathrm{O}$ & 0,22 & 0,27 & 0,15 & 0,64 & 0,25 & 0,54 & 0,54 & 0,43 & 1,1 & 1,1 & 0,54 & 0,68 & 1,4 & 0,89 & 0,71 & 1,10 & 0,90 \\
\hline $\mathrm{P}_{2} \mathrm{O}_{5}$ & 0,16 & 0,15 & 0,14 & 0,10 & 0,12 & 0,15 & 0,12 & 0,36 & 0,35 & 0,10 & 0,13 & 0,40 & 0,43 & 0,36 & 0,42 & 0,49 & 0,21 \\
\hline $\mathrm{H}_{2} \mathrm{O}^{-}$ & 0,09 & 0,04 & 0,16 & 0,10 & 0,17 & 0,11 & 0,32 & 0,35 & 0,20 & 0,29 & 0,30 & 0,34 & 0,38 & 0,23 & 0,11 & 0,85 & 0,57 \\
\hline P.F. & 1,92 & 2,79 & 2,12 & 1,09 & 1,53 & 4,44 & 1,64 & 1,19 & 2,30 & 1,84 & 1,83 & 1,64 & 1,47 & 1,26 & 1,58 & 2,96 & 2,28 \\
\hline TOTAL & 99,54 & 100,22 & 99,82 & 99,46 & 99,62 & 99,41 & 99,60 & 98,64 & 97,45 & 99,83 & 99,56 & 99,48 & 99,49 & 100,01 & 99,69 & 100,66 & 100,19 \\
\hline
\end{tabular}

(NORMA CIPW)

\begin{tabular}{|c|c|c|c|c|c|c|c|c|c|c|c|c|c|c|c|c|c|}
\hline Ap & 0,34 & 0,34 & 0,34 & 0,34 & 0,34 & 0,34 & 0,34 & 0,84 & 0,67 & 0,23 & 0,34 & 1,0 & 1,0 & 0,84 & 1,01 & 1,16 & 0,34 \\
\hline Il & 3,04 & 3,65 & 2,89 & 2,28 & 2,43 & 2,89 & 2,43 & 6,08 & 6,08 & 2,66 & 0,83 & 5,7 & 7,22 & 4,71 & 6,08 & 6,46 & 4,41 \\
\hline Or & 1,11 & 1,67 & 1,11 & 3,89 & 1,67 & 3,34 & 3,34 & 2,78 & 6,67 & 6,51 & 3,19 & 3,89 & 8,34 & 5,0 & 4,20 & 6,5 & 5,56 \\
\hline $\mathrm{Ab}$ & 23,27 & 26,07 & 20,91 & 16,56 & 18,39 & 12,78 & 20,44 & 21,7 & 20,17 & 22,57 & 22,70 & 31,65 & 28,30 & 37,31 & 21,67 & 29,94 & 19,91 \\
\hline $\mathrm{Ne}$ & 9,54 & 5,18 & 8,55 & 8,63 & 9,34 & 12,38 & 7,38 & 20,3 & 11,50 & 10,90 & 4,91 & 0,74 & 11,64 & 13,29 & 13,81 & 1,66 & - \\
\hline An & 17,24 & 22,8 & 21,13 & 19,46 & 20,85 & 30,02 & 23,35 & 4,73 & 10,56 & 11,63 & 23,07 & 16,40 & 6,39 & 10,56 & 9,19 & 7,50 & 19,74 \\
\hline Mgt & 4,64 & 5,57 & 4,18 & 2,32 & 2,55 & 6,26 & 3,71 & 3,48 & 4,87 & 4,87 & 6,50 & 5,34 & 5,57 & 5,34 & 6,43 & 8,82 & 8,12 \\
\hline $\mathrm{Hm}$ & - & - & - & - & - & - & - & - & - & - & - & - & - & - & - & - & - \\
\hline $\mathrm{DiCa}$ & 15,08 & 11,48 & 14,85 & 16,18 & 16,0 & 7,42 & 14,38 & 15,14 & 10,67 & 16,44 & 12,76 & 10,61 & 12,30 & 10,03 & 16,36 & 14,03 & 7,54 \\
\hline DiMg & 8,80 & 6,64 & 8,89 & 9,21 & 8,77 & 4,49 & 8,55 & 6,92 & 4,10 & 10,03 & 8,70 & 5,10 & 5,05 & 4,20 & 7,66 & 7,00 & 3,60 \\
\hline $\mathrm{DiFe}$ & 5,54 & 4,30 & 5,16 & 6,26 & 6,64 & 2,52 & 5,08 & 8,09 & 6,73 & 5,47 & 3,04 & 5,35 & 7,33 & 5,87 & 8,50 & 6,73 & 3,83 \\
\hline HyMg & - & - & - & - & - & - & - & - & - & - & - & - & - & - & - & - & 7,40 \\
\hline $\mathrm{HyFe}$ & - & - & - & - & - & - & - & - & - & - & - & - & - & - & - & - & 7,92 \\
\hline Fo & 5,25 & 5,64 & 5,85 & 7,55 & 5,93 & 7,7 & 5,2 & 3,2 & 4,62 & 4,0 & 7,03 & 5,50 & 1,89 & 0,56 & 1,99 & 2,62 & - \\
\hline $\mathrm{Fa}$ & 3,67 & 4,02 & 3,76 & 5,67 & 4,97 & 4,78 & 3,4 & 4,1 & 8,36 & 2,4 & 3,67 & 6,50 & 3,01 & 0,86 & 2,43 & 2,75 & - \\
\hline $\mathrm{Qz}$ & - & - & - & - & - & - & - & - & - & - & - & $\theta$ & - & - & . & - & 9,06 \\
\hline TOTAL & 97,52 & 97,36 & 97,62 & 98,35 & 97,88 & 94,92 & 97,66 & 97,47 & 95,00 & 97,71 & 96,75 & 97,90 & 98,04 & 98,57 & 99,34 & 95,20 & 97,43 \\
\hline
\end{tabular}


Quadro 1 (continuação)

\begin{tabular}{|c|c|c|c|c|c|c|c|c|c|c|c|c|c|c|c|c|c|}
\hline & 29 & 30 & 31 & 32 & 33 & 34 & 35 & 36 & 37 & 38 & 39 & 40 & 41 & 42 & 43 & 44 & 45 \\
\hline $\mathrm{SiO}_{2}$ & 48,1 & 47,0 & 47,4 & 41,6 & 46,2 & 37,6 & 47,3 & 44,0 & 44,3 & 49,1 & 49,3 & 48,4 & 51,7 & 41,0 & 48,0 & 50.8 & 48.3 \\
\hline $\mathrm{TiO}_{2}$ & 3,7 & 3,5 & 4,0 & 3,9 & 3,7 & 1,5 & 5,4 & 4,0 & 5,2 & 0,74 & 9,97 & 1,9 & 3,1 & 0,31 & 2,7 & 2,6 & 2,6 \\
\hline $\mathrm{Al}_{2} \mathrm{O}_{3}$ & 12,5 & 12,3 & 10,0 & 17,3 & 13,3 & 15,7 & 14,7 & 14,5 & 14,0 & 16,0 & 5,9 & 13,0 & 12,5 & 1,2 & 14,2 & 12,6 & 13,6 \\
\hline $\mathrm{Fe}_{2} \mathrm{O}_{3}$ & 4,94 & 5,45 & 6,46 & 11,57 & 5,11 & 9,19 & 2,67 & 11,54 & 8,94 & 5,38 & 9,97 & 5,32 & 4,51 & $9 ; 26$ & 6,62 & 4,31 & 4,53 \\
\hline $\mathrm{FeO}^{3}$ & 11,76 & 12,19 & 12,91 & 7,17 & 11,33 & 13,20 & 13,63 & 7,53 & 8,32 & 9,32 & 4,44 & 11,62 & 12,33 & 3,73 & 10,61 & 12,05 & 11,76 \\
\hline $\mathrm{MnO}$ & 0,34 & 0,40 & 0,43 & 0,32 & 0,35 & 0,38 & 0,37 & 0,29 & 0,28 & 0,48 & 0,35 & 0,40 & 0,31 & 0,22 & 0,40 & 0,28 & 0,38 \\
\hline $\mathrm{MgO}$ & 3,8 & 4,4 & 3,5 & 2,8 & 4,3 & 4,2 & 3,1 & 3,6 & 3,7 & 4,7 & 17,2 & 2,3 & 2,60 & 32,30 & 4,30 & 3,80 & 5,20 \\
\hline $\mathrm{CaO}$ & 8,4 & 9,3 & 8,6 & 5,5 & 8,7 & 8,7 & 6,2 & 8,5 & 6,3 & 8,6 & 6,5 & 10,4 & 6,0 & $<0,10$ & 8,0 & 8,0 & 9,8 \\
\hline $\mathrm{Na}_{2} \mathrm{O}$ & 2,69 & 2,46 & 2,65 & 2,65 & 2,20 & $.4,12$ & 2,87 & 3,55 & 2,62 & 1,59 & 0,93 & 2,52 & 2,78 & 0,72 & 2,86 & 2,77 & 1,93 \\
\hline $\mathrm{K}_{2} \mathrm{O}$ & 0,95 & 0,55 & 0,98 & 0,79 & 1,41 & 0,47 & 2,16 & 1,27 & 1,73 & 0,39 & 0,21 & 0,40 & 2,58 & 0,08 & 1,38 & 1,67 & 0,54 \\
\hline $\mathrm{P}_{2} \mathrm{O}_{5}$ & 0,75 & 0,62 & 0,38 & 0,93 & 0,59 & 0,13 & 0,54 & 0,61 & 0,60 & 0,10 & 0,10 & 0,18 & 0,70 & $<0,10$ & 0,33 & 0,41 & 0,28 \\
\hline $\mathrm{H}_{2} \mathrm{O}^{-}$ & 0,56 & 0,60 & 1,09 & 0,61 & 0,78 & 2,09 & 0,45 & 1,80 & 1,31 & 0,74 & 1,52 & 0,00 & 0,09 & 0,61 & 0,13 & 0,45 & 0,07 \\
\hline P.F. & 1,90 & 1,62 & 2,59 & 5,21 & 2,67 & 4,57 & 0,88 & 0,54 & 3,53 & 3,27 & 3,86 & 0,42 & 0,65 & 10,92 & 0,33 & 0,25 & 0,65 \\
\hline TOTAL & 100,39 & 100,39 & 100,99 & 100,35 & 100,64 & 100,81 & 100,27 & 101,76 & 100,83 & 100,41 & 101,07 & 97,06 & 99,85 & 100,55 & 99,86 & 99,99 & 99,64 \\
\hline
\end{tabular}

(NORMA CIPW)

\begin{tabular}{|c|c|c|c|c|c|c|c|c|c|c|c|c|c|c|c|c|c|}
\hline $\mathrm{Ap}$ & 1,68 & 1,34 & 0,91 & $2,02^{*}$ & 1,34 & 0,34 & 1,34 & 1,34 & 1,34 & 0,34 & 0,34 & $.0,34$ & 1,68 & $* *$ & 0,67 & 1,01 & 0,67 \\
\hline II & 6,99 & 6,69 & 7,60 & 7,45 & 6,99 & 2,89 & 10,18 & 7,60 & 9,88 & 1,37 & 1,82 & 3,65 & 5,93 & 0,61 & 5,17 & 4,86 & 4,86 \\
\hline Or & 5,56 & 3,34 & 5,80 & 4,45 & 8,34 & 2,78 & 12,79 & 7,23 & 10,01 & 2,22 & 1,11 & 2,22 & 15,01 & 0,57 & 8,34 & 10,01 & 3,34 \\
\hline $\mathrm{Ab}$ & 22,56 & 20,96 & 22,39 & 22,53 & 18,34 & 11,24 & 24,10 & 29,87 & 22,01 & 13,62 & 7,86 & 21,48 & 23,58 & 5,76 & 24,10 & 23,58 & 16,24 \\
\hline $\mathrm{Ne}$ & - & - & - & - & - & 12,78 & - & - & - & - & - & - & - & - & - & - & - \\
\hline $\mathrm{An}$ & 19,18 & 20,85 & 12,46 & 22,24 & 22,24 & 23,00 & 20,85 & 20,02 & 21,41 & 34,47 & 11,40 & 22,80 & 13,90 & - & 21,68 & 16,68 & 26,69 \\
\hline Mgt & 7,19 & 7,89 & 9,28 & 12,76 & 7,42 & 13,22 & 3,94 & 13,69 & 12,53 & 7,89 & 12,76 & 7,66 & 6,50 & 11,83 & 9,51 & 6,26 & 6,50 \\
\hline $\mathrm{Hm}$ & - & - & - & 2,72 & - & - & - & 2,08 & 0,32 & - & 1,12 & - & - & 0,96 & - & - & - \\
\hline $\mathrm{DiCa}$ & 7,66 & 9,16 & 11,66 & - & 7,31 & 8,06 & 3,71 & 7,89 & 2,67 & 3,02 & 8,35 & 11,72 & 4,87 & 0,12 & 6,84 & 8,58 & 8,47 \\
\hline DiMg & 3,40 & 4,20 & 4,82 & - & 3,50 & 3,35 & 1,30 & 6,80 & 2,30 & 1,40 & 7,20 & 3,45 & 1,60 & 0,10 & 3,40 & 3,40 & 4,00 \\
\hline $\mathrm{DiFe}$ & 4,22 & 4,88 & 6,91 & - & 3,70 & 4,75 & 2,51 & - & - & 1,58 & - & 8,78 & 3,43 & - & 3,30 & 5,28 & 4,36 \\
\hline HyMg & 6,10 & 6,80 & 3,93 & 7,00 & 7,20 & - & 6,40 & 2,20 & 7,00 & 10,30 & 35,80 & 2,25 & 4,90 & 40,40 & 7,30 & 6,10 & 9,00 \\
\hline HyFe & 7,79 & 7,92 & 5,63 & - & 7,39 & - & 12,01 & - & - & 10,69 & - & 5,74 & 10,82 & - & 7,00 & 9,50 & 10,03 \\
\hline Fo & - & - & - & - & - & 5,00 & - & - & - & - & - & - & - & 28,14 & - & - & - \\
\hline $\mathrm{Fa}$ & - & - & - & - & - & 7,82 & - & - & - & - & - & - & - & - & - & - & - \\
\hline $\mathrm{Qz}$ & 5,64 & 4,26 & 5,89 & 9,42 & 3,36 & - & 0,30 & 0,66 & 7,08 & 9,24 & 8,16 & 6,30 & 6,90 & - & 1,80 & 4,08 & 4,74 \\
\hline TOTAL & 97,94 & 98,29 & 97,28 & 94,57 & 97,13 & 95,17 & 99,43 & 99,38 & 96,55 & 96,14 & 95,92 & 96,39 & 99,12 & 88,95 & 99,11 & 99,34 & 98,90 \\
\hline
\end{tabular}

* Mais 3,98 de Corindon

** Mais 0,46\% de Aegerina 
Quadro 1 (continuaşão)

\begin{tabular}{|c|c|c|c|c|c|c|c|c|c|c|c|c|c|c|c|c|c|c|}
\hline & 46 & 47 & 48 & 49 & 50 & 51 & 52 & 53 & 54 & 55 & 56 & 57 & 58 & 59 & 71 & 72 & 73 & 74 \\
\hline $\mathrm{SiO}_{2}$ & 48,2 & 48,5 & 43,9 & 45,1 & 50,7 & 32,0 & 47,0 & 46,5 & 46,0 & 47,3 & 48,3 & 47,2 & 44,3 & 47,7 & 46,9 & 43,9 & 47,2 & 46,1 \\
\hline $\mathrm{TiO}_{2}$ & 1,4 & 2,8 & 0,27 & 3,5 & 2,4 & 3,9 & 3,6 & 2,2 & 0,30 & 2,4 & 2,0 & 2,0 & 3,6 & 3,3 & 2,0 & 2,8 & 2,4 & 0,89 \\
\hline $\mathrm{Al}_{2} \mathrm{O}_{3}$ & 14,8 & 12,2 & 3,3 & 14,2 & 12,6 & 19,5 & 11,9 & 12,6 & 2,3 & 15,1 & 14,1 & 15,0 & 12,5 & 13,8 & 14,3 & 14,1 & 13,4 & 14,3 \\
\hline $\mathrm{Fe}_{2} \mathrm{O}_{3}$ & 4,25 & 5,59 & 5,18 & 8,55 & 5,24 & 19,03 & 5,48 & 6,30 & 4,69 & 4,88 & 6,01 & 6,39 & 5,75 & 5,59 & 2,44 & 3,89 & 2,96 & 2,52 \\
\hline $\mathrm{FeO}$ & 10,61 & 12,84 & 4,80 & 10,68 & 9,75 & 7,16 & 12,19 & 12,19 & 4,16 & 10,04 & 10,25 & 9,18 & 10,68 & 11,97 & 10,22 & 11,08 & 10,65 & 7,63 \\
\hline $\mathrm{MnO}$ & 0,38 & 0,39 & 0,32 & 0,36 & 0,22 & 0,22 & 0,26 & 0,39 & 0,22 & 0,32 & 0,34 & 0,31 & 0,30 & 0,32 & 0,25 & 0,23 & 0,26 & 0,19 \\
\hline $\mathrm{MgO}$ & 5,80 & 4,60 & 31,80 & 4,30 & 4,50 & 2,80 & 4,40 & 5,20 & 30,40 & 3,40 & 3,40 & 4,40 & 4,40 & 3,80 & 8,2 & 9,4 & 8,0 & 12,0 \\
\hline $\mathrm{CaO}$ & 10,3 & 7,7 & 2,8 & 4,9 & 8,7 & 3,6 & 9,4 & 9,5 & 2,7 & 8,9 & 9,0 & 8,7 & 9,5 & 7,1 & 11,5 & 9,3 & 10,3 & 12,2 \\
\hline $\mathrm{Na}_{2} \mathrm{O}$ & 2,52 & 2,91 & 0,55 & 2,78 & 2,47 & 1,46 & 2,47 & 2,62 & 0,67 & 2,38 & 2,26 & 2,38 & 4,36 & 2,65 & 1,47 & 0,93 & 1,42 & 0,55 \\
\hline $\mathrm{K}_{2} \mathrm{O}$ & 0,30 & 1,55 & 0,08 & 1,83 & 0,64 & 1,55 & 0,69 & 0,88 & 0,08 & 0,71 & 0,67 & 1,33 & 1,33 & 1,38 & 0,42 & 0,40 & 0,65 & 0,34 \\
\hline $\mathrm{P}_{2} \mathrm{O}_{5}$ & 0,11 & 0,44 & $<0,10$ & 0,40 & 0,20 & 0,47 & 0,57 & 0,20 & $<0,10$ & 0,21 & 0,20 & 0,19 & 0,42 & 0,49 & 0,24 & 0,24 & 0,30 & 0,12 \\
\hline $\mathrm{H}_{2} \mathrm{O}^{-}$ & 0,03 & 0,07 & 0,15 & 0,63 & 0,07 & 1,24 & 0,39 & 0,07 & 0,21 & 0,64 & 0,78 & 0,48 & 0,67 & 0,49 & - & - & - & - \\
\hline P.F. & 1,15 & 0,13 & 6,73 & 3,09 & 2,03 & 6,99 & 1,83 & 1,21 & 8,21 & 3,31 & $, 3,14$ & 2,71 & 2,65 & 1,63 & 1,66 & 3,10 & 1,67 & 2,68 \\
\hline TOTAL & 99,85 & 99,72 & 99,98 & 100,32 & 99,52 & 100,22 & 100,18 & 99,86 & 100,04 & 99,59 & 100,45 & 100,27 & 100,46 & 99,73 & 99,60 & 99,37 & 99,21 & 99,52 \\
\hline
\end{tabular}

(NORMA CIPW)

\begin{tabular}{l|c|c|c|c|c|c|c|c|c|c|c|c|c|c|c|c|c|c|}
\hline Ap & 0,34 & 1,01 & - & 1,01 & 0,34 & 1,01 & 1,34 & 0,34 & - & 0,34 & 0,34 & 0,34 & 1,01 & 1,01 & 0,7 & 0,7 & 0,7 & 0,3 \\
Il & 2,58 & 5,32 & 0,46 & 6,69 & 4,56 & 7,45 & 6,84 & 4,10 & 0,61 & 4,56 & 3,80 & 3,80 & 6,84 & 6,23 & 3,8 & 5,3 & 4,6 & 1,7 \\
Or & 1,67 & 8,90 & 0,56 & 10,56 & 3,89 & 8,90 & 3,89 & 5,00 & 0,56 & 4,45 & 3,89 & 7,84 & 7,84 & 8,34 & 2,2 & 2,2 & 3,9 & 2,2 \\
$\mathrm{Ab}$ & 21,48 & 24,63 & 4,72 & 23,58 & 20,96 & 12,05 & 20,96 & 22,01 & 5,56 & 19,91 & 18,86 & 19,91 & 21,48 & 22,53 & 12,6 & 7,9 & 12,0 & 4,7 \\
$\mathrm{Ne}$ & - & - & - & - & - & - & - & - & - & - & - & - & 8,24 & - & - & - & - & - \\
$\mathrm{An}$ & 28,08 & 15,85 & 6,12 & 20,85 & 21,13 & 15,29 & 18,63 & 20,02 & 2,78 & 28,36 & 26,41 & 26,41 & 10,56 & 20,29 & 31,1 & 33,1 & 28,1 & 33,5 \\
$\mathrm{Mgt}$ & 6,03 & 8,12 & 7,42 & 12,30 & 7,66 & 13,46 & 7,89 & 9,05 & 6,73 & 6,96 & 8,58 & 9,28 & 8,35 & 8,12 & 4,4 & 5,6 & 4,2 & 3,7 \\
$\mathrm{Hm}$ & - & - & - & - & - & 9,76 & - & - & - & - & - & - & - & - & - & - & - & - \\
$\mathrm{DiCa}$ & 9,28 & 8,24 & 3,25 & 0,35 & 8,82 & - & 10,32 & 11,02 & 4,41 & 6,26 & 7,31 & 6,61 & 14,27 & 5,22 & 10,1 & 4,7 & 8,9 & 10,2 \\
$\mathrm{DiMg}$ & 4,50 & 3,60 & 2,70 & 0,20 & 4,60 & - & 4,80 & 5,20 & 3,70 & 2,70 & 3,15 & 3,60 & 7,50 & 2,30 & 5,9 & 2,9 & 5,1 & 6,9 \\
$\mathrm{DiFe}$ & 4,62 & 4,62 & 0,13 & 0,13 & 3,96 & - & 5,41 & 5,68 & 0,13 & 3,56 & 4,15 & 2,77 & 6,34 & 2,90 & 3,7 & 1,6 & 3,4 & 2,5 \\
$\mathrm{HyMg}$ & 10,00 & 7,90 & 32,80 & 10,50 & 6,60 & 7,00 & 6,20 & 6,90 & 43,20 & 5,80 & 5,35 & 7,40 & - & 7,20 & 14,6 & 20,6 \\
$\mathrm{HyFe}$ & 9,90 & 10,43 & 1,85 & 7,26 & 5,94 & - & 7,00 & 7,66 & 2,11 & 7,52 & 7,06 & 5,94 & - & 9,50 & 9,2 & 11,3 & 10,3 & 17,7 \\
Fo & - & - & 30,80 & - & - & - & - & 0,63 & 20,37 & - & - & - & 2,45 & - & - & - & - & 3,8 \\
Fa & - & - & 2,04 & - & - & - & - & 0,71 & 1,12 & - & - & - & 2,34 & - & - & - & - & 1,4 \\
Qz & 0,12 & 0,96 & - & 3,12 & 8,88 & 7,14 & 4,44 & - & - & 4,14 & 7,44 & 3,12 & - & 4,14 & - & 0,4 & 1,4 & - \\
\hline TOTAL & 98,60 & 99,58 & 92,85 & 93,55 & 97,34 & 91,95 & 97,72 & 98,32 & 91,48 & 94,56 & 96,34 & 97,02 & 97,22 & 97,78 & 98,3 & 96,3 & 97,5 & 96,9 \\
\hline
\end{tabular}




\begin{tabular}{|c|c|c|c|c|c|c|c|c|c|c|c|c|c|c|c|c|c|c|}
\hline & 75 & 76 & 77 & 78 & 79 & 80 & $8 \Gamma$ & 82 & 87 & 88 & 89 & 90 & 91 & 97 & 98 & 99 & 100 & 101 \\
\hline $\mathrm{SiO}_{2}$ & 46,8 & 46,6 & 47,9 & 47,4 & 46,8 & 46,6 & 47,4 & 49,4 & 47,9 & 46,1 . & 45,3 & 46,2 & 47,9 & 47,02 & 46,68 & 46,80 & 47,07 & 46,30 \\
\hline $\mathrm{TiO}_{2}$ & 1,2 & 1,5 & 1,5 & 1,7 & 1,5 & 1,3 & 1,3 & 3,1 & 4,4 & 3,1 & 3,5 & 3,3 & 3,6 & 2,96 & 3,58 & 2,70 & 1,76 & 1,50 \\
\hline $\mathrm{Al}_{2} \mathrm{O}_{3}$ & 14,8 & 14,9 & 14,8 & 14,7 & 13,7 & 14,3 & 15,9 & 14,8 & 14,3 & 13,3 & 13,1 & 13,1 & 12,9 & 13,55 & 13,34 & 14,12 & 14,50 & 15,50 \\
\hline $\mathrm{Fe}_{2} \mathrm{O}_{3}^{3}$ & 2,46 & 2,94 & 4,23 & 3,36 & 3,31 & 4,59 & 2,7 & 5,26 & 4,24 & 3,02 & 6,24 & 2,86 & 4,99 & 5,89 & 4,27 & 3,64 & 3,39 & 2,90 \\
\hline $\mathrm{FeO}$ & 7,77 & 8,78 & 8,06 & 8,49 & 9,35 & 7,48 & 7,20 & 10,65 & 8,78 & 9,07 & 7,34 & 10,65 & 8,92 & 11,02 & 8,95 & 9,93 & 8,94 & 8,20 \\
\hline $\mathrm{MnO}$ & 0,19 & 0,21 & 0,20 & 0,22 & 0,22 & 0,18 & 0,17 & 0,28 & 0,20 & 0,22 & 0,22 & 0,22 & 0,22 & 0,37 & 0,22 & 0,27 & 0,22 & 0,27 \\
\hline $\mathrm{MgO}$ & 9,8 & 10,0 & 8,6 & 8,2 & 10,2 & 9,7 & 8,7 & 4,8 & 5,3 & 10,0 & 10,4 & 10,0 & 7,4 & 4,30 & 8,62 & 4,65 & 8,85 & 6,70 \\
\hline $\mathrm{CaO}$ & 12,3 & 10,7 & 11,8 & 10,8 & 9,6 & 11,2 & 12,0 & 3,8 & 9,1 & 9,7 & 9,4 & 9,8 & 9,7 & 8,14 & 9,54 & 8,68 & 10,46 & 11,20 \\
\hline $\mathrm{Na}_{2} \mathrm{O}$ & 1,08 & 0,96 & 1,38 & 1,60 & 1,05 & 1,00 & 1,60 & 2,55 & 2,79 & 2,89 & 2,22 & 1,05 & 1,68 & 2,63 & 2,13 & 5,47 & $\begin{array}{r}10,70 \\
1,30\end{array}$ & $\begin{array}{r}1,20 \\
4,25\end{array}$ \\
\hline $\mathrm{K}_{2} \mathrm{O}$ & 0,31 & 0,30 & 0,19 & 0,37 & 0,72 & 0,27 & 0,27 & 1,05 & 0,84 & 0,67 & 0,81 & 0,72 & 0,90 & 1,09 & 0,79 & 0,86 & 0,44 & 0,37 \\
\hline $\mathrm{P}_{2} \mathrm{O}_{5}$ & 0,13 & 0,14 & 0,17 & 0,18 & 0,19 & 0,10 & 0,14 & 0,10 & 0,57 & 0,45 & 0,49 & 0,47 . & 0,54 & 0,40 & 0,50 & 0,32 & 0,17 & 0,13 \\
\hline $\mathrm{H}_{2} \mathrm{O}^{-}$ & - & - & - & - & - & - & - & - & - & - & - & - & - & 0,59 & - & 0,28 & - & 0,14 \\
\hline P.F. & 2,86 & 2,19 & 2,04 & 2,19 & $2 ; 51$ & 2,76 & 2,27 & 2,78 & 0,74 & 0,81 & 0,42 & 0,98 & 1,08 & 2,04 & 0,81 & 1,14 & 2,35 & 2,36 \\
\hline TOTAL & 99,70 & 99,22 & 99,87 & 99,21 & 99,15 & 99,48 & 99,65 & 98,57 & 99,16 & 99,33 & 99,44 & 99,35 & 99,83 & 99,43 & 98,86 & 99,45 & 99,82 & 99,82 \\
\hline
\end{tabular}

(NORMA CIPW)

\begin{tabular}{|c|c|c|c|c|c|c|c|c|c|c|c|c|c|c|c|c|c|c|}
\hline$A p$ & 0,3 & 0,3 & 0,3 & 0,3 & 0,3 & 0,3 & 0,3 & 0,3 & 1,3 & 1,0 & 1,0 & 1,0 & 1,3 & 1,0 & 1,3 & 0,7 & 0,3 & 0,3 \\
\hline $11^{2}$ & 2,3 & 2,9 & 2,9 & 3,2 & 2,9 & 2,4 & 2,4 & 5,9 & 8,4 & 5,9 & 6,7 & 6,2 & 6,8 & 5,6 & 6,8 & $\checkmark 5,2$ & 3,3 & 2,9 \\
\hline Or & 1,7 & 1,7 & 1,1 & 2,2 & 4,4 & 1,7 & 1,7 & 6,1 & 5,0 & 3,9 & 5,0 & 4,4 & 5,6 & 6,7 & 4,4 & 5,0 & 2,8 & 2,2 \\
\hline $\mathrm{Ab}$ & 8,9 & 7,9 & 11,5 & 13,6 & 8,9 & 8,4 & 13,6 & 21,5 & 23,6 & 23,6 & 18,9 & 8,9 & 14,1 & 22,0 & 17,8 & 26,9 & 11,0 & 19,7 \\
\hline $\mathrm{Ne}$ & - & - & - & - & - & - & - & - & - & 2,0 & - & - & - & - & - & 10,4 & - & 8,9 \\
\hline An & 34,8 & 35,6 & 33,6 & 31,7 & 30,3 & 33,6 & 35,3 & 18,1 & 23,9 & 19,7 & 23,1 & 28,6 & 24,7 & 22,0 & 24,7 & 11,4 & 32,2 & 22,0 \\
\hline Mgt & 3,5 & 4,2 & 6,0 & 4,9 & 4,9 & 6,7 & 3,9 & 7,7 & 6,0 & 4,4 & 9,0 & 4,2 & 7,2 & 8,6 & 6,3 & 5,3 & 4,9 & 4,2 \\
\hline $\mathrm{Hm}$ & - & - & - & - & - & - & - & - & - & - & - & - & - & - & - & - & - & - \\
\hline $\mathrm{DiCa}$ & 10,7 & 7,0 & 10,1 & 8,8 & 6,8 & 8,8 & 9,7 & - & 7,5 & 10,8 & 8,8 & 7,3 & 8,3 & 6,6 & 8,0 & 12,5 & 7,9 & 13,7 \\
\hline DiMa & 4,4 & 6,6 & 5,5 & 4,3 & - & 6,1 & 6,4 & - & 4,9 & 7,2 & 7,0 & 4,6 & 5,6 & 3,2 & 5,5 & 6,2 & 4,9 & 8,0 \\
\hline $\mathrm{DiFe}$ & 3,0 & 2,1 & 2,8 & 2,8 & 2,1 & 2,0 & 2,6 & - & 2,1 & 2,8 & 0,8 & 2,2 & 2,1 & 3,3 & 1,8 & 6,1 & 2,5 & 5,0 \\
\hline HyMg & 16,4 & 20,6 & 14,9 & 15,0 & 21,2 & 18,1 & 14,1 & 12,0 & 8,4 & - & 11,8 & 18,7 & 12,9 & 7,6 & 16,1 & - & 17,2 & - \\
\hline $\mathrm{HyFe}$ & 7,1 & 9,5 & 6,5 & 7,7 & 10,2 & 6,1 & 5,9 & 10,6 & 3,7 & - & 1,3 & 9,9 & 4,6 & 7,8 & 5,4 & - & 8,6 & - \\
\hline $\mathrm{Fo}$ & 0,8 & - & - & - & - & - & 0,8 & - & - & 12,4 & 5,0 & - & - & - & - & 3,8 & - & 6,2 \\
\hline $\mathrm{Fa}$ & 0,4 & - & - & - & - & - & 0,4 & - & - & 5,1 & 0,6 & - & - & - & - & 4,0 & - & 4,4 \\
\hline $\mathrm{Qz}$ & - & 0,9 & 1,4 & 1,3 & 0,3 & 2,5 & - & 10,9 & 3,6 & - & - & 1,6 & 5,4 & 3,2 & 0,3 & - & 1,4 & $\ddot{-}$ \\
\hline TOTAL & 96,8 & 97,1 & 97,7 & 97,0 & 96,6 & 96,7 & 97,1 & $96,0^{(3)}$ & 98,4 & 98,8 & 97,6 & 98,6 & 98,6 & 97,6 & 98,4 & 97,5 & 97,0 & 97,5 \\
\hline
\end{tabular}

(1) $+2,9 \%$ de Corindon 
Entende-se que isto seja devido à variação, no caso, do teor de $\mathrm{CaO}$ da rocha, a correção sendo feita traçando-se $\overline{\mathbf{P}^{\prime} \mathrm{P}^{\prime \prime}}$ corresponde à variação de $\mathrm{CaO}$, no exemplo, sofrida pela rocha e corrigida, admitindo-se que a posição primativa de $\mathrm{P}$ foi em $\mathrm{A}$ (Fig. 1A). Caso não se saiba a priori qual teria sido a posição primitiva da rocha, as correções são feitas por tentativa, deslocando-se A dentro da sequiência de referência, até que se obtenha uma posição de correção que aprove nos diagramas de teste ( $\mathrm{E} \mathrm{e} \mathrm{G}$ de Beswick e Soucie, 1978 ou Figs. 6 e 8 a seguir). Na correção por tentativas, a mais comum, é fácil concluir que há mais de uma solução para a posição primitiva de cada rocha, ou seja, existem diversas posições para A (Fig. 1A) dentro da sequiência de referência que satisfazem os diagramas de teste. O problema, portanto, é determinar qual a melhor posição entre as diversas possíveis. Adotou-se para isto a premissa de que, estudando-se diversas amostras de um mesmo corpo, a melhor situação primitiva é aquela onde o maior número de amostras é concomitantemente aprovado nos testes. Fazendo-se o estudo por grupo de amostras e não para cada amostra individual, as possibilidades de erro são, naturalmente, reduzidas.

As Figs. 2 a 8 situam as análises dos basitos do Espinhaço e da região Sul de Minas (quadro 1) em relação às sequiências de referência determinadas por Beswick e Soucie. No primeiro diagrama (Fig. 2) para as análises do Espinhaço, foram consideradas as posições $\mathrm{A}$ e $\mathrm{C}$ como referência de comparação; $\mathrm{A}$ correspondendo à análise com maior teor $\mathrm{em} \mathrm{K}_{2} \mathrm{O}$, e $\mathrm{C}$ àquela com o menor teor. Admitiu-se portanto, primeiramente, que a posição primitiva de todas as análises plotadas tenha sido em $\mathrm{A}$, os deslocamentos em relação a este ponto sendo devidos ao ganho ou perda de algum óxido. O mesmo raciocínio foi desenvolvido em relação ao ponto C. Uma terceira posição de comparação, denominada $\mathrm{B}$, foi considerada individualmente para cada análise corrigida. Neste caso, determinou-se o menor movimento possível de $\mathrm{K}_{2} \mathrm{O}$ necessário para ligar cada análise da sua posição atual com a sequiência de referência. Finalmente, para os maciços do Serro e São Gonçalo, foi também considerada a posição $\mathrm{D}$, empobrecida em $\mathrm{K}_{2} \mathrm{O}$ ao máximo, que logo se revelou imprópria, tendo sido abandonada.

As correções desenvolvidas geometricamente em relação aos pontos $\mathrm{A}, \mathrm{B}, \mathrm{C}$ e $\mathrm{D}$ resultaram nos quadros 2 a 4, parte denominada unidades logarítmicas. Estes quadros contêm, expressos em unidades logarítmicas, os ganhos $(+)$ ou perdas $(-)$ em óxidos determinados para as diversas amostras analisadas, valores estes calculados conforme a técnica descrita por Beswick e Soucie (1978). Cada um dos quadros, refere-se a uma das posições de comparação A, B ou C. Notar que não foram consideradas todas as

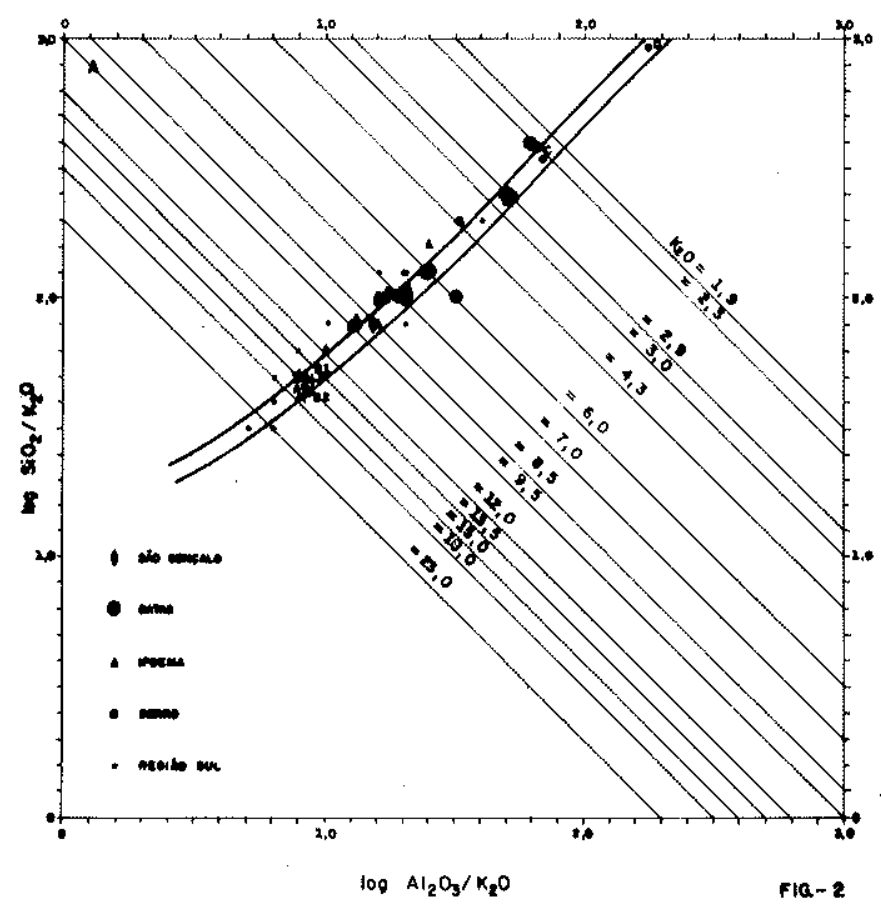

Figuras 2-8 - Diagramas tipo. $\mathrm{X} / \mathrm{Z}$ vs. $\mathrm{Y} / \mathrm{Z}$ usados no dimensionamento geométrico das variações químicas das rochas. As sequiências de referência (linhas curvas paralelas) são de Beswick e Soucie (1978). Os valores de $\mathrm{K}_{2} \mathrm{O}$ crescem uniformemente devido a todas as rochas diagramadas terem uma mineralogia primitiva qualitativamente igual. E o posicionamento destas linhas que permite a quantificação das variações químicas. Notar que as Figs. 6 e 8 são diagramas de teste que permitem selecionar a melhor posição de correção. Ver textos para expliçacões. Os pontos marcados $B_{1}$ e $B_{2}$ (Fig. 2) são traquitos com 23 moles de $\mathrm{K}_{2} \mathrm{O}$ que, por terem composição mineralógica qualitativa diferente dos basitos, quebram a uniformidade da seqüência de aumento de $\mathrm{K}_{2} \mathrm{O}$ 

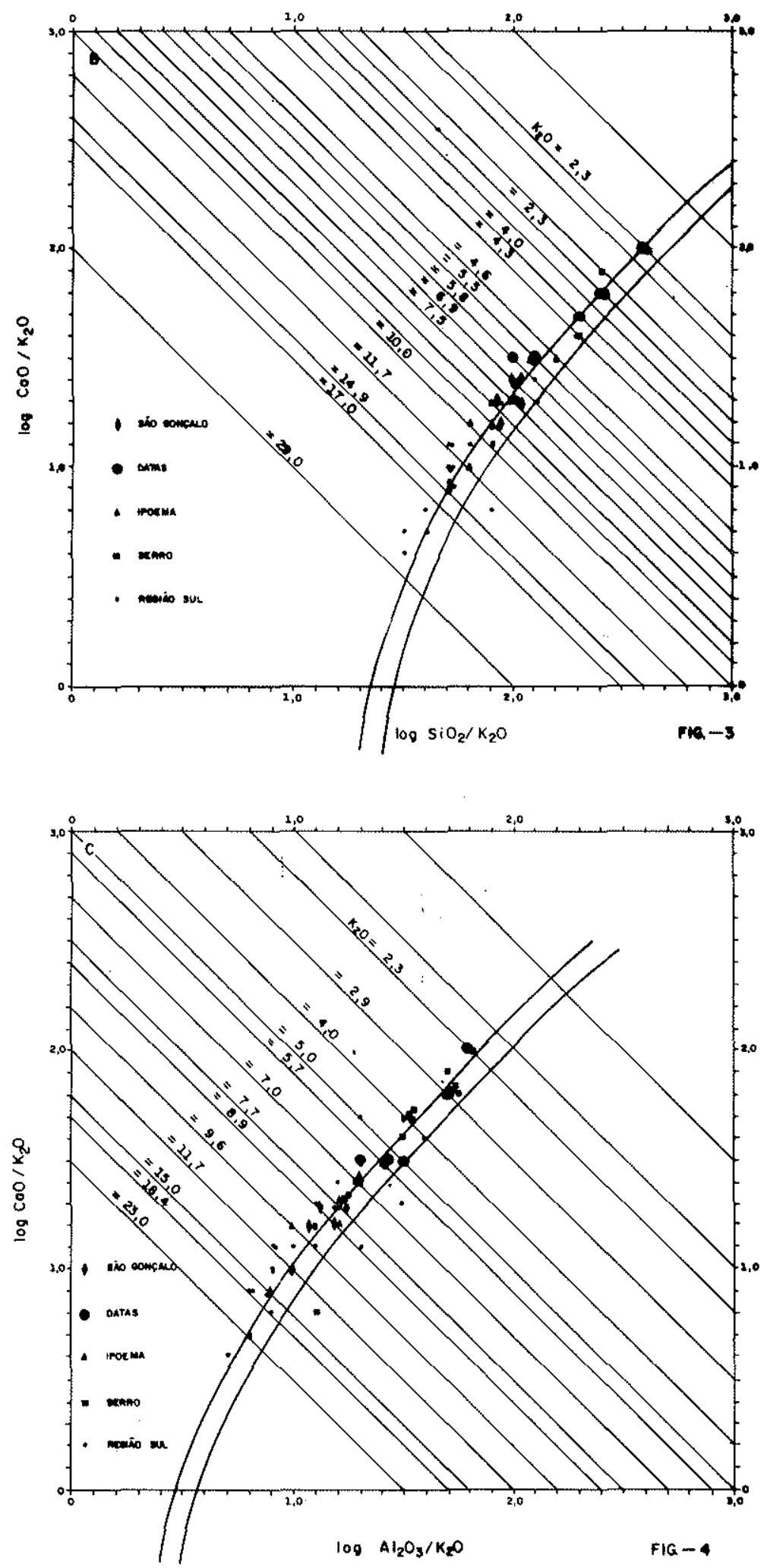

Figuras 2-8 - Diagramas tipo $\mathrm{X} / \mathrm{Z}$ vs. $\mathrm{Y} / \mathrm{Z}$ usados no dimensionamento geométrico das variações químicas das rochas. As sequiências de referência (linhas curvas paralelas) são de Beswick e Soucie (1978). Os valores de $\mathrm{K}_{2} \mathrm{O}$ crescem uniformemente devido a todas as rochas diagramadas terem uma mineralogia primitiva qualitativamente igual. E o posicionamento destas linhas que permite a quantificação das variações químicas. Notar que as Figs. 6 e 8 são diagramas de teste que permitem selecionar a melhor posição de correção. Ver textos para explicações. Os pontos marcados $\mathrm{B}_{1}$ e $\mathrm{B}_{2}$ (Fig. 2) são traquitos com 23 moles de $\mathrm{K}_{2} \mathrm{O}$ que, por terem composição mineralógica qualitativa diferente dos basitos, quebram a uniformidade da sequiência de aumento de $\mathrm{K}_{2} \mathrm{O}$ 


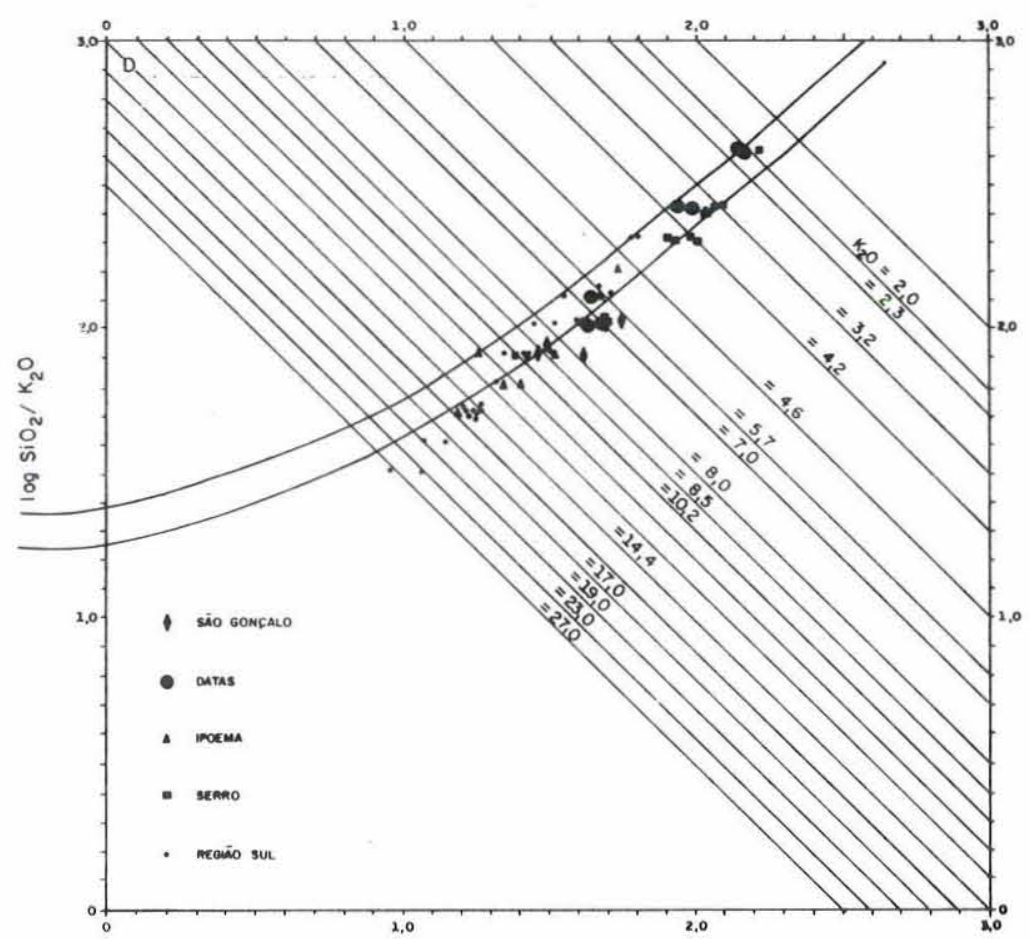

$\log \mathrm{Fm} / \mathrm{K}_{2} \mathrm{O} \quad \mathrm{FIG}-5$

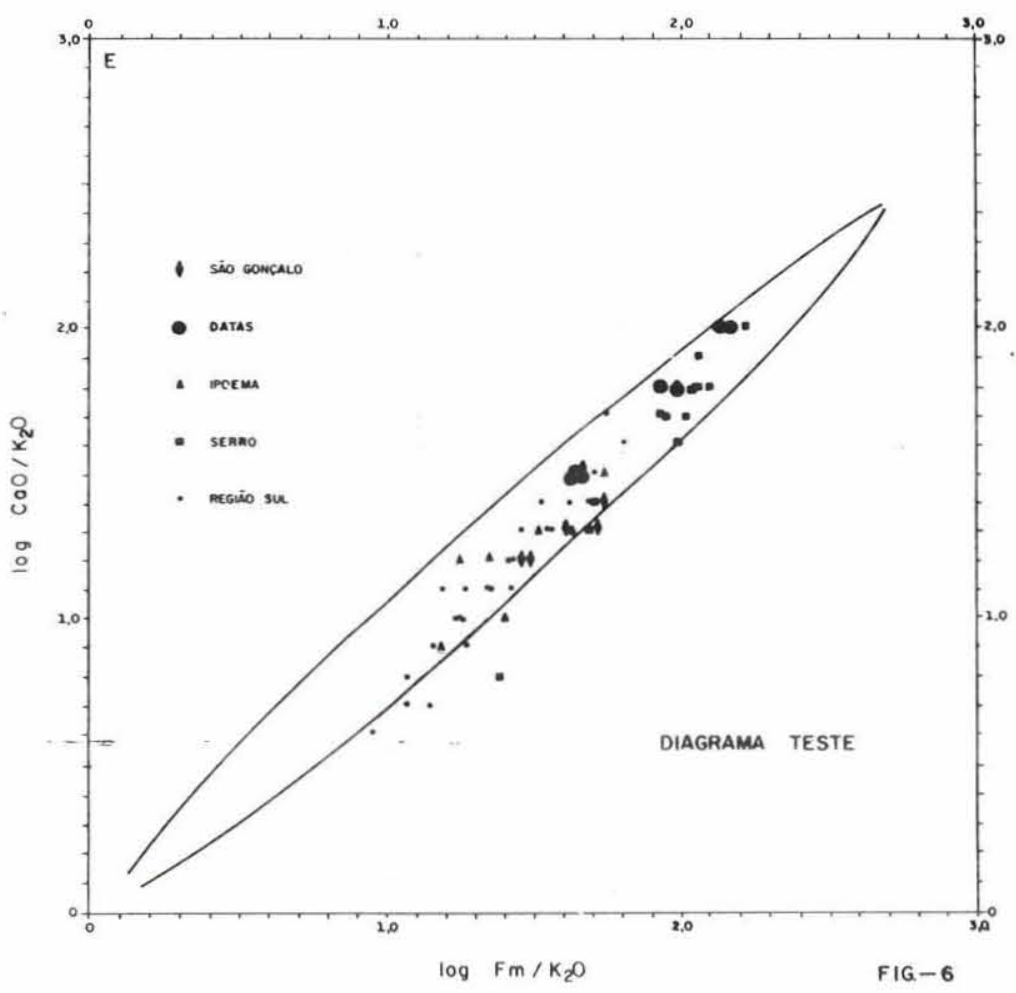

Figuras 2-8 - Diagramas tipo $\mathrm{X} / \mathrm{Z}$ vs. $\mathrm{Y} / \mathrm{Z}$ usados no dimensionamento geométrico das variações químicas das rochas. As seqüências de referência (linhas curvas paralelas) são de Beswick e Soucie (1978). Os valores de $\mathrm{K}_{2} \mathrm{O}$ crescem uniformemente devido a todas as rochas diagramadas terem uma mineralogia primitiva qualitativamente igual. E o posicionamento destas linhas que permite a quantificação das variações químicas. Notar que as Figs. 6 e 7 são diagramas de teste que permitem selecionar a melhor posição de correção. Ver textos para explicações. Os pontos marcados B e B $_{2}$ (Fig. 2) são traquitos com 23 moles de $\mathrm{K}_{2} \mathrm{O}$ que, por terem composição mineralógica qualitativa diferente dos basitos, quebram a uniformidade da sequiência de aumento de $\mathrm{K}_{2} \mathrm{O}$ 


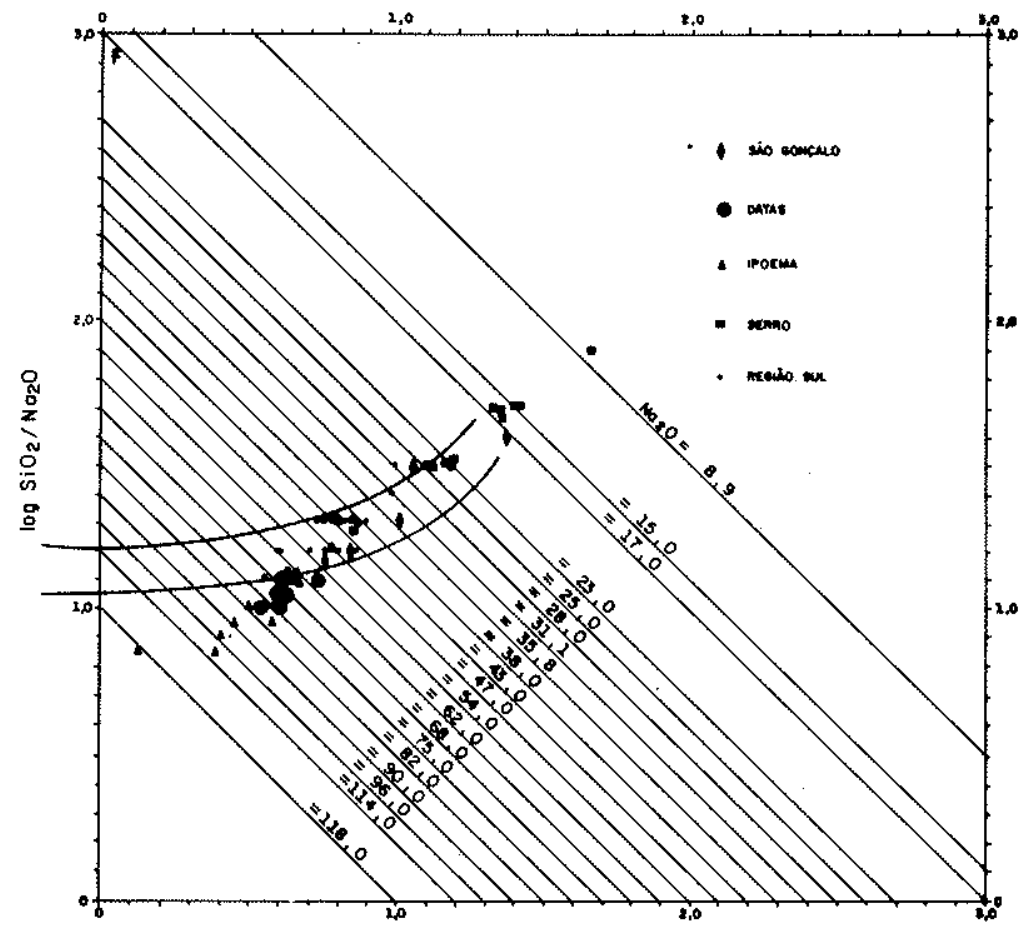

$100 \mathrm{Fm} / \mathrm{Na}_{2} \mathrm{O}$

F16. -7

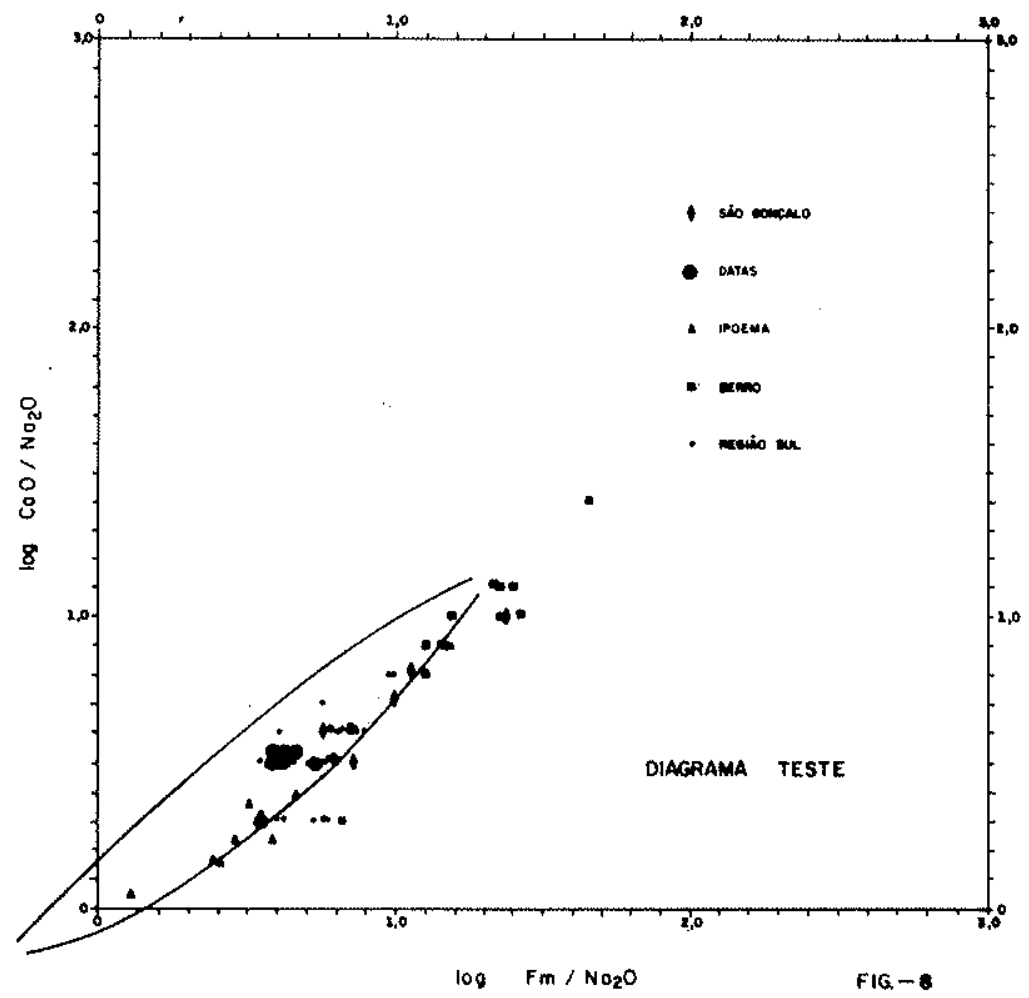

Figuras 2-8 - Diagramas tipo $\mathrm{X} / \mathrm{Z}$ vs. $\mathrm{Y} / \mathrm{Z}$ usados no dimensionamento geométrico das variaçóes quimicas das rochas. As seqüências de referência (linhas curvas paralelas) são de Beswick e Soucie (1978). Os valores de $\mathrm{K}_{2} \mathrm{O}$ crescem uniformemente devido a todas as rochas diagramadas terem uma mineralogia primitiva qualitativamente igual. E o posicionamento destas linhas que permite a quantificação das variações químicas. Notar que as Figs. 6 e 8 são diagramas de teste que permitem selecionar a melhor posição de correção. Ver textos para explicações. Os pontos marcados $B_{1}$ e $B_{2}$ (Fig. 2) são traquitos com 23 moles de $\mathrm{K}_{2} \mathrm{O}$ que, por terem composição mineralógica qualitativa diferente dos basitos, quebram a uniformidade da sequiência de aumento de $\mathrm{K}_{2} \mathrm{O}$ 
análises do quadro 1 , tendo sido escolhidas, para cada sistema, as duas análises mais distantes da seqüência de referencia (Fig. 2) e uma perfeitamente centrada, esta tendo sido marcada com *. Os resultados obtidos deste modo, serão certamente representativos do sistema total. As duas últimas colunas da primeira metade dos quadros mostram, com afirmativas (sim) ou negativas (não), se a correção do $\mathrm{Na}_{2} \mathrm{O}$ para cada análise, feita em relação à posição de referência dada, foi ou não aprovada no diagrama de teste para $\mathrm{O} \mathrm{Na}_{2} \mathrm{O}$ (Fig. 8).

Até então têm-se, conforme determinado pela técnica de Beswick e Soucie, valores expressos em unidades logarítmicas que dão uma idéia da mobilidade relativa dos diversos óxidos estudados. O problema, não resolvido pelos autores da técnica de base, é transformar estes valores em porcentagens de óxidos, ou seja, expressar em valor absoluto de porcentagem de peso as perdas ou ganhos de cada óxido devidos às transformações ocorridas durante a história geológica dos maciços rochosos estudados.

Das Figs. IA e B é fácil notar que os pontos $\mathrm{P}$ e $\mathrm{P}^{\prime}$, correspondentes aos extremos do vetor de correção do $\mathrm{SiO}_{2}$, ou $\mathrm{P}^{\prime}$ e $\mathrm{P}^{\prime \prime}$, correspondentes aos vetores de correçấo de qualquer outro dos óxidos expressos nas Figs. 2 a 8 , correspondem, em abscissa e ordenada, a valores diretamente visíveis de $\log x / z$, onde $x$ corresponde ao número de moles de um dos óxidos estudados e $z$ ao $\mathrm{K}_{2} \mathrm{O}$. Portanto, a subtração de $\log$ $x^{\prime} / z^{\prime}$ de $\mathrm{P}^{\prime}$ do $\log x / z$ de $\mathrm{P}$, corresponde à variação determinada para o óxido $x$ em relação a uma das posições de referência $A, B, C$ ou $D$. Valores calculados deste modo $(\Delta \mathrm{P})$, constam na primeira metade dos quadros 2 a 4 . A transformação de $\Delta \mathrm{P}$ (Fig. 1A) em $\%$ de peso de óxido, depende unicamente do conhecimento do valor do número de moles de $\mathrm{K}_{2} \mathrm{O}$ em $\mathrm{P}$ e em $\mathrm{P}^{\prime}$ (ou $\mathrm{P}^{\prime}$ e $\mathrm{P}^{\prime \prime}$ para os outros óxidos além do $\mathrm{SiO}_{2}$ ). Tem-se, portanto

$$
\begin{gathered}
\mathrm{P}^{\prime}-\mathrm{P}=\Delta \mathrm{P} \text { ou } \\
\log \frac{x^{\prime}}{z^{\prime}}-\log \frac{x}{z}=\log \Delta \mathrm{P}
\end{gathered}
$$

de onde se conclui que, a determinação da variação do número de moles de qualquer dos óxidos estudados $(\Delta x)$, pode ser feita pela resolução da equação seguinte:

$$
\Delta x_{\text {(males) }}=\left(\mathrm{K}_{2} \mathrm{O}_{\mathrm{p}} \cdot-\mathrm{K}_{2} \mathrm{O}_{\mathrm{p}}\right) \cdot(\operatorname{antilog} \Delta \mathrm{P})
$$

A ressaltar (Fig. 1B) que para a determinação de $\Delta x$ de qualquer óxido que não o $\mathrm{SiO}_{2}$, os valores de $\mathrm{K}_{2} \mathrm{O}_{\mathrm{p}^{\prime}}$ e $\mathrm{K}_{2} \mathrm{O}_{\mathrm{p}}$ devem sempre ser considerados a partir do ponto $\mathrm{P}$, onde se situa a análise atual nos diversos diagramas (Figs. 3 a 8 ).

Segundo a equação acima, a determinação de $\Delta x$ depende exclusivamente do conhecimento do $\mathrm{K}_{2} \mathrm{O}$ em qualquer ponto dos diagramas. Em diagramas do tipo considerado, as variações de $\mathrm{K}_{2} \mathrm{O}$ (ou $\mathrm{Na}_{2} \mathrm{O}$ para as Figs. 7 e 8 ) correspondem a deslocamentos segundo linhas inclinadas de $45^{\circ}$ (Figs. 1A e B). Desde que as rochas estudadas tenham tido na origem composiৎ̧ões mineralógicas qualitativas pouco diferentes, o número de moles de $\mathrm{K}_{2} \mathrm{O}$ das rochas lançadas nos diagramas crescerá logaritmicamente de modo uniforme

\begin{tabular}{|c|c|c|c|c|c|c|c|c|c|c|c|c|c|c|c|c|c|}
\hline \multirow{3}{*}{ Localização } & \multirow{3}{*}{$\begin{array}{c}\text { Amostra } \\
\text { N. }\end{array}$} & \multicolumn{8}{|c|}{ Unidades logaritmicas $(\Delta P)$} & \multicolumn{8}{|c|}{ Porcentagens dos óxidos } \\
\hline & & \multirow{2}{*}{$\mathrm{O}_{2}$} & \multicolumn{2}{|c|}{$\mathrm{CaO}$} & \multirow{2}{*}{$\mathrm{m}$} & \multirow{2}{*}{$\mathrm{K}_{2} \mathrm{O}$} & \multicolumn{3}{|c|}{$\mathrm{Na}_{2} \mathrm{O}$} & \multirow{2}{*}{$\mathrm{SiO}_{2}$} & \multicolumn{2}{|c|}{$\mathrm{CaO}$} & \multirow{2}{*}{$\mathrm{Fm}$} & \multirow{2}{*}{$\mathrm{K}_{2} \mathrm{O}$} & \multicolumn{3}{|c|}{$\mathrm{Na}_{2} \mathrm{O}$} \\
\hline & & & $\mathrm{Si}$ & $\mathrm{Al}$ & & & $\mathrm{Si}$ & $\mathrm{CaSi}$ & $\mathrm{CaAl}$ & & $\mathrm{Si}$ & Al & & & $\mathrm{Si}$ & $\mathrm{CaSi}$ & $\mathrm{CaAl}$ \\
\hline Ipoer & $\begin{array}{c}9 \\
13 \\
15^{*}\end{array}$ & $\begin{array}{r}+0,05 \\
+0,05 \\
-0,04\end{array}$ & $\begin{array}{l}+0,22 \\
+0,20 \\
+0,26\end{array}$ & $\begin{array}{r}+0,11 \\
+0,11 \\
0,00\end{array}$ & $\begin{array}{r}+0,20 \\
+0,27 \\
0,00\end{array}$ & $\begin{array}{l}-0,68 \\
-0,41 \\
-0,41\end{array}$ & $\begin{array}{l}+0,41 \\
+0,07 \\
+0,32\end{array}$ & $\begin{array}{l}\text { não } \\
\text { sim } \\
\text { não }\end{array}$ & $\begin{array}{l}\operatorname{sim} \\
\text { sim } \\
\text { sim }\end{array}$ & $\begin{array}{l}+1,71 \\
+1,78 \\
-1,55\end{array}$ & $\begin{array}{r}+2,09 \\
+1,60 \\
+1,66\end{array}$ & $\begin{array}{r}+0,76 \\
+0,98 \\
0,00\end{array}$ & $\begin{array}{r}+2,94 \\
+5,25 \\
0,00\end{array}$ & $\begin{array}{l}-0,59 \\
-0,44 \\
-0,30\end{array}$ & $\begin{array}{r}+3,14 \\
+0,43 \\
+1,85\end{array}$ & $\begin{array}{l}\text { não } \\
\text { sim } \\
\text { não }\end{array}$ & $\begin{array}{l}\operatorname{sim} \\
\text { sim } \\
\text { sim }\end{array}$ \\
\hline Datas & $\begin{array}{l}1 \\
2 * \\
6\end{array}$ & $\begin{array}{r}+0,04 \\
-0,04 \\
-0,24\end{array}$ & $\begin{array}{l}+0,11 \\
+0,22 \\
+0,27\end{array}$ & $\begin{array}{l}+0,23 \\
+0,11 \\
+0,01\end{array}$ & $\begin{array}{r}+0,18 \\
+0,11 \\
0,00\end{array}$ & $\begin{array}{l}-1,26 \\
-1,11 \\
-0,82\end{array}$ & $\begin{array}{r}+0,19 \\
0,00 \\
0,00\end{array}$ & \begin{tabular}{|l|}
$\operatorname{sim}$ \\
sim \\
não
\end{tabular} & $\begin{array}{l}\text { não } \\
\text { sim } \\
\text { sim }\end{array}$ & $\begin{array}{r}+2,05 \\
-2,72 \\
-6,46\end{array}$ & $\begin{array}{l}+0,10 \\
+1,37 \\
+2,60\end{array}$ & $\begin{array}{l}+2,97 \\
+1,21 \\
+0,10\end{array}$ & $\begin{array}{r}+0,54 \\
+0,43 \\
0,00\end{array}$ & $\begin{array}{l}-0,73 \\
-0,70 \\
-0,53\end{array}$ & $\begin{array}{r}+1,15 \\
0,00 \\
0,00\end{array}$ & $\begin{array}{l}\text { sim } \\
\text { sim } \\
\text { não }\end{array}$ & $\begin{array}{l}\text { não } \\
\text { sim } \\
\text { sim }\end{array}$ \\
\hline Serro & $\begin{array}{l}74 \\
75^{*} \\
79\end{array}$ & $\begin{array}{r}+0,06 \\
-0,04 \\
+0,06\end{array}$ & $\begin{array}{l}+0,31 \\
+0,31 \\
+0,24\end{array}$ & $\begin{array}{l}+0,23 \\
+0,22 \\
+0,14\end{array}$ & $\begin{array}{l}+0,37 \\
+0,19 \\
+0,35\end{array}$ & $\begin{array}{l}-0,83 \\
-1,11 \\
-0,40\end{array}$ & $\left|\begin{array}{l}-0,71 \\
-0,61 \\
-0,49\end{array}\right|$ & \begin{tabular}{|c|} 
sim \\
não \\
sim
\end{tabular} & $\begin{array}{l}\operatorname{sim} \\
\operatorname{sim} \\
\operatorname{sim}\end{array}$ & $\begin{array}{l}+0,95 \\
-1,10 \\
+3,71\end{array}$ & $\begin{array}{r}+4,90 \\
+4,48 \\
+2,64\end{array}$ & $\begin{array}{l}+2,66 \\
+3,88 \\
+1,48\end{array}$ & $\begin{array}{l}+7,27 \\
+0,23 \\
+8,07\end{array}$ & $\begin{array}{l}-0,65 \\
-0,67 \\
-0,41\end{array}$ & $\begin{array}{r}-1,00 \\
-1,30 \\
-0,94\end{array}$ & \begin{tabular}{|l|} 
sim \\
não \\
sim \\
\end{tabular} & $\begin{array}{l}\operatorname{sim} \\
\text { sim } \\
\text { sim }\end{array}$ \\
\hline São Gonçalo & $\begin{array}{l}88^{*} \\
89 \\
90\end{array}$ & $\begin{array}{l}-0,05 \\
+0,05 \\
+0,06\end{array}$ & $\begin{array}{l}+0,12 \\
+0,31 \\
+0,25\end{array}$ & $\begin{array}{l}+0,12 \\
+0,23 \\
+0,12\end{array}$ & $\begin{array}{l}+0,30 \\
+0,37 \\
+0,37\end{array}$ & $\begin{array}{l}-0,55 \\
-0,26 \\
-0,41\end{array}$ & $\begin{array}{r}0,00 \\
0,00 \\
-0,32\end{array}$ & $\begin{array}{l}\operatorname{sim} \\
\operatorname{sim} \\
\operatorname{sim}\end{array}$ & $\begin{array}{l}\operatorname{sim} \\
\operatorname{sim} \\
\operatorname{sim}\end{array}$ & $\begin{array}{l}-4,25 \\
+1,28 \\
+3,55\end{array}$ & $\begin{array}{l}+1,05 \\
+3,26 \\
+2,67\end{array}$ & $\begin{array}{r}+1,39 \\
+2,89 \\
+0,89\end{array}$ & $\begin{array}{l}+5,95 \\
+5,52 \\
+8,82\end{array}$ & $\begin{array}{l}-0,44 \\
-0,35 \\
-0,41\end{array}$ & $\begin{array}{l}0,00 \\
0,00 \\
0,61\end{array}$ & $\begin{array}{l}\operatorname{sim} \\
\operatorname{sim} \\
\operatorname{sim}\end{array}$ & $\begin{array}{l}\operatorname{sim} \\
\text { sim } \\
\text { sim }\end{array}$ \\
\hline Região Sul & $\begin{array}{l}32 \\
35 \\
50\end{array}$ & $\begin{array}{l}-0,12 \\
-0,05 \\
+0,16\end{array}$ & $\begin{array}{r}0,00 \\
0,00 \\
+0,22\end{array}$ & $\begin{array}{r}-0,14 \\
0,00 \\
-0,15\end{array}$ & $\begin{array}{r}0,00 \\
+0,13 \\
+0,22\end{array}$ & $\begin{array}{r}-0,54 \\
+0,18 \\
-0,40\end{array}$ & $\begin{array}{r}-0,08 \\
0,00 \\
0,00\end{array}$ & $\begin{array}{c}\text { não } \\
\text { não } \\
\text { sim }\end{array}$ & $\begin{array}{l}\operatorname{sim} \\
\text { não } \\
\text { sim }\end{array}$ & $\begin{array}{r}-3,81 \\
-0,77 \\
+5,49\end{array}$ & $\begin{array}{r}0,00 \\
0,00 \\
+2,34\end{array}$ & $\begin{array}{r}-1,95 \\
0,00 \\
-1,18\end{array}$ & $\begin{array}{r}0,00 \\
+1,35 \\
+3,89\end{array}$ & $\begin{array}{r}-0,37 \\
+0,51 \\
-0,46\end{array}$ & $\begin{array}{r}-0,44 \\
0,00 \\
0,00\end{array}$ & $\begin{array}{l}\text { não } \\
\text { não } \\
\text { sim }\end{array}$ & $\begin{array}{l}\text { sim } \\
\text { não } \\
\text { sim }\end{array}$ \\
\hline
\end{tabular}
em direção à origem (Figs. 2 a 8, traços diagonais).

Quadro 2 - Posição A ( $\mathrm{K}_{2} \mathrm{O}=14,5$ Moles). Quadro geral de variação em unidades logaritmicas e porcentagem de óxidos

* Amostras situadas dentro da seqüência de referência 
Quadro 3 - Posição $\mathrm{B}\left(\mathrm{K}_{2} \mathrm{O}\right.$ mínimo). Quadro geral de variação em unidades logarítmicas e porcentagem de óxidos

\begin{tabular}{|c|c|c|c|c|c|c|c|c|c|c|c|c|c|c|c|c|c|}
\hline \multirow{3}{*}{ Localização } & \multirow{3}{*}{$\begin{array}{c}\text { Amostra } \\
\mathrm{N}^{\circ}{ }^{\circ}\end{array}$} & \multicolumn{8}{|c|}{ Unidades logarítmicas $(\Delta \mathrm{P})$} & \multicolumn{8}{|c|}{ Porcentagens dos óxidos } \\
\hline & & \multirow{2}{*}{$\mathrm{SiO}_{2}$} & \multicolumn{2}{|c|}{$\mathrm{CaO}$} & \multirow{2}{*}{$\mathrm{Fm}$} & \multirow{2}{*}{$\mathrm{K}_{2} \mathrm{O}$} & \multicolumn{3}{|c|}{$\mathrm{Na}_{2} \mathrm{O}$} & \multirow{2}{*}{$\mathrm{SiO}_{2}$} & \multicolumn{2}{|c|}{$\mathrm{CaO}$} & \multirow{2}{*}{$\mathrm{Fm}$} & \multirow{2}{*}{$\mathrm{K}_{2} \mathrm{O}$} & \multicolumn{3}{|c|}{$\mathrm{Na}_{2} \mathrm{O}$} \\
\hline & & & $\mathrm{Si}$ & $\mathrm{Al}$ & & & $\mathrm{Si}$ & $\mathrm{CaSi}$ & $\mathrm{CaAl}$ & & $\mathrm{Si}$ & Al & & & $\mathrm{Si}$ & $\mathrm{CaSi}$ & $\mathrm{CaAl}$ \\
\hline lpoema & $\begin{array}{c}9 \\
13 \\
15^{*}\end{array}$ & $\begin{array}{r}+0,07 \\
+0,06 \\
0,00\end{array}$ & $\begin{array}{r}+0,02 \\
+0,08 \\
0,00\end{array}$ & $\begin{array}{r}0,00 \\
+0,03 \\
0,00\end{array}$ & $\begin{array}{r}0,00 \\
+0,11 \\
0,00\end{array}$ & $\begin{array}{l}- \\
-\end{array}$ & $\begin{array}{l}+0,53 \\
+0,14 \\
+0,32\end{array}$ & $\begin{array}{l}\operatorname{sim} \\
\operatorname{sim} \\
\operatorname{sim}\end{array}$ & $\begin{array}{l}\operatorname{sim} \\
\operatorname{sim} \\
\operatorname{sim}\end{array}$ & $\begin{array}{r}+0,58 \\
+4,84 \\
0,00\end{array}$ & $\begin{array}{r}+0,17 \\
+0,33 \\
0,00\end{array}$ & $\begin{array}{r}0,00 \\
+0,10 \\
0,00\end{array}$ & $\begin{array}{r}0,00 \\
+1,51 \\
0,00\end{array}$ & $\begin{array}{r}-0,01 \\
-0,03 \\
0,00\end{array}$ & $\begin{array}{r}+3,89 \\
+0,79 \\
+1,88\end{array}$ & $\begin{array}{l}\operatorname{sim} \\
\operatorname{sim} \\
\operatorname{sim}\end{array}$ & $\begin{array}{l}\text { sim } \\
\text { sim } \\
\text { sim }\end{array}$ \\
\hline Datas & $\begin{array}{l}1 \\
2^{*} \\
6\end{array}$ & $\begin{array}{r}+0,04 \\
0,00 \\
-0,13\end{array}$ & $\begin{array}{r}+0,04 \\
0,00 \\
0,00\end{array}$ & $\begin{array}{r}+0,07 \\
0,00 \\
0,00\end{array}$ & $\begin{array}{l}0,00 \\
0,00 \\
0,00\end{array}$ & $\begin{array}{l}- \\
- \\
-\end{array}$ & $\begin{array}{l}+0,25 \\
+0,12 \\
+0,19\end{array}$ & $\begin{array}{l}\operatorname{sim} \\
\operatorname{sim} \\
\operatorname{sim}\end{array}$ & $\begin{array}{l}\text { não } \\
\text { sim } \\
\text { sim }\end{array}$ & $\begin{array}{r}+1,84 \\
0,00 \\
-0,39\end{array}$ & $\begin{array}{r}+0,20 \\
0,00 \\
0,00\end{array}$ & $\begin{array}{r}+0,28 \\
0,00 \\
0,00\end{array}$ & $\begin{array}{l}0,00 \\
0,00 \\
0,00\end{array}$ & $\begin{array}{r}0,00 \\
0,00 \\
+0,02\end{array}$ & $\begin{array}{l}+1,56 \\
+0,56 \\
+0,77\end{array}$ & $\begin{array}{l}\operatorname{sim} \\
\operatorname{sim} \\
\operatorname{sim}\end{array}$ & $\begin{array}{l}\text { não } \\
\text { sim } \\
\text { sim }\end{array}$ \\
\hline Serro & $\begin{array}{l}74 \\
75^{*} \\
79\end{array}$ & $\begin{array}{r}+0,08 \\
0,00 \\
+0,05\end{array}$ & $\begin{array}{r}+0,11 \\
+0,11 \\
0,00\end{array}$ & $\begin{array}{r}+0,10 \\
+0,08 \\
+0,01\end{array}$ & $\begin{array}{r}+0,17 \\
0,00 \\
+0,18\end{array}$ & $\begin{array}{l}- \\
- \\
-\end{array}$ & $\begin{array}{l}-0,26 \\
-0,08 \\
-0,38\end{array}$ & $\begin{array}{c}\text { não } \\
\text { não } \\
\text { não }\end{array}$ & $\begin{array}{l}\text { sim } \\
\text { não } \\
\text { não }\end{array}$ & $\begin{array}{r}+2,99 \\
0,00 \\
+1,67\end{array}$ & $\begin{array}{r}+1,39 \\
+0,52 \\
0,00\end{array}$ & $\begin{array}{l}+1,39 \\
+0,67 \\
+0,01\end{array}$ & $\begin{array}{r}+2,00 \\
0,00 \\
+4,58\end{array}$ & $\begin{array}{l}-0,04 \\
-0,01 \\
-0,03\end{array}$ & $\begin{array}{l}-0,28 \\
-0,10 \\
-0,61\end{array}$ & $\begin{array}{l}\text { não } \\
\text { não } \\
\text { não }\end{array}$ & $\begin{array}{l}\text { sim } \\
\text { não } \\
\text { não }\end{array}$ \\
\hline São Gonçalo & $\begin{array}{l}88^{*} \\
89 \\
90\end{array}$ & $\begin{array}{r}0,00 \\
+0,03 \\
+0,05\end{array}$ & $\begin{array}{l}+0,09 \\
+0,16 \\
+0,05\end{array}$ & $\begin{array}{r}0,00 \\
+0,16 \\
+0,02\end{array}$ & $\begin{array}{l}+0,17 \\
+0,22 \\
+0,13\end{array}$ & $\begin{array}{l}- \\
-\end{array}$ & $\begin{array}{l}0,00 \\
0,00 \\
0,00\end{array}$ & $\begin{array}{l}\operatorname{sim} \\
\text { sim } \\
\text { não }\end{array}$ & $\begin{array}{l}\operatorname{sim} \\
\operatorname{sim} \\
\operatorname{sim}\end{array}$ & $\begin{array}{r}0,00 \\
+0,61 \\
+2,56\end{array}$ & $\begin{array}{r}0,56 \\
+1,83 \\
+0,51\end{array}$ & $\begin{array}{r}0,00 \\
+2,07 \\
+0,01\end{array}$ & $\begin{array}{l}+3,27 \\
+3,17 \\
+3,27\end{array}$ & $\begin{array}{l}-0,01 \\
-0,06 \\
-0,02\end{array}$ & $\begin{array}{l}0,00 \\
0,00 \\
0,00\end{array}$ & $\begin{array}{l}\operatorname{sim} \\
\operatorname{sim} \\
\text { não }\end{array}$ & $\begin{array}{l}\operatorname{sim} \\
\operatorname{sim} \\
\operatorname{sim}\end{array}$ \\
\hline Região Sul & $\begin{array}{l}32 \\
35 \\
50\end{array}$ & $\begin{array}{l}-0,06 \\
-0,03 \\
+0,16\end{array}$ & $\begin{array}{r}-0,02 \\
+0,16 \\
+0,07\end{array}$ & $\begin{array}{r}-0,16 \\
0,00 \\
-0,19\end{array}$ & $\begin{array}{r}0,00 \\
+0,28 \\
+0,07\end{array}$ & $\begin{array}{l}- \\
-\end{array}$ & $\begin{array}{l}0,00 \\
0,00 \\
0,00\end{array}$ & $\begin{array}{l}\text { sim } \\
\text { não } \\
\text { sim }\end{array}$ & $\begin{array}{l}\text { sim } \\
\text { não } \\
\text { sim }\end{array}$ & $\begin{array}{l}-1,55 \\
-0,79 \\
+7,00\end{array}$ & $\begin{array}{r}-1,28 \\
+0,39 \\
+2,22\end{array}$ & $\begin{array}{r}-1,99 \\
0,00 \\
-1,52\end{array}$ & $\begin{array}{r}0,00 \\
+4,09 \\
+1,16\end{array}$ & $\begin{array}{l}+0,03 \\
-0,24 \\
-0,01\end{array}$ & $\begin{array}{l}0,00 \\
0,00 \\
0,00\end{array}$ & $\begin{array}{c}\text { sim } \\
\text { não } \\
\text { sim }\end{array}$ & $\begin{array}{l}\text { sim } \\
\text { não } \\
\text { sim }\end{array}$ \\
\hline
\end{tabular}

* Amostras situadas dentro da sequiência de referência

Quadro 4 - Posição $C\left(\mathrm{~K}_{2} \mathrm{O}=2,3\right.$ moles). Quadro geral de variação em unidades logarítmicas e porcentagem de óxidos

\begin{tabular}{|c|c|c|c|c|c|c|c|c|c|c|c|c|c|c|c|c|c|}
\hline \multirow{3}{*}{ Localização } & \multirow{3}{*}{$\begin{array}{c}\text { Amostra } \\
\text { N. }\end{array}$} & \multicolumn{8}{|c|}{ Unidades logarítmicas $(\Delta \mathrm{P})$} & \multicolumn{8}{|c|}{ Porcentagens dos óxidos } \\
\hline & & \multirow{2}{*}{$\mathrm{SiO}_{2}$} & \multicolumn{2}{|c|}{$\mathrm{CaO}$} & \multirow{2}{*}{ n } & \multirow{2}{*}{$\mathrm{K}_{2} \mathrm{O}$} & \multicolumn{3}{|c|}{$\mathrm{Na}_{2} \mathrm{O}$} & \multirow{2}{*}{$\mathrm{SiO}_{2}$} & \multicolumn{2}{|c|}{$\mathrm{CaO}$} & \multirow{2}{*}{$\mathrm{Fm}$} & \multirow{2}{*}{$\mathrm{K}_{2} \mathrm{O}$} & \multicolumn{3}{|c|}{$\mathrm{Na}_{2} \mathrm{O}$} \\
\hline & & & $\mathrm{Si}$ & $\mathrm{Al}$ & & & $\mathrm{Si}$ & $\mathrm{CaSi}$ & $\mathrm{CaAl}$ & & Si & $\mathrm{Al}$ & & & $\mathrm{Si}$ & $\mathrm{CaSi}$ & $\mathrm{CaAl}$ \\
\hline Ipoema & $\begin{array}{c}9 \\
13 \\
15^{*}\end{array}$ & $\begin{array}{l}+0,11 \\
+0,12 \\
+0,01\end{array}$ & $\begin{array}{r}+0,02 \\
+0,04 \\
0,00\end{array}$ & $\begin{array}{l}0,00 \\
0,00 \\
0,00\end{array}$ & $\begin{array}{r}0,00 \\
+0,04 \\
-0,17\end{array}$ & $\begin{array}{l}+0,62 \\
+0,89 \\
+0,89\end{array}$ & $\begin{array}{l}+0,59 \\
+0,27 \\
+0,37\end{array}$ & $\begin{array}{l}\text { sim } \\
\text { sim } \\
\text { sim }\end{array}$ & $\begin{array}{l}\operatorname{sim} \\
\operatorname{sim} \\
\operatorname{sim}\end{array}$ & $\begin{array}{l}+3,13 \\
+1,02 \\
+1,35\end{array}$ & $\begin{array}{r}+0,17 \\
+0,11 \\
0,00\end{array}$ & $\begin{array}{l}0,00 \\
0,00 \\
0,00\end{array}$ & $\begin{array}{r}0,00 \\
+0,38 \\
-4,20\end{array}$ & $\begin{array}{l}+0,14 \\
+0,29 \\
+0,43\end{array}$ & $\begin{array}{l}+4,13 \\
+1,36 \\
+2,15\end{array}$ & $\begin{array}{l}\operatorname{sim} \\
\operatorname{sim} \\
\operatorname{sim}\end{array}$ & $\begin{array}{l}\operatorname{sim} \\
\operatorname{sim} \\
\operatorname{sim}\end{array}$ \\
\hline Datas & $\begin{array}{l}1 \\
2^{*} \\
6\end{array}$ & $\begin{array}{r}+0,10 \\
0,00 \\
-0,20\end{array}$ & $\begin{array}{r}+0,11 \\
0,00 \\
0,00\end{array}$ & $\begin{array}{r}+0,07 \\
0,00 \\
0,00\end{array}$ & $\begin{array}{r}0,00 \\
0,00 \\
-0,10\end{array}$ & $\begin{array}{r}+0,04 \\
+0,19 \\
+0,47\end{array}$ & $\begin{array}{r}+0,36 \\
+0,12 \\
0,00\end{array}$ & $\begin{array}{l}\text { não } \\
\text { sim } \\
\text { sim }\end{array}$ & $\begin{array}{l}\text { não } \\
\text { sim } \\
\text { sim }\end{array}$ & $\begin{array}{r}+6,00 \\
0,00 \\
-7,71\end{array}$ & $\begin{array}{r}+1,60 \\
0,00 \\
0,00\end{array}$ & $\begin{array}{r}+0,71 \\
0,00 \\
0,00\end{array}$ & $\begin{array}{r}0,00 \\
0,00 \\
-3,55\end{array}$ & $\begin{array}{l}+0,01 \\
+0,04 \\
+0,20\end{array}$ & $\begin{array}{r}+2,02 \\
+0,50 \\
0,00\end{array}$ & $\begin{array}{l}\text { não } \\
\text { sim } \\
\text { sim }\end{array}$ & $\begin{array}{l}\text { não } \\
\text { sim } \\
\text { sim }\end{array}$ \\
\hline Serro & $\begin{array}{l}74 \\
75^{*} \\
79\end{array}$ & $\begin{array}{r}+0,11 \\
0,00 \\
+0,11\end{array}$ & $\begin{array}{l}+0,11 \\
+0,11 \\
+0,03\end{array}$ & $\begin{array}{r}+0,07 \\
+0,07 \\
0,00\end{array}$ & $\begin{array}{r}+0,11 \\
0,00 \\
+0,12\end{array}$ & $\begin{array}{l}+0,48 \\
+0,18 \\
+0,91\end{array}$ & $\begin{array}{r}-0,36 \\
-0,80 \\
0,00\end{array}$ & $\begin{array}{l}\text { não } \\
\text { não } \\
\text { não }\end{array}$ & $\begin{array}{l}\text { não } \\
\text { não } \\
\text { sim }\end{array}$ & $\begin{array}{r}+4,07 \\
0,00 \\
+6,14\end{array}$ & $\begin{array}{l}+1,39 \\
+0,52 \\
+0,43\end{array}$ & $\begin{array}{r}+0,89 \\
+0,40 \\
0,00\end{array}$ & $\begin{array}{r}+0,31 \\
0,00 \\
+2,11\end{array}$ & $\begin{array}{l}+0,08 \\
+0,06 \\
+0,32\end{array}$ & $\begin{array}{r}-0,41 \\
-0,10 \\
0,00\end{array}$ & $\begin{array}{l}\text { não } \\
\text { não } \\
\text { não }\end{array}$ & $\begin{array}{l}\text { não } \\
\text { não } \\
\text { sim }\end{array}$ \\
\hline São Gonçalo & $\begin{array}{l}88^{*} \\
89 \\
90\end{array}$ & $\begin{array}{r}0,00 \\
+0,10 \\
+0,10\end{array}$ & $\begin{array}{r}0,00 \\
+0,10 \\
0,00\end{array}$ & $\begin{array}{r}0,00 \\
+0,04 \\
0,00\end{array}$ & $\begin{array}{l}+0,05 \\
+0,12 \\
+0,11\end{array}$ & $\begin{array}{l}+0,76 \\
+1,06 \\
+0,91\end{array}$ & $\begin{array}{l}0,00 \\
0,00 \\
0,00\end{array}$ & $\begin{array}{l}\text { sim } \\
\text { sim } \\
\text { não }\end{array}$ & $\begin{array}{l}\operatorname{sim} \\
\operatorname{sim} \\
\operatorname{sim}\end{array}$ & $\begin{array}{r}0,00 \\
+4,86 \\
+5,02\end{array}$ & $\begin{array}{r}0,00 \\
+1,25 \\
0,00\end{array}$ & $\begin{array}{r}0,00 \\
+0,04 \\
0,00\end{array}$ & $\begin{array}{l}+0,01 \\
+1,37 \\
+2,44\end{array}$ & $\begin{array}{l}+0,29 \\
+0,38 \\
+0,32\end{array}$ & $\begin{array}{l}0,00 \\
0,00 \\
0,00\end{array}$ & $\begin{array}{l}\text { sim } \\
\text { sim } \\
\text { não }\end{array}$ & $\begin{array}{l}\operatorname{sim} \\
\operatorname{sim} \\
\operatorname{sim}\end{array}$ \\
\hline Regiâ & $\begin{array}{l}32 \\
35 \\
50\end{array}$ & $\begin{array}{r}-0,11 \\
0,00 \\
+0,20\end{array}$ & $\begin{array}{r}-0,05 \\
-0,07 \\
0,00\end{array}$ & $\begin{array}{l}-0,21 \\
-0,10 \\
-0,23\end{array}$ & $\begin{array}{r}-0,20 \\
0,00 \\
0,00\end{array}$ & $\begin{array}{l}+0,77 \\
+1,48 \\
+0,90\end{array}$ & $\begin{array}{r}-0,05 \\
0,00 \\
+0,12\end{array}$ & $\begin{array}{l}\text { não } \\
\text { não } \\
\text { sim }\end{array}$ & $\begin{array}{l}\text { sim } \\
\text { não } \\
\text { sim }\end{array}$ & $\begin{array}{r}-5,47 \\
0,00 \\
+9,47\end{array}$ & $\begin{array}{r}-0,96 \\
-1,55 \\
0,00\end{array}$ & $\begin{array}{l}-2,91 \\
-1,17 \\
-1,39\end{array}$ & $\begin{array}{r}-4,83 \\
0,00 \\
0,00\end{array}$ & $\begin{array}{l}+0,37 \\
+1,24 \\
+0,27\end{array}$ & $\begin{array}{r}-0,14 \\
0,00 \\
+0,24\end{array}$ & $\begin{array}{l}\text { não } \\
\text { não } \\
\text { sim }\end{array}$ & $\begin{array}{l}\text { sim } \\
\text { não } \\
\text { sim }\end{array}$ \\
\hline
\end{tabular}

* Amostras situadas dentro da sequiência de referência

Caso na origem as rochas tenham tido composições qualitativas diferentes, a variação de $\mathrm{K}_{2} \mathrm{O}$ não será uniforme, aparecendo intercalações de valores altos de $\mathrm{K}_{2} \mathrm{O}$ em uma zona de baixos valores ou vice-versa. Isto se explica pela tendência que mostram os minerais, não importando as suas quantidades mas sim as suas qualidades (tipo), de se comportarem do mesmo modo, perdendo ou ganhando $\mathrm{K}_{2} \mathrm{O}$ quando submetidos às mesmas condições de transformação. Naturalmente, por exemplo, um feldspato de um tipo dado tenderá sempre a perder $\mathrm{K}_{2} \mathrm{O}$ durante uma fase de transformação, e a perda total de $\mathrm{K}_{2} \mathrm{O}$ será proporcional à quantidade do feldspato na rocha. Uma outra rocha do mesmo maciço, com um feldspato diferente, subme- 
tida às mesmas condições de transformação da primeira amostra, deverá reagir de modo diferente, talvez ganhando $\mathrm{K}_{2} \mathrm{O}$. O lançamento destas duas amostras em um mesmo diagrama não dará uma sequiência uniforme de variação do $\mathrm{K}_{2} \mathrm{O}$. Já o lançamento de amostras com composições qualitativas comparáveis resultará em um crescimento uniforme do $\mathrm{K}_{2} \mathrm{O}$, devido às diferentes quantidades de cada um dos minerais nas diferentes amostras. Os mesmos minerais de todas as amostras sempre perderão (ou ganharão) $\mathrm{K}_{2} \mathrm{O}$ para uma dada condição de transformação, e esta perda (ou ganho) será proporcional (crescimento uniforme) à quantidade dos minerais nas rochas.

Portanto, a equação de determinação de $\Delta x$, dependente dos valores de $\mathrm{K}_{2} \mathrm{O}$, só é resolvida caso seja feita uma seleção petrográfica das amostras diagramadas. Cada diagrama deverá conter somente amostras cujas composições mineralógicas originais não tenham sido qualitativamente muito diferentes. Foi, provavelmente, este o ponto onde Beswick e Soucie tiveram problemas para a determinação quantitativa, em porcentagem de peso, das variações de éxidos das amostras por eles estudadas. No estudo daqueles autores foram diagramadas 250 amostras de composições variando entre riolitos e basaltos de tipos diversos. São rochas de composiçoes mineralógicas qualitativas muito diferentes, cujas porcentagens de $\mathrm{K}_{2} \mathrm{O}$ dependem não somente da quantidade de uma espécie mineral, caso em que haveria uma variação uniforme, mas também da presença de diversas espécies minerais não existentes em todas as amostras. O problema teria sido resolvido com a seleção petrográfica das amostras, juntando-as em grupos de composição minera- lógica qualitativa semelhantes, que seriam estudados em separado.

Para cada uma das amostras estudadas (quadros 2 a 4) foram determinadas as variações de $\mathrm{K}_{2} \mathrm{O}$ nas Figs. 2 a 8 e calculadas as variações quantitativas de cada um dos óxidos. Os resultados são mostrados nos quadros 2 a 5 , na parte denominada "porcentagens de óxidos". Das quatro posições de comparação adotadas $(A, B, C$ e D) foi selecionada a melhor para cada um dos sistemas (Ipoema, Datas, Serro e São Gonçalo) com base nos diagramas de teste (Figs. 6 e 8 ). As posiçōes selecionadas (B e C para Ipoema, B para Datas, A para Serro e A para São Gonçalo, nos quadros 6 e 10) correspondem, para cada maciço, à situação mais provável da composição química das amostras antes das transformações que causaram as variações dos teores originais dos diversos óxidos.

Os quadros 5 a 10 mostram, para cada maciço e para cada amostra estudada, a composição atual da amostra, as três possibilidades de correção (A, B e C) e a composição original da rocha, segundo a melhor das possibilidades de correção. Notar que os valores expressos em A, B e C são os valores de porcentagem de peso de óxidos correspondentes aos da análise atual, subtraídos ou somados à variação em porcentagem de peso de óxidos mostradas nos quadros 2 a 4 . Naturalmente, a soma dos valores corrigidos correspondentes aos casos de correção A, B e C. não soma o mesmo que a análise atual, visto não corresponderem a uma análise química. Somente para o caso de correção selecionada como a melhor (composição original da rocha), os valores foram recalculados a $100 \%$, a fim de serem expressos como uma

Quadro 5-Datas

\section{CORREÇ̃̃O DE ANÁLISES}

\begin{tabular}{|c|c|c|c|c|c|c|c|c|c|c|c|c|c|c|c|}
\hline \multirow{2}{*}{$\begin{array}{l}\text { Amostra } \\
\text { Situação }\end{array}$} & \multicolumn{5}{|c|}{1} & \multicolumn{5}{|c|}{2} & \multicolumn{5}{|c|}{6} \\
\hline & Atual & A & B & C. & $\begin{array}{c}\text { Ori- } \\
\text { ginal } \\
\text { B }\end{array}$ & Atual & A & B & C & $\begin{array}{c}\text { Ori- } \\
\text { ginal } \\
\mathrm{B}\end{array}$ & Atual & A & B & C. & $\begin{array}{c}\text { Ori- } \\
\text { ginal } \\
B\end{array}$ \\
\hline $\mathrm{SiO}_{2}$ & 47,1 & 45,05 & 45,3 & 41,1 & 48,3 & 46,5 & 49,2 & 46,5 & 46,5 & 48,0 & 41,5 & 47,95 & 41,9 & 49,2 & 44,3 \\
\hline $\mathrm{TiO}_{2}$ & 1,6 & 1,5 & 1,5 & 1,4 & 1,6 & 1,9 & 1,95 & 1,9 & 1,9 & 2,0 & 1,5 & 1,6 & 1,5 & 1,7 & 1,6 \\
\hline $\mathrm{Al}_{2} \hat{O}_{3}$ & 14,5 & 14,5 & 14,5 & 14,5 & 15,5 & 15,6 & 15,6 & 15,6 & 15,6 & 16,1 & 18,6 & 18,6 & 18,6 & 18,6 & 19,7 \\
\hline $\mathrm{Fe}_{2} \mathrm{O}_{3}$ & 3,18 & 2,97 & 3,05 & 2,88 & 3,25 & 3,91 & 4,02 & 3,89 & 3,89 & 4,01 & 4,26 & 4,59 & 4,24 & 4,79 & 4,4 \\
\hline $\mathrm{FeO}$ & 8,21 & 7,91 & 8,21 & 8,21 & 8,77 & 8,36 & 8,61 & 8,36 & 8,36 & 8,63 & 7,78 & 7,78 & 7,78 & 9,71 & 8,23 \\
\hline $\mathrm{MnO}$ & 0,31 & 0,30 & 0,31 & 0,31 & 0,35 & 0,26 & 0,27 & 0,26 & 0,26 & 0,25 & 0,29 & 0,29 & 0,29 & 0,36 & 0,31 \\
\hline $\mathrm{MgO}$ & 6,5 & 6,3 & 6,5 & 6,5 & 6,9 & 5,9 & 6,1 & 5,9 & 5,9 & 6,1 & 6,2 & 6,2 & 6,2 & 7,7 & 6,6 \\
\hline $\mathrm{aO}$ & 10,9 & 7,9 & 10,6 & 10,2 & 11,5 & 10,3 & 9,1 & 10,3 & 10,3 & 10,6 & 9,8 & 9,7 & 9,8 & 9,8 & 10,4 \\
\hline $\mathrm{Na}_{2} \mathrm{O}$ & 4,85 & 3,70 & 3,29 & 2,83 & 3,51 & 4,24 & 4,24 & 3,68 & 3,74 & 3,80 & 4,24 & 4,24 & 3,47 & 4,24 & 3,67 \\
\hline $\mathrm{K}_{2} \mathrm{O}$ & 0,22 & 0,95 & 0,23 & 0,22 & 0,24 & 0,27 & 0,97 & 0,27 & 0,23 & 0,28 & 0,54 & 1,07 & 0,50 & 0,34 & 0,53 \\
\hline $\mathrm{P}_{2} \mathrm{O}_{5}$ & 0,16 & 0,15 & 0,15 & 0,14 & 0,16 & 0,15 & 0,15 & 0,15 & 0,15 & 0,13 & 0,15 & 0,16 & 0,15 & 0,17 & 0,12 \\
\hline $\mathrm{H}_{2} \mathrm{O}$ & 0,09 & 0,10 & 0,10 & 0,10 & 0,10 & 0,04 & 0,10 & 0,10 & 0,10 & 0,10 & 0,11 & 0,10 & 0,10 & 0,10 & 0,10 \\
\hline P.F. & 1,92 & 0,00 & 0,00 & 0,00 & 0,00 & 2,79 & 0,00 & 0,00 & 0,00 & 0,00 & 4,44 & 0,00 & 0,00 & 0,00 & 0,00 \\
\hline TOTAL & 99,54 & 91,33 & 93,74 & 88,39 & 100,00 & 100,22 & 100,31 & 96,91 & 96,93 & 100,00 & 99,41 & 102,28 & 94,53 & 106,71 & 100,00 \\
\hline
\end{tabular}


análise química total. Cabem aqui diversas observações relativas aos cálculos feitos.

1) Pela técnica descrita, são corrigidos diretamente os valores de $\mathrm{SiO}_{2}, \mathrm{Al}_{2} \mathrm{O}_{3}$ (constante) $\mathrm{CaO}$, $\mathrm{Na}_{2} \mathrm{O}, \mathrm{K}_{2} \mathrm{O}$ e $\mathrm{Fm}(\mathrm{FeO}+\mathrm{MgO}+\mathrm{MnO})$. Os valores individuais de $\mathrm{FeO}, \mathrm{MgO}$ e $\mathrm{MnO}$, adotados como sendo os originais, foram calculados se fazendo uma proporção entre o valor atual e o valor original do Fm de cada uma das amostras.

2) $\mathrm{O}$ valor adotado como original para $\mathrm{o}_{2} \mathrm{O}$ foi de $0,10 \%$, constante para todas as amostras. A perda ao fogo da rocha original foi considerada zero.
3) Restaram, portanto, o $\mathrm{TiO}_{2}, \mathrm{o}_{\mathrm{Fe}} \mathrm{O}_{3}$ e o $\mathrm{P}_{2} \mathrm{O}_{5}$ a serem corrigidos. Os valores atuais destes óxidos foram recalculados na mesma proporção em que variou a soma dos óxidos corrigidos da análise atual em relação à soma dos mesmos óxidos participantes da composição das "situações de correção" adotadas (A, B e C). Este cálculo tem boas probabilidades de aproximar os valores atuais daqueles originais.

4) Determinada a melhor "situação de correção", os valores dos óxidos foram recalculados a $100 \%$, perfazendo a provável composição original da rocha.

Quadro 6-Ipoema

CORREÇÃO DE ANÁLISES

\begin{tabular}{|c|c|c|c|c|c|c|c|c|c|c|c|c|c|c|c|c|c|c|}
\hline \multirow{2}{*}{$\frac{\text { Amostra }}{\text { Situação }}$} & \multicolumn{6}{|c|}{9} & \multicolumn{6}{|c|}{13} & \multicolumn{6}{|c|}{15} \\
\hline & Atual & A & B & C & $\begin{array}{c}\text { Ori- } \\
\text { ginal } \\
B\end{array}$ & $\begin{array}{c}\text { Ori- } \\
\text { ginal } \\
\mathrm{C}\end{array}$ & Atual & A & B & C & $\begin{array}{c}\text { Ori- } \\
\text { ginal } \\
\mathrm{B}\end{array}$ & $\begin{array}{l}\text { Ori- } \\
\text { ginal } \\
\mathrm{C}\end{array}$ & Atual & A & B & C & $\begin{array}{c}\text { Ori- } \\
\text { ginal } \\
\mathrm{B}\end{array}$ & $\begin{array}{c}\text { Ori- } \\
\text { ginal } \\
\mathrm{C}\end{array}$ \\
\hline $\mathrm{SiO}_{2}$ & 45,6 & 43,9 & 45,0 & 42,5 & 48,5 & 47,4 & 46,9 & 44,9 & 51,7 & 45,9 & 51,6 & 48,1 & 49,9 & 51,45 & 49,9 & 48,55 & 51,6 & 49,1 \\
\hline $\mathrm{TiO}_{z}$ & 3,2 & 2,9 & 3,05 & 2,94 & 3,29 & 3,28 & 3,0 & 2,73 & 3,08 & 2,94 & 3,07 & 3,07 & 2,5 & 2,5 & 2,45 & 2,51 & 2,52 & 2,50 \\
\hline $\mathrm{Al}_{2} \mathrm{O}_{3}$ & 13,8 & 13,8 & 13,8 & 13,8 & 14,9 & 15,4 & 13,2 & 13,2 & 13,2 & 13,2 & 13,2 & 13,8 & 16,8 & 16,8 & 16,8 & 16,8 & 17,4 & 17,0 \\
\hline $\mathrm{Fe}_{2} \mathrm{O}_{3}$ & 2,37 & 2,16 & 2,25 & 2,18 & 2,42 & 2,44 & 3,63 & 3,30 & 3,73 & 3,55 & 3,72 & 3,72 & 3,66 & 3,66 & 3,58 & 3,67 & 3,71 & 3,71 \\
\hline $\mathrm{FeO}$ & 11,10 & 9,05 & 11,10 & 11,10 & 11,93 & 12,38 & 11,67 & 8,10 & 10,65 & 11,41 & 10,62 & 11,95 & 7,42 & 7,42 & 7,42 & 10,63 & 7,68 & 10,75 \\
\hline $\mathrm{MnO}$ & 0,21 & 0,17 & 0,21 & $0,2]$ & 0,23 & 0,23 & 0,30 & 0,21 & 0,27 & 0,29 & 0,27 & 0,30 & 0,28 & 0,28 & 0,28 & 0,40 & 0,29 & 0,40 \\
\hline $\mathrm{MgO}$ & 4,6 & 3,75 & 4,6 & 4,6 & 4,96 & 5,13 & 5,2 & 3,61 & 4,74 & 5,09 & 4,73 & 5,33 & 2,0 & 2,0 & 2,0 & 2,87 & 2,1 & 2,90 \\
\hline $\mathrm{CaO}$ & 8,7 & 7,9 & 8,7 & 8,7 & 9,4 & 9,7 & 8,6 & 7,6 & 8,5 & 8,6 & 8,44 & 9,00 & 7,4 & 7,4 & 7,4 & 7,4 & 7,7 & 7,5 \\
\hline $\mathrm{Na}_{2} \mathrm{O}$ & 7,03 & 3,89 & 3,14 & 2,90 & 3,38 & 3,24 & 3,92 & 3,49 & 3,13 & 3,65 & 3,12 & 3,82 & 7,31 & 5,46 & 5,43 & 5,16 & 5,62 & 5,22 \\
\hline $\mathrm{K}_{2} \mathrm{O}$ & 0,43 & 1,02 & 0,48 & 0,29 & 0,52 & 0,32 & 0,68 & 1,12 & 0,73 & 0,39 & 0,73 & 0,41 & 0,89 & 1,19 & 0,89 & 0,46 & 0,92 & 0,46 \\
\hline $\mathrm{P}_{2} \mathrm{O}_{5}$ & 0,36 & 0,33 & 0,34 & 0,33 & 0,37 & 0,38 & 0,40 & 0,36 & 0,41 & 0,39 & 0,40 & 0,40 & 0,36 & 0,36 & 0,35 & 0,36 & 0,36 & 0,36 \\
\hline $\mathrm{H}_{2} \mathrm{O}$ & 0,35 & 0,10 & 0,10 & 0,10 & 0,10 & 0,10 & 0,34 & 0,10 & 0,10 & 0,10 & 0,10 & 0,10 & 0,23 & 0,10 & 0,10 & 0,10 & 0,10 & 0,10 \\
\hline P.F. & 1,19 & 0,00 & 0,00 & 0,00 & 0,00 & 0,00 & 1,64 & 0,00 & 0,00 & 0,00 & 0,00 & 0,00 & 1,26 & 0,00 & 0,00 & 0,00 & 0,00 & 0,00 \\
\hline TOTAL & 98,64 & 88,97 & 92,77 & 89,65 & 100,00 & 100,00 & 99,48 & 88,72 & 100,24 & 95,51 & 100,00 & 100,00 & 100,01 & 98,62 & 96,6 & 98,91 & 100,00 & 100,00 \\
\hline
\end{tabular}

Quadro 7 - Serro

\section{CORREÇÃO DE ANÁLISE}

\begin{tabular}{|c|c|c|c|c|c|c|c|c|c|c|c|c|c|c|c|}
\hline \multirow{2}{*}{$\begin{array}{l}\text { Amostra } \\
\text { Situação }\end{array}$} & \multicolumn{5}{|c|}{74} & \multicolumn{5}{|c|}{75} & \multicolumn{5}{|c|}{79} \\
\hline & Atual & A & B & C & $\begin{array}{c}\text { Ori- } \\
\text { ginal } \\
\text { A }\end{array}$ & Atual & A & B & C & $\begin{array}{c}\text { Ori- } \\
\text { ginal } \\
\mathrm{A}\end{array}$ & Atual & A & B & C & $\begin{array}{c}\text { Ori- } \\
\text { ginal } \\
\text { A }\end{array}$ \\
\hline $\mathrm{SiO}_{2}$ & 46,1 & 45,15 & 43,1 & 42,0 & 52,0 & 46,8 & 47,9 & 46,8 & 46,8 & 50,3 & 46,8 & 43,1 & 45,1 & 40,7 & 51,7 \\
\hline $\mathrm{TiO}_{2}$ & 0,89 & 0,77 & 0,81 & 0,82 & 0,89 & 1,2 & 1,14 & 1,15 & 1,16 & 1,20 & 1,5 & 1,26 & 1,36 & 1,32 & 1,51 \\
\hline $\mathrm{Al}_{2} \mathrm{O}_{3}$ & 14,3 & 14,3 & 14,3 & 14,3 & 16,5 & 14,8 & 14,8 & 14,8 & 14,8 & 15,5 & 13,7 & 13,7 & 13,7 & 13,7 & 16,4 \\
\hline $\mathrm{Fe}_{2} \mathrm{O}_{3}$ & 2,52 & 2,19 & 2,29 & 2,32 & 2,52 & 2,46 & 2,34 & 2,36 & 2,39 & 2,46 & 3,31 & 2,78 & 3,01 & 2,91 & 3,33 \\
\hline $\mathrm{FeO}$ & 7,63 & 4,83 & 6,86 & 7,51 & 5,56 & 7,77 & 7,76 & 7,77 & 7,77 & 8,06 & 9,35 & 5,53 & 7,18 & 8,35 & 6,63 \\
\hline $\mathrm{MnO}$ & 0,19 & 0,12 & 0,17 & 0,19 & 0,14 & 0,19 & 0,19 & 0,19 & 0,19 & 0,21 & 0,22 & 0,13 & 0,17 & 0,20 & 0,16 \\
\hline $\mathrm{MgO}$ & 12,0 & 7,6 & 10,8 & 11,8 & 8,75 & 9,8 & 9,7 & 9,8 & 9,8 & 10,2 & 10,2 & 6,0 & 7,8 & 9,1 & 7,2 \\
\hline $\mathrm{CaO}$ & 12,2 & 9,5 & 10,8 & 11,3 & 10,9 & 12,3 & 8,4 & 11,6 & 11,9 & 8,9 & 9,6 & 8,1 & 9,6 & 9,6 & 9,7 \\
\hline $\mathrm{Na}_{2} \mathrm{O}$ & 0,55 & 1,20 & 0,83 & 0,96 & 1,38 & 1,08 & 1,75 & 1,18 & 1,18 & 1,84 & 1,05 & 1,41 & $1,61^{\circ}$ & 1,00 & 1 , \\
\hline $\mathrm{K}_{2} \mathrm{O}$ & 0,34 & 0,99 & 0,39 & 0,2 & 1,14 & 0,31 & 0,99 & 0,33 & 0,25 & 1,04 & 0,72 & 1,13 & 0,76 & 0,40 & 1 , \\
\hline $\mathrm{P}_{2} \mathrm{O}_{5}$ & 0,12 & 0,10 & 0,11 & 0,12 & 0,11 & 0,13 & 0,12 & 0,12 & 0,13 & 0,19 & 0,19 & 0,16 & 0,17 & 0,17 & 0 \\
\hline $\mathrm{H}_{2} \mathrm{O}$ & - & 0,10 & 0,10 & 0,10 & 0,10 & - & 0,10 & 0,10 & 0,10 & 0,10 & - & 0,10 & 0,10 & 0,10 & 0 , \\
\hline P.F. & 2,68 & 0,00 & 0,00 & 0,00 & 0,00 & 2,86 & 0,00 & 0,00 & 0,00 & 0,00 & 2,51 & 0,00 & 0,00 & 0,00 & 0,00 \\
\hline TOTAL & 99,52 & 86,85 & 90,56 & 91,67 & 100,00 & 99,70 & 95,10 & 96,2 & 96,47 & 100,00 & 99,15 & 83,40 & 90,56 & 87,15 & 100,00 \\
\hline
\end{tabular}


Quadro 8 - São Gonçalo

CORREC̄̃̃ DE ANÁLISES

\begin{tabular}{|c|c|c|c|c|c|c|c|c|c|c|c|c|c|c|c|}
\hline \multirow{2}{*}{$\begin{array}{l}\text { Amostra } \\
\text { Situação }\end{array}$} & \multicolumn{5}{|c|}{88} & \multicolumn{5}{|c|}{89} & \multicolumn{5}{|c|}{90} \\
\hline & Atual & A & B & $\mathrm{C}$ & $\begin{array}{c}\text { Ori- } \\
\text { ginal } \\
\text { A }\end{array}$ & Atual & A & B & $\mathrm{C}$ & $\begin{array}{c}\text { Ori- } \\
\text { ginal } \\
\mathrm{A}\end{array}$ & Atual & A & B & $\mathrm{C}$ & $\begin{array}{c}\text { Ori- } \\
\text { ginal } \\
\mathrm{A}\end{array}$ \\
\hline $\mathrm{SiO}_{2}$ & 46,1 & 50,35 & 46,1 & 46,1 & 52,35 & 45,3 & 44,0 & 44,7 & 40,4 & 49,5 & 46,2 & 42,65 & 43,6 & 41,2 & 50,1 \\
\hline $\mathrm{TiO}_{2}$ & 3,1 & 3,0 & 3,0 & 3,1 & 3,1 & 3,5 & 3,1 & 3,25 & 3,2 & 3,5 & 3,3 & 2,8 & 3,1 & 3,0 & 3,3 \\
\hline $\mathrm{Al}_{2} \mathrm{O}_{3}$ & 13,3 & 13,3 & 13,3 & 13,3 & 13,8 & 13,3 & 13,1 & 13,1 & 13,1 & 14,7 & 13,1 & 13,1 & 13,1 & 13,1 & 15,4 \\
\hline $\mathrm{Fe}_{2} \mathrm{O}_{3}$ & 3,02 & 2,93 & 2,90 & 2,99 & 3,07 & 6,24 & 5,55 & 5,80 & 5,74 & 6,24 & 2,86 & 2,46 & 2,66 & 2,60 & 2,89 \\
\hline $\mathrm{FeO}$ & 9,07 & 6,27 & 7,53 & 9,07 & 6,52 & 7,34 & 5,08 & 6,04 & 6,78 & 5,71 & 10,65 & 6,15 & 8,98 & 9,40 & 7,23 \\
\hline $\mathrm{MnO}$ & 0,22 & 0,15 & 0,18 & 0,22 & 0,16 & 0,22 & 0,15 & 0,18 & 0,20 & 0,17 & 0,22 & 0,13 & 0,18 & 0,19 & 0,1 \\
\hline $\mathrm{MgO}$ & 10,0 & 6,9 & 8,3 & 10,0 & 7,2 & 10,4 & 7,2 & 8,6 & 9,6 & 8,1 & 10,0 & 5,8 & 8,4 & 8,8 & 6,8 \\
\hline $\mathrm{CaO}$ & 9,7 & 8,3 & 9,7 & 9,7 & 8,6 & 9,4 & 6,5 & 7,3 & 9,4 & 7,3 & 9,8 & 8,9 & 9,8 & 9,8 & 10,5 \\
\hline $\mathrm{Na}_{2} \mathrm{O}$ & 2,89 & 3,33 & 2,89 & 2,89 & 3,46 & 2,22 & 2,57 & 2,22 & 2,22 & 2,89 & 1,05 & 1,46 & 1,05 & 1,05 & 1,72 \\
\hline $\mathrm{K}_{2} \mathrm{O}$ & 0,67 & 1,11 & 0,69 & 0,38 & 1,15 & 0,81 & 1,16 & 0,90 & 0,43 & 1,30 & 0,72 & 1,13 & 0,77 & 0,40 & 1,33 \\
\hline $\mathrm{P}_{2} \mathrm{O}_{5}$ & 0,45 & 0,44 & 0,43 & 0,45 & 0,49 & 0,49 & 0,44 & 0,46 & 0,45 & 0,49 & 0,47 & 0,40 & 0,44 & 0,43 & 0,48 \\
\hline $\mathrm{H}_{2} \mathrm{O}$ & - & 0,10 & 0,10 & 0,10 & 0,10 & - & 0,10 & 0,10 & 0,10 & 0,10 & - & 0,10 & 0,10 & 0,10 & 0,10 \\
\hline P.F. & 0,81 & 0,00 & 0,00 & 0,00 & 0,00 & 0,42 & 0,00 & 0,00 & 0,00 & 0,00 & 0,98 & 0,00 & 0,00 & 0,00 & 0,00 \\
\hline TOTAL & 99,33 & 96,18 & 95,12 & 98,3 & 100,00 & 99,44 & 88,95 & 92,65 & 91,62 & 100,00 & 99,35 & 85,08 & 92,18 & 90,07 & 100,00 \\
\hline
\end{tabular}

Quadro 9-Região Sul

CORREÇÃO DE ANÁLISES

\begin{tabular}{|c|c|c|c|c|c|c|c|c|c|c|c|c|c|c|c|}
\hline \multirow{2}{*}{$\begin{array}{l}\text { Amostra } \\
\text { Situação }\end{array}$} & \multicolumn{5}{|c|}{32} & \multicolumn{5}{|c|}{35} & \multicolumn{5}{|c|}{50} \\
\hline & Atual & A & B & $\mathrm{C}$ & $\begin{array}{c}\text { Ori- } \\
\text { ginal } \\
B\end{array}$ & Atual & A & B & $\mathrm{C}$ & $\begin{array}{c}\text { Ori- } \\
\text { ginal } \\
C\end{array}$ & Atual & A & B & $\mathrm{C}$ & $\begin{array}{l}\text { Ori- } \\
\text { ginal } \\
\text { B }\end{array}$ \\
\hline $\mathrm{SiO}_{2}$ & 41,6 & 45,4 & 43,15 & 47,1 & 44,2 & 7,3 & 48,1 & 48,1 & 47,3 & 47,8 & 50,7 & 45,2 & 43,7 & 41,2 & 48,5 \\
\hline $\mathrm{TiO}_{2}$ & 3,9 & 3,9 & 3,8 & 4,25 & 3,9 & 5,4 & 5,2 & 5,1 & 5,3 & 5,4 & 2,4 & 2,2 & 2,2 & 2,1 & 2,4 \\
\hline $\mathrm{Al}_{2} \mathrm{O}_{3}$ & 17,3 & 17,3 & 17,3 & 17,3 & 17,7 & 14,7 & 14,7 & 14,7 & 14,7 & 14,9 & 12,6 & 12,6 & 12,6 & 12,6 & 14,0 \\
\hline $\mathrm{Fe}_{2} \mathrm{O}_{3}$ & 11,57 & 11,69 & 11,22 & 12,61 & 11,49 & 2,67 & 2,56 & 2,54 & 2,64 & 2,67 & 5,24 & 4,72 & 4,72 & 4,61 & 5,24 \\
\hline $\mathrm{FeO}$ & 7,17 & 7,17 & 7,17 & 10,53 & 7,33 & 13,63 & 12,2 & 10,37 & 13,63 & 13,78 & 9,75 & 7,13 & 8,97 & 9,75 & 9,96 \\
\hline $\mathrm{MnO}$ & 0,32 & 0,32 & 0,32 & 0,47 & 0,30 & 0,37 & 0,33 & 0,28 & 0,37 & 0,37 & 0,22 & 0,16 & 0,20 & 0,22 & 0,23 \\
\hline $\mathrm{MgO}$ & 2,8 & 2,8 & 2,8 & 4,1 & 2,9 & 3,1 & 2,8 & 2,4 & 3,1 & 3,1 & 4,5 & 3,3 & 4,1 & 4,50 & 4,57 \\
\hline $\mathrm{CaO}$ & 5,5 & 7,45 & 7,5 & 8,4 & 7,7 & 6,2 & 6,2 & 6,2 & 7,4 & 7,5 & 8 , & 9,9 & 10,2 & 10,1 & 11,3 \\
\hline $\mathrm{Na}_{2} \mathrm{O}$ & 2,65 & 3,02 & 2,65 & 2,79 & 2,71 & 2,87 & 2,36 & 2,87 & 2,87 & 2,90 & 2,47 & 2,93 & 2,47 & 2,23 & 2,74 \\
\hline $\mathrm{K}_{2} \mathrm{O}$ & 0,79 & 1,16 & 0,75 & 0,47 & 0,77 & 2,16 & 1,65 & 2,09 & 0,92 & 0,93 & 0,64 & 1,10 & 0,65 & 0,37 & 0,72 \\
\hline $\mathrm{P}_{2} \mathrm{O}_{5}$ & 0,93 & 0,94 & 0,90 & 1,01 & 0,90 & 0,54 & 0,52 & 0,51 & 0,53 & 0,55 & 0,20 & 0,18 & 0,18 & 0,18 & 0,24 \\
\hline $\mathrm{H}_{2} \mathrm{O}$ & 0,61 & 0,10 & 0,10 & 0,10 & 0,10 & 0,45 & 0,10 & 0,10 & 0,10 & 0,10 & 0,07 & 0,10 & 0,10 & 0,10 & 0,10 \\
\hline P.F. & 5,21 & 0,00 & 0,00 & 0,00 & 0,00 & 0,88 & 0,00 & 0,00 & 0,00 & 0,00 & 2,03 & 0,00 & 0,00 & 0,00 & 0,00 \\
\hline TOTAL & 100,35 & 101,25 & 97,66 & 109,13 & 100,00 & 100,27 & 96,72 & 95,26 & 98,86 & 100,00 & 99,52 & 89,52 & 90,09 & 87,96 & 100,00 \\
\hline
\end{tabular}

5) $\mathrm{O}$ valor de $\mathrm{K}_{2} \mathrm{O}$ e $\mathrm{Na}_{2} \mathrm{O}$ para os casos, $\mathrm{A}$, C e D são lidos diretamente nas Figs. 2, 3, 4, 5 e 7. Para o caso $\mathrm{B}$, os valores de $\mathrm{K}_{2} \mathrm{O}$ mostrados no quadro 3 são médias dos valores de $\mathrm{K}_{2} \mathrm{O}$ medidos para cada um dos óxidos estudados.

\section{METABASITOS DO ESPINHACO MERIDIONAL}

Generalidades Biondi, Schrank e Pinheiro (1978), baseados em uma série de análises de metabasitos e xistos do Espinhaço e do Macaúbas, deduzem o tipo de magmatismo da região e fornecem duas opções magmatogenéticas. Já na época é expressa a preocupação dos autores quanto à hermeticidade química do sistema analisado, da qual dependeria a validade das conclusões obtidas. Uma análise qualitativa da possibilidade de migração dos alcalinos é feita baseada no diagrama de Miyashiro (1975), da qual se deduziu a pouca probabilidade de que tivessem ocorrido grandes deslocamentos químicos durante as transformações sofridas pelas rochas estudadas. 
Quadro 10 - Normas CIPW das análises corrigidas, originais, conforme quadros $6,7,8,9$ e 10

\begin{tabular}{l|r|r|r|r|r|r|r|r|r|r|r|r|r|r|r|r|r|r}
\hline & \multicolumn{1}{c|}{$1 \mathrm{~B}$} & $2 \mathrm{~B}$ & $6 \mathrm{~B}$ & $9 \mathrm{~B}$ & $9 \mathrm{C}$ & $13 \mathrm{~B}$ & $13 \mathrm{C}$ & $15 \mathrm{~B}$ & $15 \mathrm{C}$ & $74 \mathrm{~A}$ & $75 \mathrm{~A}$ & $79 \mathrm{~A}$ & $88 \mathrm{~A}$ & $89 \mathrm{~A}$ & $90 \mathrm{~A}$ & $32 \mathrm{~B}$ & $35 \mathrm{C}$ & $50 \mathrm{~B}$ \\
\hline $\mathrm{Ap}$ & 0,4 & 0,3 & 0,3 & 0,8 & 0,9 & 0,9 & 0,9 & 0,8 & 0,8 & 0,3 & 0,4 & 0,5 & 1,1 & 1,1 & 1,1 & 2,1 & 1,3 & 0,6 \\
$\mathrm{Ilm}$ & 3,0 & 3,8 & 3,0 & 6,2 & 6,2 & 5,8 & 5,8 & 4,8 & 4,7 & 1,7 & 2,3 & 2,9 & 5,9 & 6,6 & 6,3 & 7,4 & 1,2 & 4,6 \\
$\mathrm{Ort}$ & 1,4 & 1,7 & 3,1 & 3,1 & 1,9 & 4,3 & 2,5 & 5,5 & 2,7 & 6,7 & 6,2 & 8,0 & 6,8 & 7,7 & 7,8 & 4,6 & 5,5 & 4,3 \\
$\mathrm{Ab}$ & 25,8 & 28,8 & 17,0 & 28,6 & 27,4 & 26,4 & 32,3 & 44,0 & 39,9 & 11,7 & 15,6 & 14,3 & 29,2 & 24,4 & 14,5 & 22,9 & 24,5 & 23,2 \\
$\mathrm{Ne}$ & 2,1 & 1,8 & 7,6 & - & - & - & - & 1,9 & 2,3 & - & - & - & - & - & - & - & - & - \\
$\mathrm{An}$ & 25,8 & 26,0 & 35,7 & 23,9 & 26,5 & 19,8 & 19,3 & 19,5 & 21,6 & 35,4 & 30,9 & 33,1 & 18,7 & 23,3 & 30,4 & 33,0 & 24,9 & 23,7 \\
$\mathrm{Mgt}$ & 4,6 & 5,8 & 6,4 & 3,5 & 3,5 & 5,4 & 5,4 & 5,3 & 5,4 & 3,6 & 3,5 & 4,8 & 4,5 & 8,8 & 4,2 & 13,3 & 3,9 & 7,6 \\
$\mathrm{Hm}$ & - & - & - & - & - & - & - & - & - & - & - & - & - & 0,2 & - & 2,3 & - & - \\
$\mathrm{Di}\{\mathrm{Ca}$ & 12,7 & 10,8 & 6,4 & 8,5 & 8,1 & 8,2 & 9,5 & 6,9 & 5,7 & 7,5 & 5,1 & 5,7 & 8,8 & 4,2 & 7,9 & - & 3,8 & 12,9 \\
$\mathrm{Mg}$ & 7,3 & 6,3 & 3,9 & 3,8 & 3,6 & 4,0 & 4,6 & 2,9 & 2,0 & 5,2 & 3,3 & 3,8 & 6,4 & 3,6 & 5,4 & - & 1,3 & 6,6 \\
$\mathrm{Fe}$ & 4,8 & 4,0 & 2,2 & 4,6 & 4,4 & 4,0 & 4,9 & 4,0 & 3,7 & 1,7 & 1,4 & 1,5 & 1,6 & - & 1,8 & - & 2,6 & 6,0 \\
$\mathrm{Hg}\{\mathrm{Mg}$ & - & - & - & 5,0 & 3,8 & 7,8 & 2,4 & - & - & 16,6 & 20,4 & 14,2 & 11,6 & 16,6 & 11,6 & 7,4 & 6,4 & 4,8 \\
$\mathrm{Fe}$ & - & - & - & 6,1 & 4,7 & 7,8 & 2,6 & - & - & 5,3 & 8,9 & 5,7 & 3,0 & - & 3,9 & - & 12,3 & 4,4 \\
$\mathrm{Ol}\{\mathrm{Mg}$ & 7,0 & 6,3 & 8,8 & 2,5 & 3,8 & - & 4,5 & 1,7 & 3,6 & - & 1,3 & - & - & - & - & - & - & - \\
$\mathrm{Fe}$ & 5,0 & 4,3 & 5,5 & 3,3 & 5,1 & - & 5,2 & 2,6 & 7,5 & - & 0,6 & - & - & - & - & - & - & - \\
$\mathrm{Qz}$ & - & - & - & - & - & 5,5 & - & - & - & 4,2 & - & 5,4 & 2,3 & 3,4 & 5,0 & 6,9 & 3,2 & 1,2 \\
\hline TOTAL & 99,9 & 99,9 & 99,9 & & & & & & & & & & & & & & & \\
\hline
\end{tabular}

1B - Basalto alcalino a olivina

2B - Basalto alcalino a olivina

6B - Basanito

$9 \mathrm{~B}$ e $9 \mathrm{C}$ - Olivina toleito

$13 \mathrm{~B}$ e $13 \mathrm{C}$ - Olivina toleito
$15 \mathrm{~B}$ e $15 \mathrm{C}$ - Basalto alcalino a olivina

74A - Quartzo toleito

$75 \mathrm{~A}$ - Toleito a Olivina toleito

79A - Quartzo toleito

88A - Quartzo toleito
89A - Quartzo toleito

90A - Quartzo toleito

32B - Quartzo toleito

35C - Quartzo toleito

50B - Quartzo toleito
Os mesmos metabasitos mencionados serão reestudados, tendo agora em mãos uma técnica de determinação quantitativa das transformações químicas sofridas pelas rochas. Modificações importantes foram tectadas, que mudam radicalmente várias das conclusões obtidas na primeira interpretação feita (Biondi et al., 1978).

Os metabasitos do Espinhaço Meridional são usados como um primeiro teste da técnica de correção proposta. A relativa homogeneidade qualitativa da mineralogia destas rochas e a existência de estudos já publicados, que permitem uma comparação direta de resultados, torna-as um exemplo privilegiado. Novos testes serão feitos abordando séries vulcânicas mais complexas, na tentativa de se estabelecer parâmetros universạis de correção, válidos para qualquer outro ambiente de vulcanismo. Este primeiro exemplo será suficiente, ao menos para demonstrar a necessidade dos estudos de correção de análises.

METAMORFISMOE METASSOMATISMO $P e$ trografia Os metabasitos são rochas de cor cinza escura com poucas evidências macroscópicas de metamorfismo. A textura original foi, via de regra, totalmente destruída, percebendo-se alguns poucos resíduos de uma possível textura ofitica sob a textura metamórfica superimposta. O plagioclásio é ídio-hipidiomórfico com maclas albitacarlsbad, frequientemente zonado e substituido por clorita, biotita (rara) e epidoto. São, geralmente, oligoclásios, mais raramente oligoclásios-andesina. Não são raros os intercrescimentos mimerquíticos. A pistacita é frequiente ao lado dos plagioclásios. O anfibólio é o mineral mais comum, geralmente presente em bem maior quantidade que o plagioclásio, ambos constituindo mais de $80 \%$ em volume dos basitos. São actinolitas, raramente tremolitas, prováveis transformações de piroxênios e, talvez, peridotos primários. Algumas vezes têm os bordos ladeados por lamelas de biotita que contêm, junto ao anfibólio, zonas ricas em óxido de titânio, segregações de piroxênios transformados pelo metamorfismo.

O quartzo, sempre mostrando extinção ondulante, é encontrado freqüentemente. Os opacos, abundantes sobretudo no maciço de Ipoema, devem corresponder à série magnetita-ilmenita. $O$ feldspato potássico, pouco freqüente foi identificado em algumas amostras do maciço de Datas.

São comuns os efeitos de tensão a que foram submetidos os basitos, refletindo-se na extinção ondulante do quartzo, no fraturamento dcs cristais de plagioclásio e proporcionando a existência de microrejeitos e arqueamentos nas lamelas dos plagioclásios.

É aparentemente paradoxal que rochas que contêm quartzo tenham sido rochas alcalinas portadoras de até $7 \%$ de nefelina, como o indicam as composições normativas das análises corrigidas de Datas (quadro $n .^{\circ} 10$ ). A comparação entre as composições modais e normativas evidencia também a presença de um plagioclásio ácido (An 20-30) em contraste com 
aquele muito mais básico anterior (An 60-70). A norma tem como máficos, sobretudo o diopsídio, o hiperstênio e o peridoto que, juntamente com os opacos, devem corresponder ao anfibólio, epidoto, clorita e biotita atuais. Nos casos de Datas e Ipoema, a paragênese atual é, portanto, ácida sobre-saturada, em contraste com a paragênese subssaturada alcalina primitiva (quadro 10). A maioria destas modificações encontram explicação sobretudo nas transformações mineralógicas conseqüentes do metassomatismo, mas também do metamorfismo. Com efeito, a uralitização e a oxidação da rocha liberam grande quantidade de sílica que, muitas vezes, não chega a ser totalmente absorvida pela acidificação do plagioclásio neoformado, recristalizando-se como quartzo. Além do aporte metassomático de sódio, a destruição da nefelina primitiva fornece o sódio necessário para a albitização (An 60-70 para An 20-30). Ao cálcio liberado desta transformação, soma-se o cálcio trazido pelo metassomatismo (quadros 2 a 4), recristalizando-se sobretudo no anfibólio, mas também no epidoto e clorita. O ferro e o magnésio do piroxênio e peridoto devem ser admitidos, na clorita, biotita e anfibólio. O titânio liberado dos piroxênios deve ilmenitizar a magnetita.

Os metabasitos da região Sul têm comportamento químico diversificado, dependendo das suas posiçòes geográficas de origem. Todas as amostras analisadas são de rochas com composições modais e normativas saturadas.

Petroquimica As profundas modificações químicas detectadas causadas pelo metassomatismo, foram dimensionadas e suas influências devem ser analisadus em função das consequiências dela decorrentes, no que concerne à gênese das rochas estudadàs.

Caracterização dos anfibolitos As características geológicas, mineralógicas e texturais dos metabasitos anfibolitizados do Espinhaço não deixam dúvidas quanto às suas origens ígneas, o mesmo, entretanto, não podendo ser dito quanto aos anfibolitos amostrados na região Sul. Neste caso são sempre corpos pequenos, com poucas centenas de metros de rochas aflorantes, em sua maioria encaixados em gneisses e freqüentemente associados a xistos e quartzitos. O diagrama de Moine e de La Roche (Fig. 9) separa, em domínios distintos, os anfibolitos derivados de rochas ígneas daqueles derivados de sedimentos. A média de todas as análises de rochas da região Sul ocupa um lugar quase central no domínio correspondente aos anfibolitos de derivação ígnea. O diagrama mostra, também neste domínio, os pontos correspondentes às composições médias não corrigidas dos maciços de Datas, São Gonçalo e Serro, do Espinhaço. A composição média não corrigida de Ipoema, situa-se fora do domínio principal, mas ainda no domínio dos anfibolitos ígneos. Ainda no mesmo diagrama foram lançadas todas as análises químicas corrigidas, segundo a técnica proposta anteriormente. Notar que, para Ipoema, para cada uma das análises existe um forte deslocamento do ponto correspondente à análise não corrigida, fora do domínio típico dos anfibolitos, em direção a este domínio, após feita a correção. Este comportamento faz supor a interiorização do ponto médio de Ipoema após a correção dos efeitos do metassomatismo. Amostras que, não corrigidas, situam-se dentro do domínio dos anfibolitos; após correção sempre continuam neste domínio. Em nenhum caso pode haver dúvidas quanto à derivação ígnea das rochas estudadas.

Modificações metassomáticas Os quadros 2, 3 e 4 contêm todas as informações obtidas quanto aos ganhos e perdas de elementos químicos diagnosticados pela correção feita. Para o Espinhaço, os maciços de Datas e Ipoema geralmente ganharam sílica com o metassomatismo. Serro e São Gonçalo tiveram, quanto à sílica, um comportamento menos regular, com perdas e ganhos alternados. Notar que a variação do teor de $\mathrm{SiO}_{2}$ se dá no intervalo de $-4,25 \%$ a $+6,14 \%$, a maioria das vezes, porém, oscilando entre $\pm 1,0 \%$ absoluto.

O cálcio, tomado em relação à referência alumina (Al nos quadros 2 a 4), tem um comportamento constante, tendo se mantido invariável para a maioria das amostras de Ipoema e Datas ou, em alguns casos, mostra um ligeiro ganho. Já para Serro e São Gonçalo o comportamento em bloco é evidente, tendo havido ganho de cálcio para todas as amostras analisadas. Em valores absolutos, as rochas do Espinhaco sofreram durante suas histórias geológicas um aporte de $\mathrm{CaO}$, variando entre $0,0 \% \mathrm{e}+3,88 \% \mathrm{em}$ média este aporte, tendo sido da ordem de $+2,0 \%$.

$\mathrm{O}$ valor $\mathrm{Fm}$ correspondente a $\mathrm{FeO}+\mathrm{MgO}+\mathrm{MnO}$ teve, a exemplo do cálcio, variações positivas unânimes para amostras do Serro e São Gonçalo. Para Datas, o total $\mathrm{FeO}+\mathrm{MgO}+\mathrm{MnO}$ não sofreu qualquer modificação durante o metassomatismo, o mesmo não acontecendo em Ipoema, onde as modificações se fizeram entre a invariabilidade dos teores até ganhos de $+1,51 \%$ e perdas de $-4,20 \%$. Em média, para o Serro e São Gonçalo, houve um ganho de Fm da ordem de $+5,0 \%$, para Ipoema houve uma tendência de perda da ordem de $-0,5 \%$ e em Datas Fm foi constante.

Em relação ao potássio, as amostras do Serro e São Gonçalo se comportam de modo uniforme, tendo havido uma forte perda de $\mathrm{K}_{2} \mathrm{O}$ durante a história geológica destes maciços. Em Datas, a tendência foi pelo imobilismo e em Ipoema a tendência foi pelo ganho em $\mathrm{K}_{2} \mathrm{O}$, embora o comportamento cenha variado conforme a amostra. Para Serro e São Gonçalo, a perda de $\mathrm{K}_{2} \mathrm{O}$ variou entre $-0,35 \%$ e $-0,67 \%$. Para Datas, uma das amostras ganhou $+0,02 \%$ de $\mathrm{K}_{2} \mathrm{O}$, as outras tendo permanecido invariáveis. Em Ipoema as variações ocorreram entre $-0,03 \%$ e $+0,43 \%$, havendo em média uma tendência de ganho da ordem de $+0,3 \%$. 


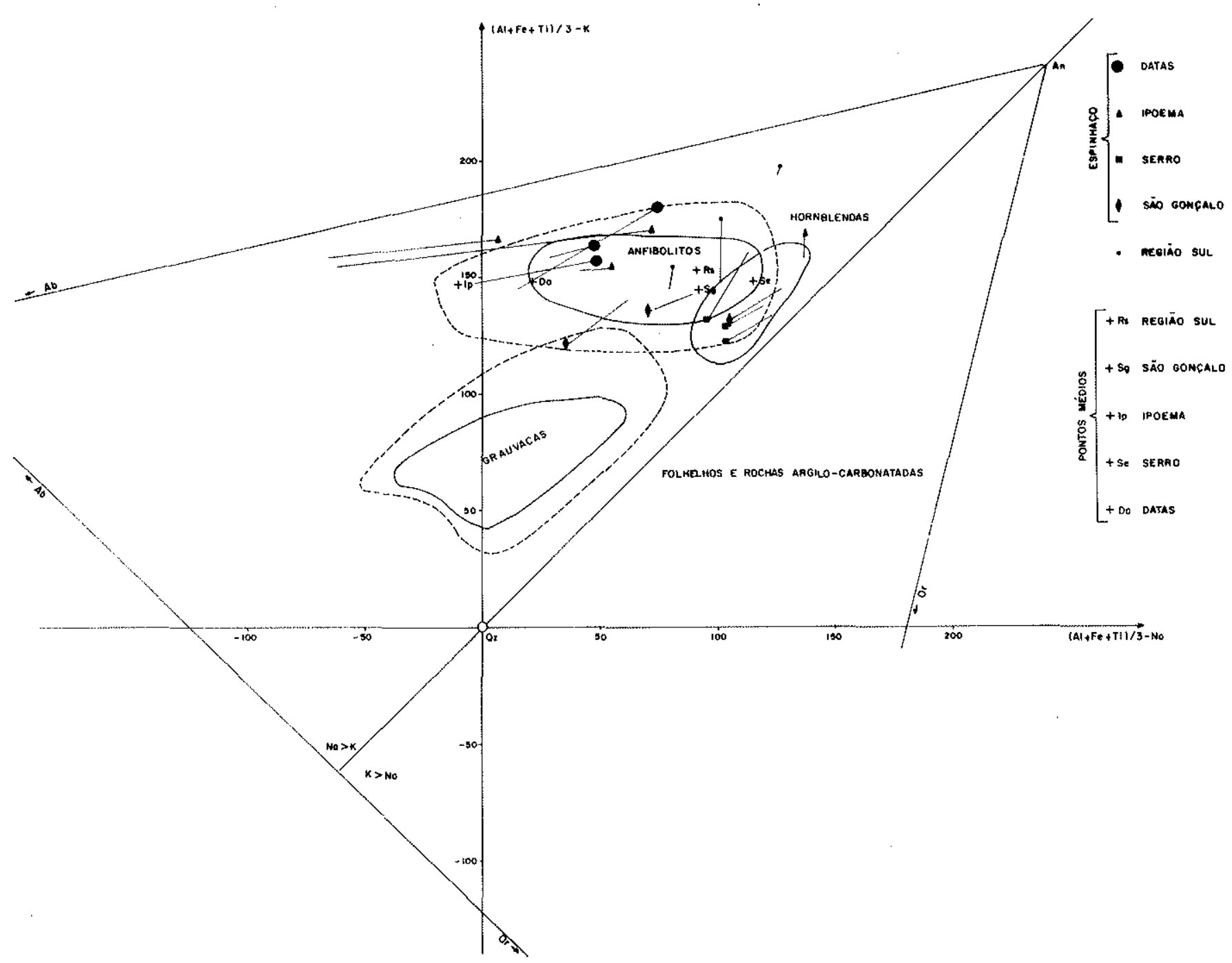

Figura 9 - Dominio ocupado pelas rochas estudadas em função do comportamento diferencial de Na, K e Al. Notar que todas as rochas ocupam o domínio dos anfibolitos de derivação ígnea. A correção das análises tende a deslocá-las em direção a este domínio quando se situavam fora dele (caso de Ipoema). Os valores de $\mathrm{Na}, \mathrm{K}$ e Al são expressos em miliátomos em $100 \mathrm{~g}$ de rocha

Em Ipoema e Datas, o sódio foi o elemento de comportamento mais regular, tendo havido uniformemente um forte ganho de $\mathrm{Na}_{2} \mathrm{O}$ em todas as amostras estudadas. Ao contrário de Datas e I poema, para Serro e São Gonçalo as variações se fizeram do imobilismo até valores negativos, a tendência geral tendo sido de perda de $\mathrm{Na}_{2} \mathrm{O}$. Em valores absolutos, no Serro e São Gonçalo o $\mathrm{Na}_{2} \mathrm{O}$ varia de $0,0 \%$ até $-1,30 \%$ e em Datas e Ipoema de $+0,56 \%$ a $+4,13 \%$.

Em resumo, Datas e Ipoema ganharam alcalinos, tiveram muito pouca variação nos seus teores de $\mathrm{CaO}$ e $\mathrm{FeO}+\mathrm{MgO}+\mathrm{MnO}$ e mostraram tendência a se enriquecerem em sílica. Serro e São Gonçalo perderam alcalinos, enriqueceram-se fortemente em $\mathrm{CaO}$ e $\mathrm{FeO}+\mathrm{MgO}+\mathrm{MnO}$ e tiveram comportamento variável quanto ao $\mathrm{SiO}_{2}$.

Desta análise, alguns fatos devem ser ressaltados, a exemplo do comportamento em bloco mostrado pelas amostras de um mesmo maciço. Todas as amos- tras de Ipoema ou Datas foram enriquecidas em $\mathrm{Na}_{2} \mathrm{O}$ e todas as amostras de Serro e São Gonçalo perderam $\mathrm{K}_{2} \mathrm{O}$ e ganharam $\mathrm{CaO}$ e $\mathrm{FeO}+\mathrm{MgO}+$ $+\mathrm{MnO}$. Em se tratando de amostras coletadas em diferentes posições do maciço e sendo estes maciços formações rochosas com até 25 quilômetros de comprimento por 4-5 quilômetros de largura (Serro e Ipoema), deve-se admitir que tenha havido deslocamentos de elementos por distância equivalentes ao menos à largura média dos maciços, cerca de 4-5 quilômetros. Derivado deste raciocínio, deve-se também admitir que os fronts metassomáticos abrangeram regiões de dimensões no mínimo iguais ao maior comprimento do maior maciço estudado, cerca de 25 quilômetros (Serro).

Um outro fato a ressaltar seria a dimensão das variações químicas devidas ao metassomatismo. Para elementos como o sódio, houve ganhos de mais de $110 \%$ relativos em algumas amostras (amostra n." 9 , 
quadro 6, $\mathrm{Na}_{2} \mathrm{O}$ original de $3,24 \%$ aumenta para $7,03 \%$ ), sendo comum variações da ordem de $30-40 \%$. $\mathrm{O}$ mesmo pode ser dito quanto às perdas de $\mathrm{K}_{2} \mathrm{O}$, determinadas para o Serro, como sendo de até $200 \%$ (amostras 74 e 75, quadro 7). Para o $\mathrm{CaO}$ foram comuns variações de 20 a $30 \%$ relativos no Serro e São Gonçalo. A sílica raramente mostrou variações de mais de $8,0^{\circ}$, relativas, a média tendo sido de menos de $5 \%$.

As amostras da região Sul, cada uma provindo de uma formação diferente, distantes uma das outras, mostram comportamentos variados quanto à capacidade de migração dos diferentes elementos analisados. Houve, em todas as amostras analisadas, uma perda de $\mathrm{CaO}$ e o $\mathrm{Na}_{2} \mathrm{O}$ permaneceu constante, características estas que diferenciam nitidamente o metassomatismo ocorrido na região Sul daquele do Espinhaço. As ordens de grandeza de variação de teores são aproximadamente as mesmas do Espinhaço.
Análise de comportamento das rochas em relação às transformações metassomáticas O domínio hachurado da Fig. 10 foi determinado para os metabasitos (Biondi et al, 1978) a partir da composição não corrigida de todas as rochas analisadas (quadro 1). Feitas as correções, todas as análises permanecem neste domínio, algumas nele adentrando, provindas da sua borda externa. É nitida a tendência geral mostrada por todas as rochas do Espinhaço em se aproximar do polo F, afastando-se de A como conseqüência do metassomatismo. Esta tendência é sobretudo devida ao aporte em alcalinos para Ipoema e Datas e ao enriquecimento em $\mathrm{FeO}+\mathrm{MgO}+\mathrm{MnO}$ para Serro e São Gonçalo, diminuindo A no primeiro caso e aumentando $\mathrm{F}$ no segundo, a tendência geral sendo o deslocamento para F. Esta variação justifica também o aparecimento da clorita e da actinolita a partir dos minerais primários, a migração geral dos pontos sendo em direção aos pólos representativos destes mine-

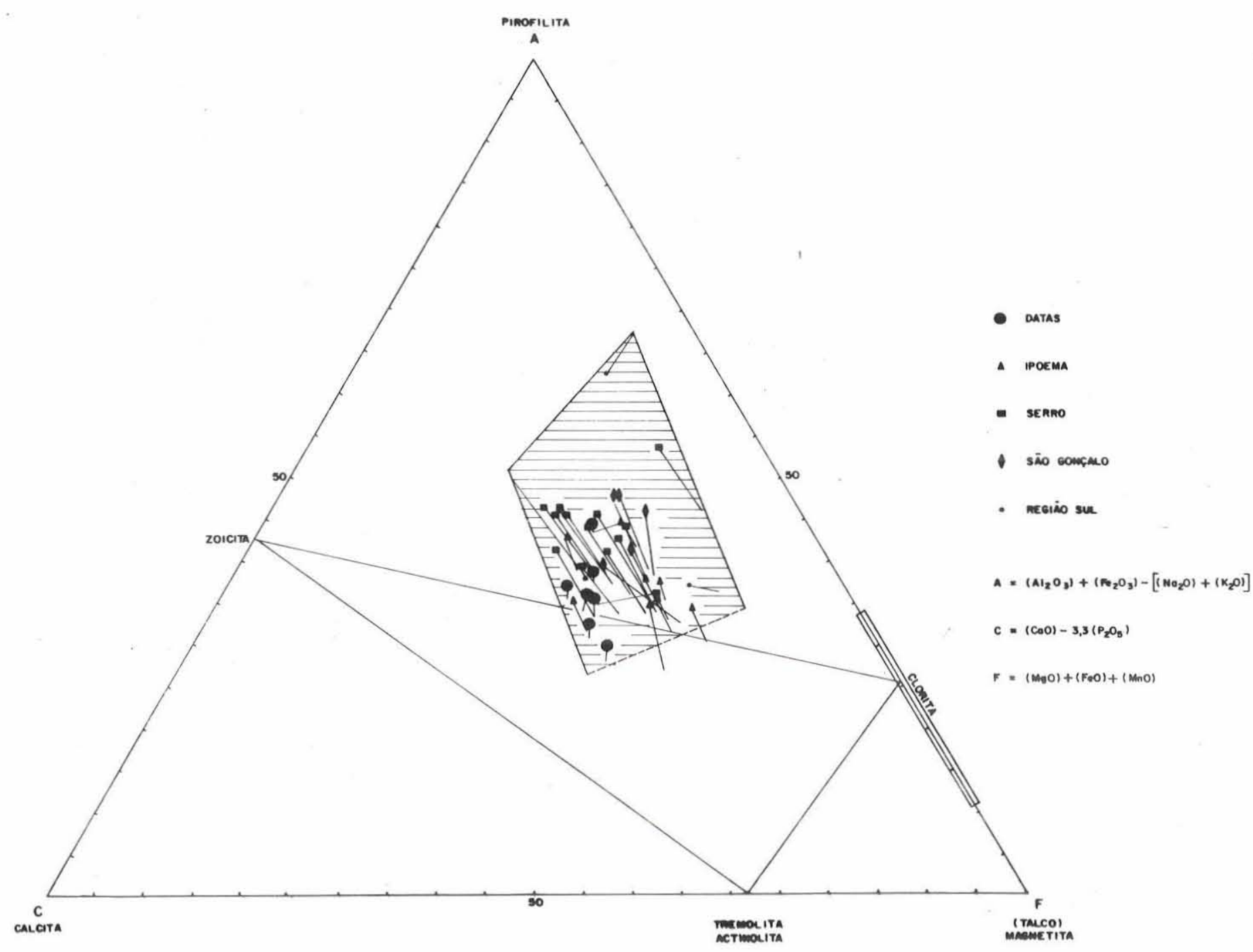

Figura 10 - Diagrama ACF mostrando o domínio ocupado pelos anfibolitos estudados. Notar que o deslocamento devido às correções não afastou os pontos do dominio anteriormente determinado por Biondi et al. (1978) 
rais no diagrama considerado (fáceis xisto verde ou de metamorfismo de grau muito baixo). Nada pode ser dito em relação às amostras de rochas da região Sul, cada uma delas mostrando deslocamentos em direções diferentes.

Do ponto de vista da composição normativa (Fig. 11 e quadros 1 e 10), a tendência geral do metassomatismo para Serro, São Gonçalo e Ipoema, foi de alcalinizar as rochas, diminuindo a quantidade de quartzo e hiperstênio normativos e causando o aparecimento do peridoto e da nefelina. Datas, como exceção, empobreceu-se em diopsídio normativo, ganhando iguais quantidades de nefelina e peridoto. Nada pode ser dito quanto às amostras da região Sul.

Também as transformações normativas, justificam-se pelas variações dos teores de álcalis para Ipoema e de $\mathrm{FeO}+\mathrm{MgO}+\mathrm{MnO}$ para Serro e São Gonçalo. Tanto a formação da albita + nefelina com o sódio metassomático, quanto o uso de $\mathrm{FeO}$ e $\mathrm{MgO}$ pelo peridoto e diopsídio, consomem sílica, o que se reflete na diminuição e no desaparecimento do quartzo normativo em função do aparecimento, primeiro, do hiperstênio, depois do peridoto e, ainda depois, da nefelina. No caso de Datas, o enriquecimento em sílica foi quase contrabalançado pelo também enriquecimento em álcalis, o que justifica a migração dos pontos perpendicularmente à diagonal quartzo-nefe- lina (Fig. 10), afastando-se do pólo diopsídio, mineral mais saturado que o peridoto e, naturalmente, que a nefelina.

MAGMATISMO Em comparação com os dados apresentados anteriormente por Biondi et al, (1978), o advento do metassomatismo teve como consequiências, modificações importantes.

Efeitos do metassomatismo No primeiro estudo feito, foram definidas no Espinhaço duas séries magmáticas distintas, uma toleítica, outra alcalina-basanítica, individualizadas pela existência de um vazio quanto à presença de lavas de composição intermediária. A definição destas séries foi feita com base nos diagramas de Coombs (1963) e AFM (Kuno, 1968) representativos, respectivamente, da evolução normativa e química de séries vulcânicas. As mesmas análises, usadas anteriormente por Biondi et al, (1978), foram corrigidas dos efeitos de metassomatismo, sendo mostradas nas Figs. 11 e 12. Nestas figuras, as linhas unem a posição da análise corrigida (figurada) à sua posição antes da correção (Figs. 4 e 5 de Biondi et al, 1978). Nota-se que o vazio anteriormente existente na posição das séries transicionais é, após a correção, ocupado pelas análises correspondentes ao maciço de Ipoema, deslocadas de entre os basanitos e

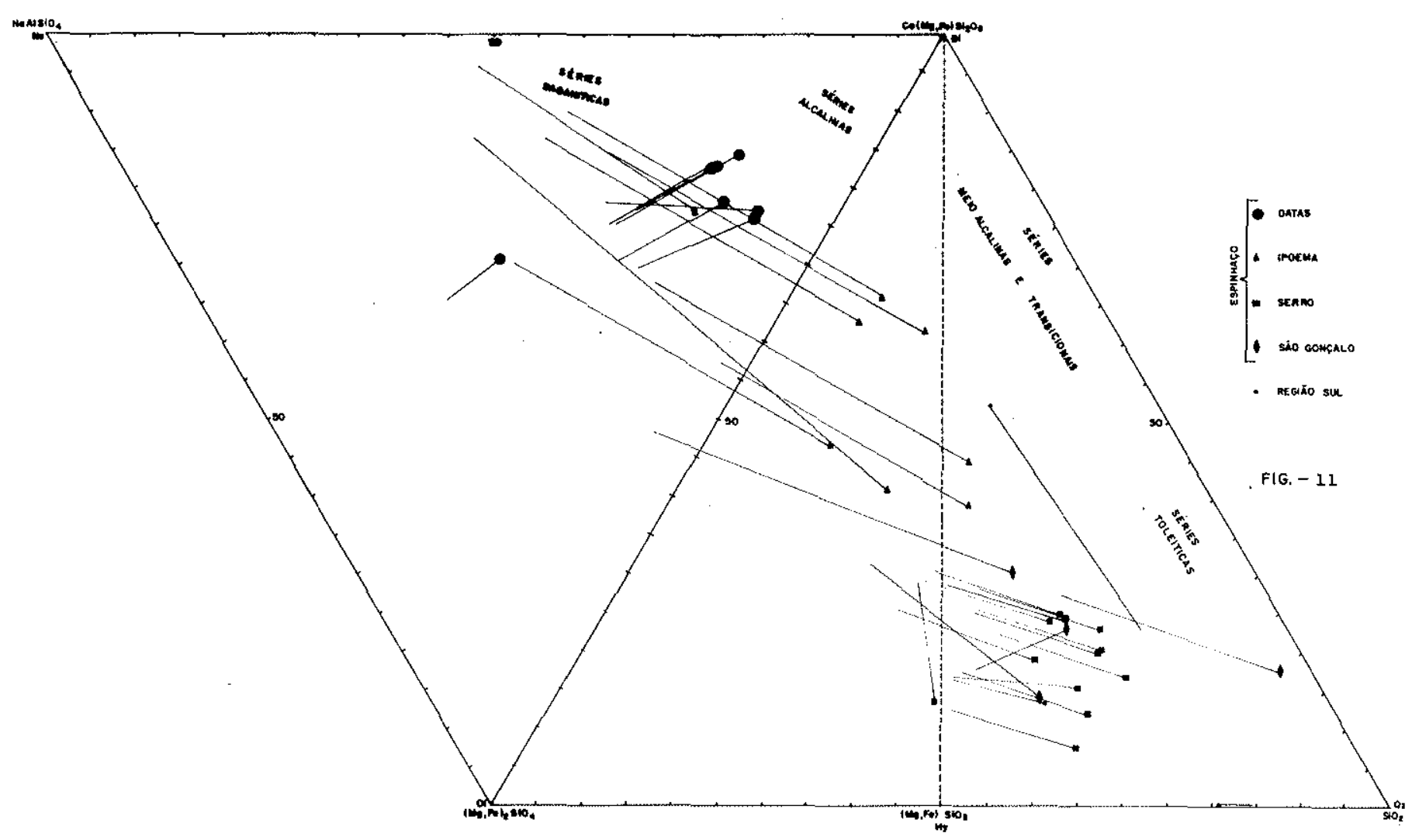

Figura 11 - Diagrama quartzo-hiperstênio-diopsidio-peridoto-nefelina, expressos em número de moles de minerais normativos. Notar o grande deslocamento dos pontos relativos às rochas de Ipoema, que deixam a posição das séries basaníticas vindo a ocupar aquela das séries transicionais. A tendência geral das análises corrigidas foi de saturação 
basaltos alcalinos. A tendência das análises do Serro e São Gonçalo é de tornar mais nítidas as suas características toleíticas, enriquecendo-se em quartzo normativo. A tendência geral da sequiência do Espinhaço foi no sentido de saturar-se, desaparecendo os termos basaníticos da série, surgindo os termos transicionais e fortalecendo a tendência tolética das lavas saturadas existentes. As amostras corrigidas das formações da região Sul não caracterizaram nenhuma tendência geral de deslocamento quando corrigidas.

A Fig. 12 mostra, juntamente às análises corrigidas, os domínios anteriormente definidos para as mesmas análises antes da correção. Os pontos anteriormente correspondentes a Serro e São Gonçalo, deslocaram-se em direção ao pólo A e aqueles de Ipoema e Datas afastaram-se de $\mathrm{A}$, todos ocupando exatamente o vazio entre os domínios defínido em função das análises não corrigidas. As rochas do Espinhaço, ajustam-se bastante bem à linha de evolução das séries alcalinas. $\mathrm{O}$ domínio anteriormente definido para as rochas da região Sul (Fig. 12) continua ocupa- do por estas rochas, após efetuadas as correções relativas ao metassomatismo.

A tendência geral do metassomatismo foi de dar características de um maior grau de diferenciação para as lavas de Datas e Ipoema e, ao contrário, de um menor grau para lavas do Serro e São Gonçalo. Esta tendência é bem marcada quando são comparados os Índices de Solidificação (Kuno, 1968) de Serro e São Gonçalo com aqueles de Ipoema e Datas (Fig. 13). Feitas as correções, os pontos correspondentes a estas formações se deslocaram em sentidos opostos, passando a caracterizar o Espinhaço como uma série menos diferenciada (IS variando em um intervalo menor) que o faria supor as análises não corrigidas.

Tipologia magmática Nos estudos de lavas basálticas, onde a composição química é de maior utilidade, é conveniente a adoção de uma classificação normativa para a nomenclatura das rochas. No estudo de lavas metamorfoseadas e metassomatisadas, sobretudo, este artificio é fundamental, dada a impos-

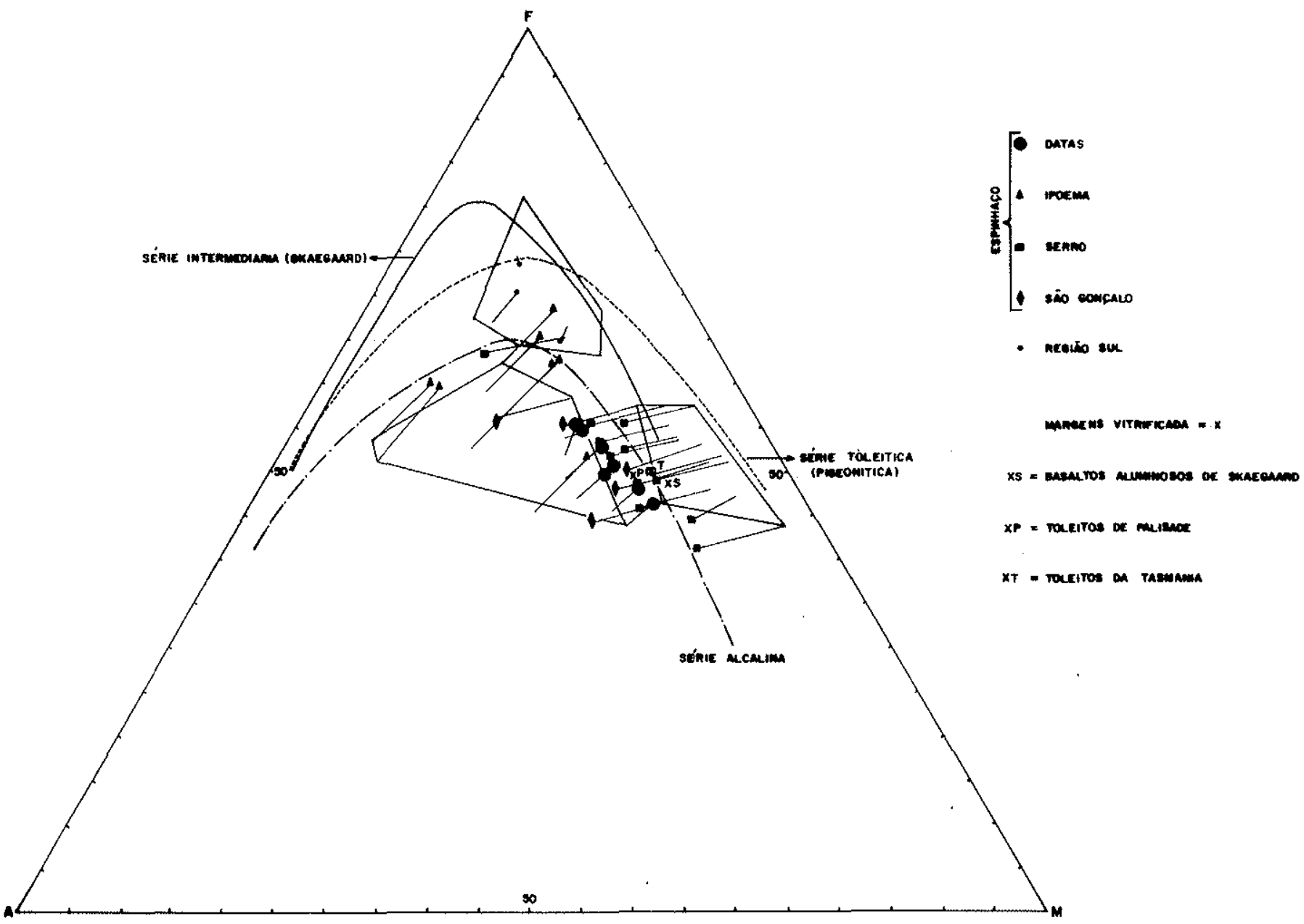

Figura $12-$ Diagrama $\mathrm{Na}_{2} \mathrm{O}+\mathrm{K}_{2} \mathrm{O} / \mathrm{FeO}+\mathrm{Fe}_{2} \mathrm{O}_{2}+\mathrm{MnO} / \mathrm{MgO}$ dos metabasitos estudados. Notar os deslocamentos em sentidos inversos de Ipoema + Datas que deixam o pólo alcalino (A) contra São Gonçalo + Serro que se dirigem para este pólo. Estes deslocamentos, condicionados pelas correções efetuadas permitiram que todos os basitos se unissem em um único "trend" típico de série alcalina. Os domínios desenhados eram ocupados pelas análises antes das correções, conforme determinado por Biondi et al. (1978) 

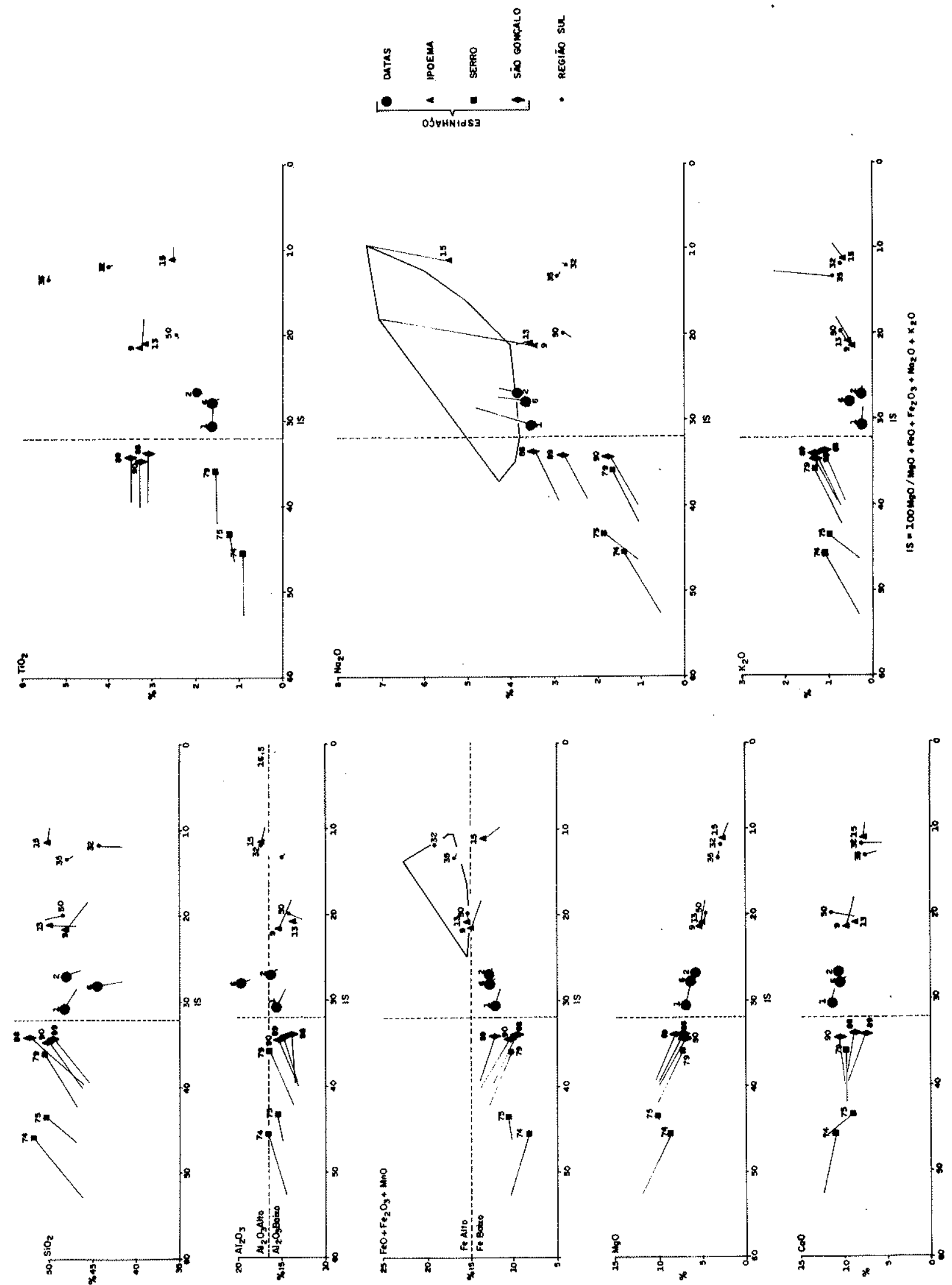

Figura 13 - Diagrama de variação dos óxidos analisados em relação ao índice de solidificação. O domínio definido no diagrama do $\mathrm{Na}_{2} \mathrm{O}$ era ocupado pelas análises de Ipoema + Datas antes das correções. Notar os deslocamentos em sentidos inversos de Ipoema + Datas contra Serro + São Gonçalo, mostrando que as correções diminuíram o intervalo de variação de IS, ou seja, restringiram a gama de diferenciação anteriormente determinada por Biondi et al. (1978) 
sibilidade de determinação da composição modal primitiva. Será adotada a nomenclatura sugerida por Green (1970), mais detalhada e precisa que a de Yoder e Tilley (1962, p. 352), a saber:

- Quartzo toleito: basalto com quartzo e hiperstênio normativos.

- Toleitos: basaltos com hiperstênio normativo.

- Olivina toleito : basalto com olivina e hiperstênio normativos; hiperstênio maior que $3 \%$.

- Olivina basalto: com olivina normativa e $0-3 \%$ de hiperstênio normativo. Nefelina ausente.

- Basalto alcalino a olivina : com olivina e nefelina normativos: menos que $5 \%$ de nefelina.

- Basanito: basalto com olivina, nefelina e albita normativos. Presença de mais de $5 \%$ de nefelina e mais que $2 \%$ de albita.

- Olivina nefelinito: grande quantidade de olivina e nefelina normativas. Menos que $2 \%$ de albita, presença de ortoclásio e/ou leucita normativos e ausência de larnita (ortosilicato de cálcio).

Com base nesta classificação, quatro tipos de basaltos podem ser identificados no quadro 10 e na Fig. 11. Todas as lavas de São Gonçalo são quartzo toleitos. No Serro, tem-se também quartzo toleitos e um olivina toleito (quadro 10, n." 75). Olivinas toleitos são também a maioria das lavas de lpoema. Os basaltos alcalinos predominam em Datas, uma das rochas de Ipoema sendo também desta categoria (quadro 10, n." 15). Um único basanito (quadro e Fig. 11, n." 6), do maciço de Datas, restou após as correçòes dos efeitos do metassomatismo.

Os basitos da região Sul permaneceram no domínio anteriormente definido por Biondi et al, (1978), mesmo após as correções (Fig. 12). São quartzo toleitos que se individualizam em relação àqueles do Serro e São Gonçalo, pelo teor nitidamente maior em $\mathrm{FeO}+\mathrm{Fe}_{2} \mathrm{O}_{3}+\mathrm{MnO}$, e menor em MgO. Não só por estas características químicas, mas também pelas posições geográficas e características morfológicas dos maciços, é certo tratar-se de séries diferentes. Serro, São Gonçalo, Ipoema e Datas, no Espinhaço, constituem o que será chamado de série Alcalina, em contraste com os toleitos indiferenciados da região Sul.

Tendência de diferenciação da série alcalina do Espinhaço Meridional e da região Sul A evolução de uma série vulcânica pode ser seguida no diagrama de variação de Kuno (Fig. 13) e no diagrama AFM (Fig. 12). A série alcalina do Espinhaço evolui, enriquecendo-se em ferro em relação ao magnésio, paralelamente ao lado MF do diagrama AFM (Fig. 12) mostrando, posteriormente, uma certa tendência a se afastar de $\mathrm{F}$ em direção à $\mathrm{A}$, enriquecendo-se em álcalis. A Fig. 13 permite que se visualise a evolução de cada óxido individualmente, em relação à quantidade de líquido existente na zona profunda de origem dos magnas (Kuno, 1968), expressa pelo índice IS. A sílica mostra-se invariável durante a evolução. A alumina mostra uma certa tendência a crescer. A quanti- dade de ferro das lavas cresce até $\mathrm{IS}=20$, quando parece então declinar, provavelmente devido à precipitação da magnetita. O teor em $\mathrm{MgO}$ das lavas decresce linearmente, evidenciando a participação do peridoto e do piroxênio na gênese de todos os tipos de lavas. O CaO mantém-se praticamente constante, evidenciando uma pequena participação do plagioclásio na diferenciação. $O$ teor em titânio cresce até $\mathrm{IS}=20$, aparentando decrescer após este ponto. Notar a coincidência das inflexòes das curvas para o ferro e para o titânio, explicada pela retirada deste do líquido em exsolução na magnetita. Há um forte enriquecimento em $\mathrm{Na}_{2} \mathrm{O}$ e uma diminuição nos teores de $\mathrm{K}_{2} \mathrm{O}$. Notar que o enriquecimento em $\mathrm{Na}_{2} \mathrm{O}$, a quase invariabilidade do $\mathrm{Al}_{2} \mathrm{O}_{3}$ e o decréscimo pouco importante do $\mathrm{CaO}$ reforça a hipótese da pouca participação do plagioclásio na evolução das lavas. As características descritas, constância da silica e alumina, diminuição dos teores em $\mathrm{MgO}$, aumento dos teores em $\mathrm{Na}_{2} \mathrm{O}$ e ligeira diminuição dos teores de $\mathrm{CaO}$, caracterizam uma evolução em profundidades média a baixa, comandada sobretudo pelo fraciona mento do clino e ortopiroxênios, pouco peridoto e quase ausência de plagioclásio (Green e Ringwood, 1967).

Os basitos da região Sul constituem um grupo homogêneo, sem qualquer orientação definida nos diagramas. São rochas com altos teores em ferro, classificando-se entre os toleitos ricos em ferro de Kuno (1968, in Hess e Poldervaar, 1968, p. 634) ao analisarem mais de $15 \%$ em $\mathrm{FeO}+\mathrm{Fe}_{2} \mathrm{O}_{3}+\mathrm{MnO}$ (Fig. 13). A pequena variação de IS e a dispersão dos pontos no diagrama AFM deixa claro que estas rochas não são diferenciadas.

Petrogênese A coincidência da razão AFM e da composição química dos olivina toleitos do Serro (quadro 7, n." 75) com as margens vitrificadas dos derrames da Tasmania e Palisades (Fig. 12 e Kuno, 1968, em Hess e Poldervaart, p. 628 e 630 ) permitem a suposição de que o magma primário da série do Espinhaço tenha tido uma composição próxima daquela das rochas do Serro. A diferenciação de um olivina toleito, a profundidades próximas de $30 \mathrm{~km}(9 \mathrm{~Kb})$, teria como consequiência a gênese de uma suite de lavas semelhantes àquela descrita para o Espinhaço (Green e Ringwood, 1967). Não há, entretanto, uma perfeita coerência entre a quantidade de peridoto e hiperstênio nos magmas sucessivamente fracionados (quadro 11) e o Indice de Solidificação (Fig. 13). Com efeito, o magma mais alcatino (Datas), supostamente mais diferenciado como o indicam a quantidade de peridoto e hiperstênio normativos (quadro 11), além da nefelina, tem um índice de solidificação maior que o de lpoema (Fig. 13), fazendo supor ter sido Ipoema e não Datas o último líquido gerado durante a evolução magmática. Este problema encontraria solução na evolução semi-independente dos diferentes 
Quadro i i - Quantidade de olivina e hiperstênio normativos nos maciços estudados do Espinhaço

\begin{tabular}{l|c|c}
\hline \multicolumn{1}{c|}{ Local } & Peridoto $\%$ & Hiperstênio \% \\
\hline São Gonçalo & 0 & 14 a 17 \\
Serro & 2 a 3 & 20 a 30 \\
Ipoema & 7 a 9 & 0 a 10 \\
Datas & 10 a 15 & 0 \\
\hline
\end{tabular}

maciços estudados. Nesta hipótese, o condicionamento tectônico regional, que teve como consequiência o magmatismo básico-alcalino analisado, evoluiu de maneira não rigorosamente uniforme, tendo permitido em alguns momentos a gênese de lavas de características não condizentes com a composição geral naquele momento. As lavas de Datas seriam, portanto, pertencentes a uma segunda sequiência de evolução com características genéticas diferentes dos outros maciços.

A hipótese de gênese por diferentes graus de fusão parcial permite uma interpretação mais lógica da sequiência do Espinhaço. Os basanitos e basaltos alcalinos seriam um primeiro produto de fusão $(5 \%)$, a profundidades próximas de $30 \mathrm{~km}$ (Green, 1970). O grau de fusão aumentaria e haveria uma diminuição da profundidade do foco de fusão, como indicado pela diminuiçào regular e pela pequena quantidade de peridoto das rochas dos diferentes maciços (quadro 11), tendo como conseqüência a gênese sucessiva dos basaltos aluminosos alcalinos $(10 \%-15 \%$ de fusão), dos olivina toleitos $(15 \%$ a $20 \%$ de fusão e $20 \mathrm{~km}$ de profundidade) e, finalmente, dos toleitos e quartzo toleitos $\left(10^{\circ}-20^{\circ} \%\right.$ de fusão e menos que $10 \mathrm{~km}$ de profundidade). A hipótese de fusão diferencial condiz com o distanciamento geográfico dos corpos estudados, além de explicar melhor a gênese dos diferentes tipos de lava reconhecidos.

CONSIDERAÇÕES SOBRE A TECTÔNICA Brito Neves et al. (1978, no prelo), fazendo uso do conjunto de datações existentes feitas sobre rochas do Espinhaço de Minas Gerais e Bahia, montam um esquema geral de evolução do Espinhaço. A sedimentação do Espinhaço ter-se-ia originado a cerca de 1,8 b.a., concomitantemente às primeiras emissòes vulcânicas, de caráter ácido, datadas em 1770 m.a. (quadro 12 e Jardim de Sá et al., 1976). No período entre 1,7 e 1,3 b.a. teria havido recorrência das eruptivas ácidas e as primeiras intrusões básicas. $\mathrm{O}$ vulcanismo básico teria, então, se acentuado, em detrimento daquele de composição ácida, culminando entre 1,2 e 1,0 b.a. (Brito Neves et al.).

Foram determinadas, entre 1,3 e 1,2 b.a. e entre 650 e 500 m.a. (Brasiliano), algumas idades correspondentes à rehomogeneizações isotópicas parciais e locais. A ressaltar que, considerando-se as idades $\mathrm{K} / \mathrm{Ar}$ como idades mínimas, o vulcanismo básico no Espinhaço meridional, segundo as datações feitas (quadro 12), parece se estender desde a origem da cordilheira (1,8 b.a. ou mais) até o início da sedimentação Bambuí (aproximadamente 1,0 b.a.). Somente a amostra de Datas, para os metabasitos do Espinhaço meridional, e os metavulcanitos ácidos de conceição de Mato Dentro mostram características que as indicam como rejuvenescidas pelo metamorfismo brasiliano (idades próximas de $550 \mathrm{~m}$.a.).

Portanto, as informações existentes no que concerne às datações absolutas dos metabasitos do Espinhaço meridional não dão apoio às interpretações de Plug e Renger (1973), que situam estes metabasitos

Quadro 12 - Datações absolutas de rochas vulcânicas do Espinhaço Meridional (*)

\begin{tabular}{|c|c|c|c|c|}
\hline Localização & Rocha & Método & $\begin{array}{l}\text { Idade } \\
\text { m.a. }\end{array}$ & Significado \\
\hline Conceição do Mato Dentro (MG) & Metariolito & $\mathrm{U} / \mathrm{Pb}$ & 1770 & $\begin{array}{l}\text { Idade real do zircão de cristalização do } \\
\text { riolito }\end{array}$ \\
\hline Conceição do Mato Dentro (MG) & Metariolito & Infra-Rouge (IR) & 1650 & $\begin{array}{l}\text { Não houve após formação do zircào, qual- } \\
\text { quer recristalizaçào metamórfica }\end{array}$ \\
\hline Conceição do Mato Dentro (MG) & Metariolito & $\mathrm{Rb} / \mathrm{Sr}$ & 530 e 640 & $\begin{array}{l}\text { Metamorfismo e rehomıgeneização isotó- } \\
\text { pica do brasiliano }\end{array}$ \\
\hline Perfil em Datas (MG) & Metabasito & $\mathrm{K} / \mathrm{Ar}(\mathrm{RT})$ & $934 \pm 45$ & Idade aparente minima para o Espinhaço \\
\hline Norte de Datas (MG) & Metabasito & $\mathrm{K} / \mathrm{Ar}(\mathrm{RT})$ & $472 \pm 05$ & Idade aparente minima para o Espinhaço \\
\hline Este do Morro do Pilar (MG) & Metabasito & $\mathrm{K} / \mathrm{Ar}(\mathrm{Anf})$ & $1215 \pm 40$ & Idade aparente minima para o Espinhaço \\
\hline Noroeste de Conceição do Mato & & & & \\
\hline Dentro (MG) & Metabasito & $\mathrm{K} / \mathrm{Ar}(\mathrm{ET})$ & $1459 \pm 45$ & Idade aparente minima para o Espinhaço \\
\hline Sul de Costa Sena (MG) & Metabasito & $\mathrm{K} / \mathrm{Ar}(\mathrm{RT})$ & $1188 \pm 34$ & Idade aparente mínima para o Espinhaço \\
\hline Sul de Costa Sena (MG) & Metabasito & $\mathrm{K} / \mathrm{Ar}(\mathrm{RT})$ & $2060 \pm 53$ & Idade aparente mínima para o Espinhaço \\
\hline Sul de Costa Sena (MG) & Metabasito & $\mathrm{K} / \mathrm{Ar}(\mathrm{RT})$ & $1575 \pm 45$ & Idade aparente minima para o Espinhaço \\
\hline Conceição do Mato Dentro (MG) & Quartzo Pórfiro & K/Ar (Feldsp.) & $505 \pm 16$ & Idade aparente minima para o Espinhaço \\
\hline
\end{tabular}

R.T. = Rocha Total

Anf. = Anfibolio

Feldsp. $=$ Feldspato 
entre os pertencentes à última fase magmática basáltica de um geossinclínio do tipo de Stille. São raros os estudos existentes sobre as características químicas de lavas basálticas deste tipo. As características químicas mostradas podem caracterizá-las como provenientes de um vulcanismo continental mais do que marinho pericontinental ou de arco insular, ainda que não hajam evidências plenas que permitam a sua classificação rigorosa em qualquer destes ambientes.

CONCLUSÓES A técnica proposta de correção de análise, baseia-se na premissa de que as rochas estudadas tenham tido na origem composições mineralógicas qualitativas pouco diferentes. A quantidade de qualquer espécie mineral em uma rocha, desde que todas as rochas analisadas contenham as mesmas espécies, influirá somente no crescimento uniforme do $\mathrm{K}_{2} \mathrm{O}$ contido quando as análises forem graficadas conforme mostrado.

- Quanto à movimentação de óxidos devido aos metamorfismos, os maciços estudados mostraram as seguintes características: Datas e Ipoema ganharam alcalinos, tiveram muito pouca variação nos seus teores de $\mathrm{CaO}$ e $\mathrm{FeO}+\mathrm{MgO}+\mathrm{MnO}$ e mostraram tendência a se enriquecerem em sílica. Serro e São Gon çalo perderam alcalinos, enriqueceram-se fortemente em $\mathrm{CaO}$ e $\mathrm{FeO}+\mathrm{MgO}+\mathrm{MnO}$ e tiveram comporta mento variável quanto à sílica.

- O comportamento uniforme quanto ao metassomatismo mostrado por todas as amostras analisadas de um mesmo maciço, conduz à idéia de que as migrações se fizeram por distâncias equivalentes ao menos à largura média dos corpos estudados (alguns quilômetros para Datas e Ipoema). Deduz-se ainda que os "fronts" metassomáticos abrangeram regiões no mínimo com a mesma dimensão do maior comprimento do maior maciço estudado, no caso, para o Serro, de cerca de 25 quilômetros.

- Quanto à variação relativa em porcentagens dos diversos óxidos, os alcalinos mostraram variações de até $200 \%$, tendo havido amostras cujos teores em $\mathrm{Na}_{2} \mathrm{O}$ dobraram (poema) e outras cujos teores em $\mathrm{K}_{2} \mathrm{O}$ foram reduzidos a $1 / 3$ do original (Serro). Variaçōes de $30 \%$ a $40 \%$ relativos nos teores de $\mathrm{CaO}$ foram comuns. A sílica, em média, variou de cerca de $5 \%$ relativos em relação aos seus teores originais.

- O metassomatismo total que agiu sobre os basitos da região $\mathrm{Sul}$ do Estado, diferencia-se daquele que foi ativo sobre o Espinhaço por mostrar uma perda geral de $\mathrm{CaO}$ aliada à invariabilidade dos teores de $\mathrm{Na}_{2} \mathrm{O}$ durante a sua história.

- O enriquecimento metassomático em $\mathrm{FeO}+$ $+\mathrm{MgO}+\mathrm{MnO}$ das rochas do Serro e São Gonçalo e o empobrecimento em álcalis de Datas e Ipoema condicionam uma tendência geral de migração das amostras do pólo $A$ para o pólo $F$ no diagrama $A C F$.
Esta migração tem, como consequiência, o aparecimento da actinolita e da tremolita como principais minerais originados das fases metamórfica-metassomáticas, a que foram submetidos os metabasitos do Espinhaço.

- No que concerne à composição normativa das rochas, a tendência geral do metassomatismo foi de alcalinização, fazendo a parecer a nefelina e o peridoto em detrimento do quartzo e do hiperstênio. Datas mostra-se como uma exceção, tendo-se enriquecido em nefelina e peridoto pelo desaparecimento do diopsídio normativo.

- A correção dos efeitos do metassomatismo conduziu a uma saturação das lavas do Espinhaço, deslocando a série basanítica, anteriormente definida (Ipoema), para a posição das séries transicionais, fazendo desaparecer o vazio que separava os metabasitos em duas séries vulcânicas distintas. No diagrama AFM, as análises corrigidas ocupam exatamente a posição deste vazio, alinhando-se de modo uniforme junto à linha de evolução das séries alcalinas.

- O metassomatismo deu aos metabasitos do Espinhaço características de uma série mais diferenciada, com maior intervalo de variação do índice de Solidificação (IS) que o real, como o mostram as análises corrigidas (Fig. 13).

- As características de evolução dos óxidos analisados e corrigidos plotados em relação ao IS são: constância da silica e alumina, diminuição dos teores de $\mathrm{MgO}$, aumento dos teores de $\mathrm{Na}_{2} \mathrm{O}$ e ligeira diminuição dos teores de $\mathrm{CaO}$. Estas características sugerem uma evolução magmática à profundidade entre média e baixa, comandada sobretudo pelo fracionamento dos clinos e ortopiroxênios. Os basitos da região Sul não mostram nenhuma evidência de evolução regular.

- A gênese dos metabasitos do Espinhaço é me lhor explicada, considerando-se a hipótese de fusão diferencial do manto. Esta hipótese condiz com a distribuição geográfica dos maciços estudados e com o tipo de evolução determinado. As fusões teriam começado a cerca de 30 quilômetros de profundidade e aumentariam em porcentagem concomitantemente à ascensão do foco de fusão em direção à superfície, gerando sucessivamente os basanitos, os basaltos alm calinos, os olivina toleitos e os quartzo toleitos.

- Embora não tenham sido determinadas características definitivas que permitam classificar as lavas estudadas quanto aos seus ambientes tectônicos de origem, as maiores evidências sugerem um vulcanismo em ambiente continental, mais que pericontinental ou de arco insular.

Agradecimento À METAMIG, pelas possibilidades materiais e de tempo fornecidas para a elaboração deste trabalho. 


\section{BIBLIOGRAFIA}

BESWICK, A.E. \& SOUCIE, G. - 1978-A correction procedure for metassomatism in an archean greenstone belt. Precambrian Res. 6: 235-248.

BIONDI, J.C.; SCHRANK, A. \& PINHEIRO, J.C.F. - 1978 - Basitos e ultrabasitos do Espinhaço Meridional e região Sul de Minas Gerais. Anais do XXX Cong. Bras. Geol., 3: $1213-1225$.

BRITO NEVES, B.B.; KAWASHITA, K. ; CORDANI, U.G. \& DELHAL, J. - 1979 - A evolução geocronológica da cordilheira do Espinhaço; dados novos e integração. Rev. Bras. Geociências, no prelo.

CARMICHAEL, D.M. - 1969 - On the mechanism of prograde metamorphic reactions in quartz-bearing pelitic rocks. Contrib. Mineral. Petrol., 20: 244-267.

COOMBS, D.S. - 1963 - Trends and affinities of basaltic magmas and pyroxenes as illustrated on the diopside-olivine-silica diagram. Miner. Soc. Amer., Special paper 1: 227-250.

FISHER, G.W. - 1970 - The application of ionic equilibria to metamorphic differentiation: an example. Contrib. Mineral. Petrol., 29: 91-103.

GREEN, D.H. \& RINGWOOD, A.E. - 1967 - The genesis of basaltic magmas. Contr. Mineral. Petrol., 15: 103-190.

GREEN, D.H. - 1970 - The origin of basaltic and nephelinitic magmas. Trans. Leicester Literary Philosophical Soc. (64): 26-54.

HUTCHINSON, R.W. - 1973 - Volcanogenic sulfide deposits and their metallogenic significance. Econ. Geol. 68: 1223-1246.

IARDIM DE SÁ, E.F.: BARTELS, R.L.: BRITO NEVES, B.B.; KAWASHITA, K. \& MCREATH, I. - 1976 - Geocronologia e o modelo tectomagmático da Chapada Diamantina e Espinhaço Setentrional, Bahia. Anais do XXIX Cong. Bras. Geol., 37 pp., no prelo - Belo Horizonte.

KUNO, H, - 1968 - Differentiation of basalt magmas - In: "Hess and Poldervaart" treatise on rocks of basaltic composition. John Wiley \& Sons, vol. 2, pp. 623-688.

MASON, V. - 1967 - Geochemistry of basaltic rocks: major elements. In: Hess and Poldervaart Treatise on Rocks of Basaltic Composition. Vol. 1, pp. 215-269, N.Y.

MIYASHIRO, A.: SHIDO, F. \& EWING, M. - 1971 - Metamorphism in the Mid-Atlantic Ridge $24 .^{\circ}$ and $30 .{ }^{\circ} \mathrm{N}$. Royal Soc. (London) Philos. Trans. A, 268: 443-466.

MOINE BERNARD, M.M. \& de la ROCHE, H. - 1968 - Nouvelle approache du problème de l'origine des amphibolites à partir de leur composition chimique. C.R. Acad. Sc. Paris, 267: 2084-2087.

PEARCE, T.H. - 1968 - A contribution to the theory of variation diagrams. Contrib. Mineral. Petrol. 19: 142-157.

PEARCE, T.H. - 1970 - Chemical variations in the Palisades sill. J. Petrol., 11: 15-32.

PFLUG, R. \& RENGER, F, - 1973 - Estratigrafía e evolução geológica da margen SE do Craton Sanfranciscano. XXVII. Cong. Bras. Geol. (Aracaju). $15 \mathrm{pp.}$

WHITE, R.W. \& SARCIA, C. - 1978 - Natural and artificial weathering of basalt, northwestern United States. Bull. B.R.G.M., section II, 13: 1-29.

YODER, H.S. Jr. \& TILLEY, C.E. - 1962 - Origin of basalt magmas. An experimental study of natural and synthetic rock systems, I. Petrol. 3: 342-532. 